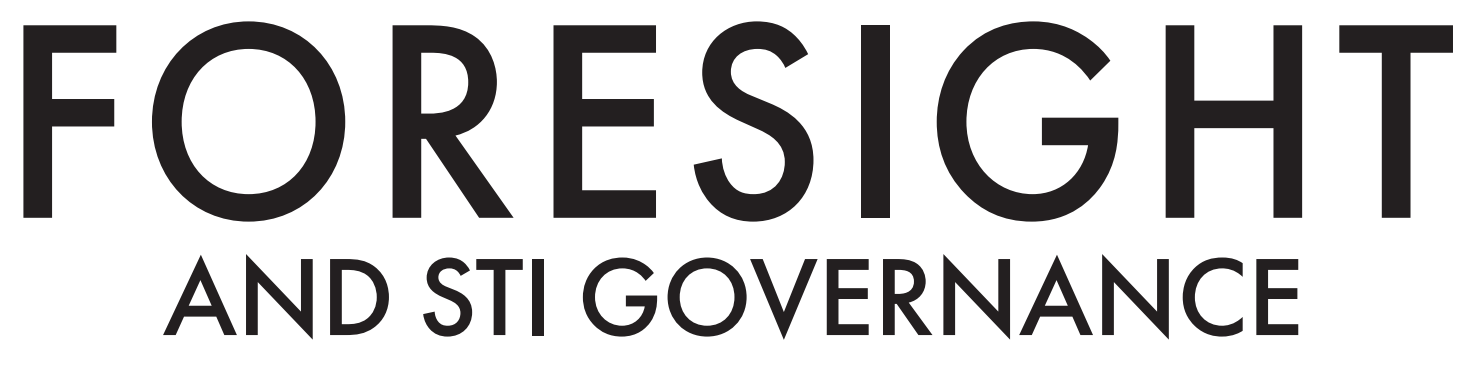

ISSN 2500-2597

2018

Vol.12 No 3

(B)

JOURNAL OF THE NATIONAL RESEARCH UNIVERSITY HIGHER SCHOOL OF ECONOMICS

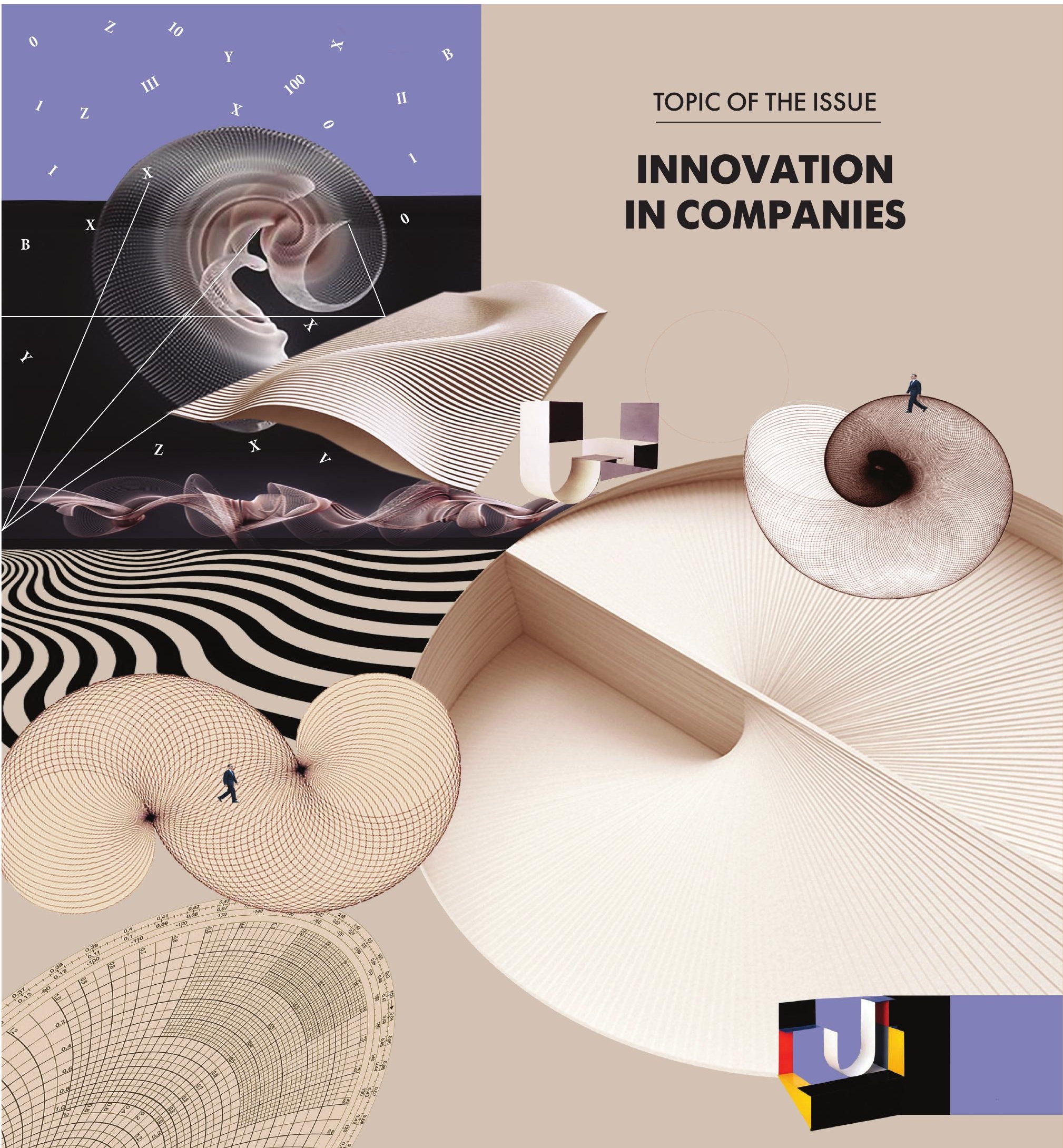



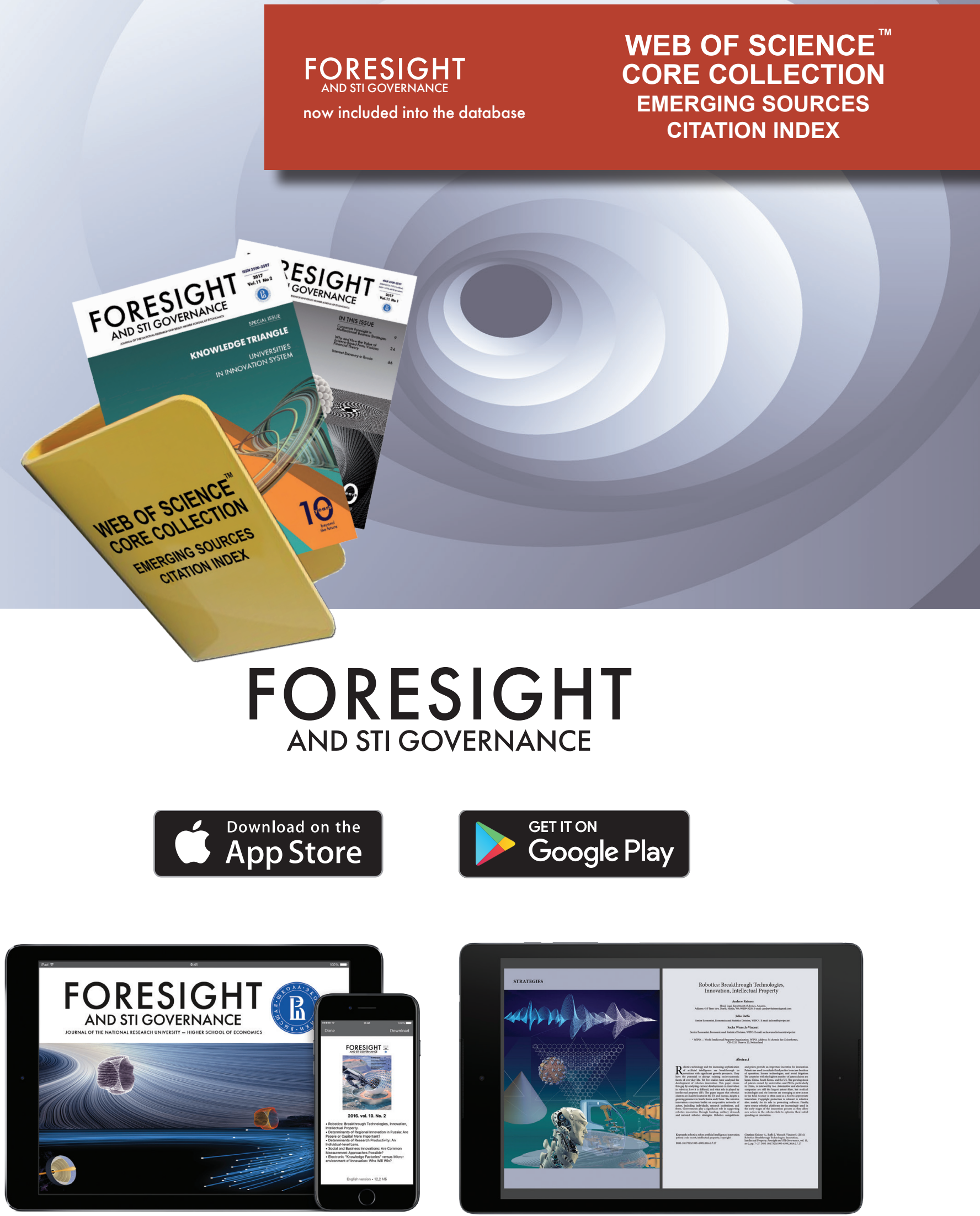


\section{ABOUT THE JOURNAL}

Foresight and STI Governance is an international interdisciplinary peer-reviewed openaccess journal. It publishes original research articles, offering new theoretical insights and practice-oriented knowledge in important areas of strategic planning and the creation of science, technology, and innovation (STI) policy, and it examines possible and alternative futures in all human endeavors in order to make such insights available to the right person at the right time to ensure the right decision.

The journal acts as a scientific forum, contributing to the interaction between researchers, policy makers, and other actors involved in innovation processes. It encompasses all facets of STI policy and the creation of technological, managerial, product, and social innovations. Foresight and STI Governance welcomes works from scholars based in all parts of the world.

Topics covered include:

- Foresight methodologies and best practices;

- Long-term socioeconomic priorities for strategic planning and policy making;

- Innovative strategies at the national, regional, sectoral, and corporate levels;

- The development of National Innovation Systems;

- The exploration of the innovation lifecycle from idea to market;

- Technological trends, breakthroughs, and grand challenges;

- Technological change and its implications for economy, policy-making, and society;

- Corporate innovation management;

- Human capital in STI;

and many others.

The target audience of the journal comprises research scholars, university professors, postgraduates, policy-makers, business people, the expert community, undergraduates, and others who are interested in S\&T and innovation analyses, foresight studies, and policy issues.

Foresight and STI Governance is published quarterly and distributed worldwide. It is an open-access electronic journal and is available online for free via:

https://foresight-journal.hse.ru/en/

\section{INDEXING AND ABSTRACTING}

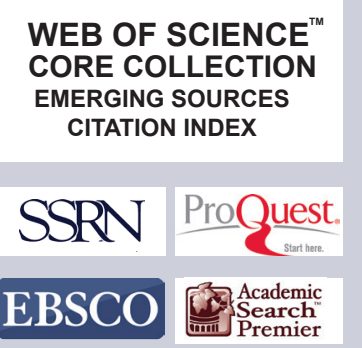

SCOPUS"

$R e P E c$ RESEARCH PAPERS

Genamics Journalseek

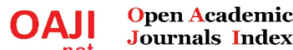




\title{
CONTENTS
}

Vol. 12 No 32018

\section{STRATEGIES}

6

Jonathan Linton

Quiet Contributors: The Role of the Arts, Humanities and Social Sciences in Innovation

\author{
13 \\ Irene Ek
}

Research Programmes that Address Societal Challenges -

Aligning Policy, Implementation, and Expected Impact

20

Vincenzo Bianco

The Future of the Italian Electricity Generation Sector.

An Analysis of the Possible Strategic Models

\section{INNOVATION IN COMPANIES}

30

Jonathan Calof

Enhancing Innovation Performance in Companies

34

Hein Roelfsema, Yi Zhang

Internationalization and Innovation in Emerging Markets

43

Elena Zavyalova, Artem Alsufyev, Inna Krakovetskaya, Wan Lijun, Jessica Li

Personnel Development in Chinese Innovation-Active Companies

53

Volker Nissen, Tatiana Lezina, Andrey Saltan

The Role of IT-Management in the Digital Transformation of Russian Companies

62

Natalia Davidson, Oleg Mariev, Andrey Pushkarev

The Impact of Externalities on the Innovation Activity of Russian Firms 


\section{STRATEGIES}
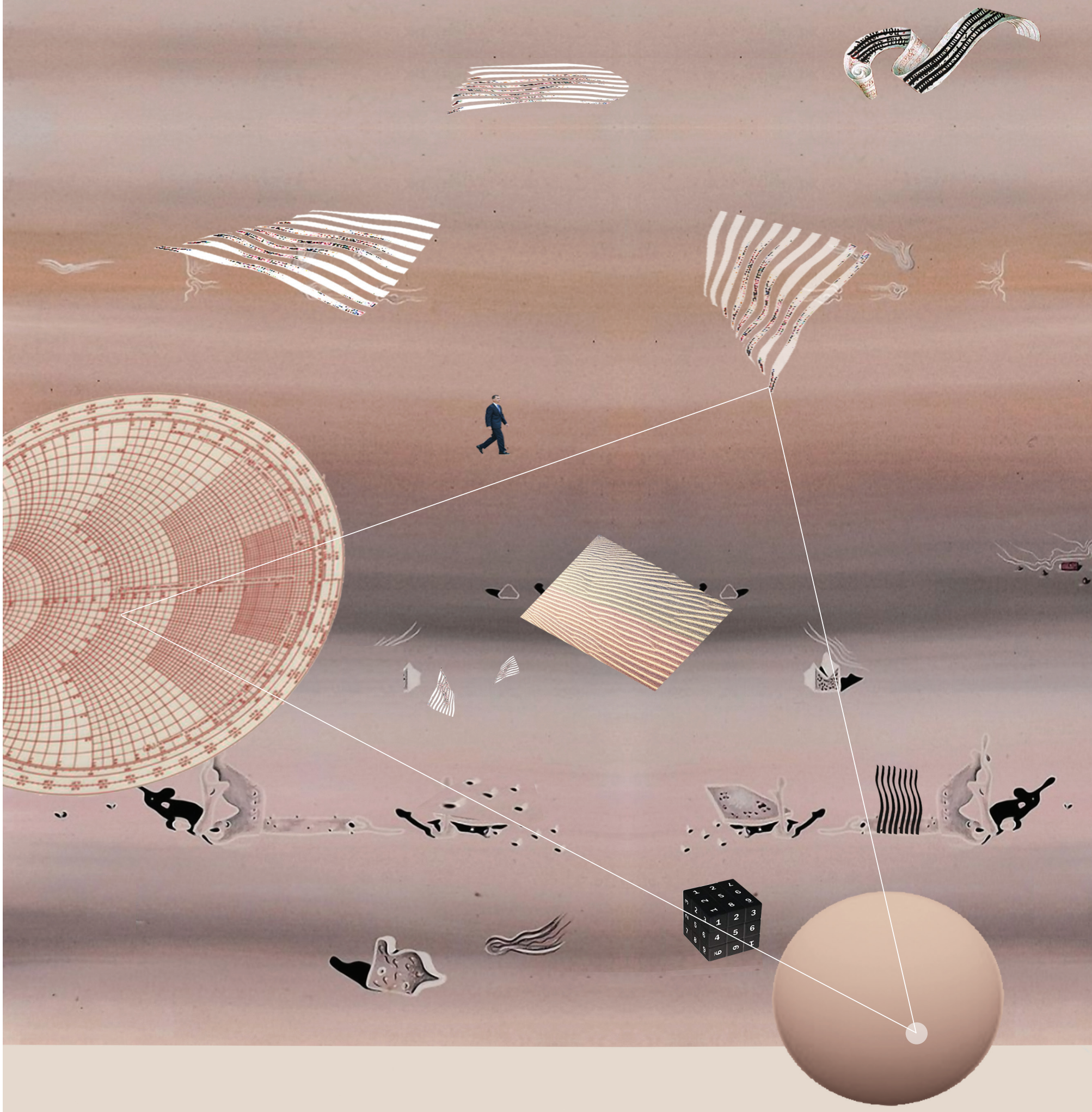


\title{
Quiet Contributors: The Role of the Arts, Humanities and Social Sciences in Innovation
}

\author{
Jonathan Linton \\ Chair in Operations and Technology Management ${ }^{\mathrm{a}}$; Head of Laboratory ${ }^{\mathrm{b}}$, j.linton@sheffield.ac.uk \\ a School of Management of the University of Sheffield, B067, Conduit Road, S10 1LF, UK \\ ${ }^{b}$ Research Laboratory for Science and Technology Studies of the Institute for Statistical Studies and Economics of \\ Knowledge (ISSEK) of the National Research University Higher School of Economics (NRU HSE), 11 Myasnitskaya str., \\ Moscow 101000, Russian Federation
}

\begin{abstract}
$\mathrm{M}$ any countries are directing their attention toward the support of technological innovation in order to obtain economic and social benefits at home while positioning themselves for high margin, high technology export markets. The under-considered and under-exploited role of arts, humanities and social science in innovation is explored in this study. Examples

of programs and activities in a variety of countries are illustrated. Insight is offered into why the arts, humanities and social sciences are important to the generation of social and economic benefits through innovation. Furthermore, recommendations are provided for better reaping the benefits that the arts, humanities and social science can provide.
\end{abstract}

Keywords: Arts, Humanities and Social Sciences;

technological innovation; social innovation; business model innovation; administrative innovation; organizational innovation; cross-disciplinary collaboration
Citation: Linton J. (2018) Quiet Contributors: The Role of the Arts, Humanities and Social Sciences in Innovation. Foresight and STI Governance, vol. 12, no 3, pp. 6-12.

DOI: 10.17323/2500-2597.2018.3.6.12 


\section{Recognizing the Limited Interplay between Innovation and Technology}

One of the challenges faced by academics and researchers in the arts, humanities and social sciences is the fact that politicians and others do not see these areas as contributors to a healthy and prosperous society. While academics often feel undervalued, calls for massive defunding are not expected, but such cutbacks have appeared in increasingly high levels in some countries. For example, in Japan, a letter from the Minister of Education encouraged universities to take "active steps to abolish [these programs]" leading to changes in the programs by close to half (26 of 60) of all Japanese universities [Jenkins, 2015]. While many stakeholders in the arts, humanities, and social sciences are aware of the lack of recognition [Bullen et al., 2004; Lavoie, 2011; Lundströma, Zhou, 2011; Fri, Savitz, 2014; Gulbrandsen, Aanstad, 2015; Hawkins et al., 2015; Murphy et al., 2016; Turcanu et al., 2016; Teixeira et al., 2017] of these disciplines as a critical part of the innovation system in many jurisdictions, the problem remains. Consequently, this paper addresses the relationship between innovation, the arts, humanities, and social sciences in an effort to assist people in understanding and clarifying the extent and nature of the relationship.

Part of the challenge facing the social sciences, arts, and humanities is a misunderstanding of what innovation is. Innovation is anything new that creates some form of value - often economic, but not always. However, innovation is often pictured as being inherently technological. Consequently, policy makers that wish to encourage innovation often end up only incentivizing technological development. While technology is a major contributor to technological innovation, there are many other types of innovation that are also required to extract value from our world. The various types of innovation include: business model innovation, social innovation, administrative innovation, and organizational innovation (Table 1). All four of these types of innovation relate to a variety of non-technological areas including: anthropology, culture/cross-cultural studies, economics, history, philosophy, political science, psychology, and sociology. Notably, a newer definition of social innovation is currently more widely used than traditional one that is part of the traditional innovation management literature.

Another challenge is finding the appropriate measurement for value creation. The adoption of innovation has often been a popular measure, however, it has severe limitations. Adoption involves tracing the pathway, or diffusion, of an innovation through various individuals, households, and firms until it fully serves the appropriate population [Rogers, 1995]. While adoption is critical in areas such as marketing and sales, it is only one of the necessary steps in the innovation process [Tornatzky, Fleischer, 1990]. Value extraction only happens later on in the process - primarily when the something new (innovation) ceases to be new. Once an innovation is adopted, the implementation process begins. The results of the implementation process govern the extent to which value extraction is successful.

Implementation is the mutual adaptation of the innovation and the adopting party (individual, household, firm) to one another. This adaptation involves changes to the innovation so that it is more suitable [Klein, Sorra, 1996] for utilization by the adopting party. Similarly, the adopting party must modify personal perceptions and practices. This allows the adopter to exploit and capture the potential value associated with the innovation. For technological innovations, this dance of mutual adaptation has technological aspects as well as non-technological features, which will be expounded upon later. Furthermore, in the case of implementing the non-technological forms of innovation, the process of mutual adaptation is completely within the realm of the arts, humanities and social sciences. This includes fields such as, but not limited to, psychology and philosophy.

The implementation process ends either when there has been a successful mutual adaptation of the innovation and adopting unit or the implementation process is discontinued prematurely. In cases of successful adaptation, the innovation becomes part of routine practice and behavior [Yin, 1978, 1992].

\section{Table 1. Definitions of Non-Technological Types of Innovations}

\begin{tabular}{|l|l|}
\hline \multicolumn{1}{|c|}{ Types of innovation } & \multicolumn{1}{c|}{ Definition } \\
\hline Business model innovation & $\begin{array}{l}\text { New ways of extracting value/making profit from a product - or goods and services - offering. } \\
\text { Examples include: making a profit on consumables or services instead of selling a capital good [ Wise, } \\
\text { Baumgartner, 2000]. }\end{array}$ \\
\hline $\begin{array}{l}\text { Social innovation (traditional } \\
\text { academic definition) }\end{array}$ & $\begin{array}{l}\text { Innovation in social systems is required for extracting value from technological innovation. For } \\
\text { example, the patent system is a social innovation intended to encourage people to invent and bring } \\
\text { inventions to the marketplace through a promise to the inventor that they will be rewarded with } \\
\text { monopoly profits for a set period of time enhancing the value extraction opportunities from the } \\
\text { innovation [Linton, 2009]. }\end{array}$ \\
\hline $\begin{array}{l}\text { Social innovation (new } \\
\text { definition) }\end{array}$ & $\begin{array}{l}\text { Innovation that is for the purpose of producing non-economic benefit. Often associated with charitable } \\
\text { or community organizations. The sharing of user innovation [von Hippel, 2017], such as open source } \\
\text { software [von Krogh, Spaeth, 2007] is included in this category. }\end{array}$ \\
\hline Administrative innovation & $\begin{array}{l}\text { An innovation to a process or system. For example, business process re-engineering [Hammer, Champy, } \\
\text { 1993]. }\end{array}$ \\
\hline Organizational innovation & $\begin{array}{l}\text { An innovation relating to a change in the structure, interactions, or management of either a group of } \\
\text { people or an organization. }\end{array}$ \\
\hline Source: compiled by the author. & \\
\hline
\end{tabular}


Table 2. Some Issues Related to the Governance of Innovation

\begin{tabular}{|l|l|}
\hline \multicolumn{1}{|c|}{ Issue } & \multicolumn{1}{c|}{ Description } \\
\hline Implementation & $\begin{array}{l}\text { The adopting party modifies perceptions and practices so that the innovation can be utilized for the intended } \\
\text { outcome. }\end{array}$ \\
\hline $\begin{array}{l}\text { Abandonment } \\
\text { decisions }\end{array}$ & $\begin{array}{l}\text { Based upon processes related to various areas of social sciences, arts and humanities - including: economics, } \\
\text { psychology, sociology, culture and philosophy. Regardless of whether the innovation is technological or non- } \\
\text { technological. }\end{array}$ \\
\hline Incorporation & The extraction of benefit is both an art and science as it relates to creativity, learning, and imitation. \\
\hline Source: compiled by the author.
\end{tabular}

Alternatively, abandonment occurs. Abandonment is often an appropriate decision. If an innovation is found unworthy of further effort, there is no reason to complete the resource-consuming mutual adaptation process. Decisions to abandon an innovation are in the realm of social sciences regardless of whether an innovation is technological or non-technological.

If an innovation is not abandoned and becomes part of the routine practice of the adopter (individual, firm or other), the level and nature of the extracted benefit can vary greatly. This is because the routinization does not relate to how efficiently or effectively an innovation has been utilized by the adopter - it simply indicates that the innovation is no longer new and can be expected to stay in use without any additional effort. To understand the extent to which the innovation is used effectively, we must consider incorporation. Incorporation [Zmud, Apple, 1992] is the term used to describe the level of value extracted from an innovation. A skilled user determines how to extract additional value from an innovation not only during the implementation process, but also long afterwards as the user learns more about the innovation and what it is capable of [Barras, 1986]. The processes associated with the extraction of benefit can be derived from the arts and humanities as it relates to creativity, learning, and imitation.

In summary, without the consideration of social sciences, humanities, and the arts, the benefits from technological innovation are at best elusive. To reap these benefits, one must appropriately utilize social sciences, arts, and humanities to understand and manage such issues as implementation, abandonment decisions, and the incorporation of the innovation (Table 2).

\section{Examples of Best Global Practices}

In support of understanding how policy and programs can better allow society to benefit from the economic and social value of innovation, leaders in Science, Technology, and Innovation Policy were interviewed. While there is agreement concerning the importance and interest across the world in the operationalization of the role of arts, humanities, and social sciences in innovation, few countries have interesting experiences in this arena. While specific examples discussed here relate to Canada, Japan, Singapore, and the United States; discussions have also occurred with policy makers in Brazil, China, the European Union, India, Israel, Mexico, OECD member countries, Russia, South Africa, and Taiwan. A subset of activities that were discussed by the policy makers are now considered to help make analysts, policy makers, and other stakeholders more aware of the opportunities for unleashing innovation based upon the social sciences, arts, and humanities. This not only supports following best practices, but also helps to offer insights into possible other future directions.

\section{Digitization and humanities}

Digitization has created many opportunities for the arts and humanities. The internet gave artists the opportunity to disintermediate the existing distribution channels. This allowed them to reach larger audiences and reduced their dependence on intermediaries and brokers that controlled access to markets and used their position to extract most of the value associated with the artistic content. Digitization offers many other opportunities. In smaller economies - such as Singapore - there is experimentation with interdisciplinary labs ${ }^{1}$. The Social Science and Humanities Research Council in Canada was an early aggressive pursuer of the digitization of the humanities ${ }^{2}$.

\section{Foresight activities}

A number of countries engage in foresight activities to provide insight into how the world may look in the future. While the developed potential future scenarios always involve advancements in technology, the focus is on how society may apply, work with, and relate to the new technology and the evolving environment. For example, the Russian government has placed a strong emphasis on how science and technology are intended to support future social goals by providing benefits that are both economic and non-economic [Ponomarev, Dezhina, 2016; Gokhberg, Sokolov, 2017; Gokhberg et al., 2017]. Foresight

\footnotetext{
See, for example, https://www.create.edu.sg/about-create/research-centres/smart, accessed 22.04.2018

${ }^{2}$ For details see: https://www.ssrc.org/programs/view/digital-culture/, accessed 22.04.2018.
} 
activities can range from asking technical experts when they feel certain goals will be achieved to a consideration of the presence or absence of resources that are likely to be needed in the future. For each scenario, consideration is given to the probable societal needs and adaptations. The results identify the sorts of activities that will be required and/or advisable for the preparation for possible future states, for example: new policies and regulations in response to technological advances that have not yet occurred.

\section{Grand challenge approach}

While numerous funding agencies are calling for proposals to meet the global grand challenges that are listed by the United Nations and other international organizations, these calls typically focus on technical solutions. Such calls should be structured in a manner that embraces the interaction between the challenges and society. When society is at the center of the grand challenges, the focus upon and importance of arts, humanities, and social sciences rapidly increases, while technological solutions take a supporting role. For example, there is a program focused on ageing society in Japan supported by NISTEP (National Institute of Science and Technology Policy). This program is focused upon the rapid demographical shift in the age of the Japanese population and the impact that ageing will have on society and its structure. NISTEP has departed from considering the traditional approach of moving elderly people to new accommodation that is specifically designed for geriatric living and/or relying upon family members to act as caregivers. Instead, several sites - villages - have been selected, while the NISTEP study assesses and experiments with what is required in terms of modifications to the home and village infrastructure to provide the ageing residents of these communities the opportunity to continue living independently in their own homes. This not only involves overcoming physical limitations in the household but also considers what else is needed within the community for a happy and healthy lifestyle [NISTEP, 2017].

\section{Government as the lead adopter}

While some governments have a policy to only adopt proven products, others use their purchasing power to encourage the development and diffusion of innovations. Because the United States Small Business Innovation Research (SBIR) and Small Business Technology TRansfer (STTR) programs are so well known and documented, this subject is only briefly mentioned here. What is important to recognize is that many countries adopt the cautious responsible steward approach to government purchasing. In this case, only products that have been proven by others are considered for purchase - for many products this means that domestic products must first be adopted by another country's government. By putting the development of innovation in one's own country at a disadvantage through either policy or habit, governments force innovators to prove their innovation in a foreign country. Often this results in a permanent relocation of innovators outside of their home country.

\section{Elevating awareness of administrative innovation}

The Innovations in American Government Program ${ }^{3}$ encourages the awareness, celebration, and diffusion of innovation at all levels of government. The program not only rewards innovation and encourages its diffusion but raises the level of understanding that high impact/high value innovation often occurs independently of technological advancements.

\section{Programmatic requirement for Social Science and Humanities}

While technological innovation always contains an arts, humanities, and social sciences component, this element is often not specifically addressed by research funding. For example, funding has focused on moving science to technology and technology from low Technology Readiness Levels (TRLs) to higher TRLs (Table 3). For example, there is a separate guide on what constitutes technological readiness in autonomous vehicles (Table 4).

However, these guidelines are based upon the assumption that autonomous transport in the future will be identical with existing transport systems - a highly unlikely situation. While models of how to address these challenges are limited, insights on how to take into account societal impacts can be gained from the Genome Canada program ${ }^{4}$.

Genome Canada's intention is to fund translational research on genetics that leads to products. While Genome Canada gives contracts as opposed to grants, academic researchers in Canada often do not distinguish between research that is funded for knowledge creation (grants) and commercialization (contracts). Genome Canada requires that $10 \%$ of each contract is dedicated to non-technical work related to translational research - referred to as GE3LS (pronounced gels). GE3LS (Genomics and its Ethical, Economic, Environmental, Legal, and Social Aspects) funds must address the interaction of genetic research and society. The initial focus of GE3LS grants was upon medical ethics and economics. This has gradually widened to include other areas with a greater focus upon value extraction: for example, management and law. Typically, the GE3LS partner is focused on a specific field like medical ethics. In

\footnotetext{
${ }^{3}$ Available at: https://ash.harvard.edu/innovations-american-government-awards, accessed 15.03.2018.

${ }^{4}$ Available at: https://www.genomecanada.ca/, accessed 15.03.2018.
} 
Table 3. The European Union Definition of Technological Readiness Levels (TRLs)

\begin{tabular}{|c|l|}
\hline $\begin{array}{c}\text { Technology Readiness } \\
\text { Level }\end{array}$ & \multicolumn{1}{c|}{ Description } \\
\hline TRL 1 & Basic principles observed \\
\hline TRL 2 & Technology concept formulated \\
\hline TRL 3 & Experimental proof of concept \\
\hline TRL 4 & Technology validated in lab \\
\hline TRL 5 & Technology validated in the relevant environment \\
\hline TRL 6 & Technology demonstrated in the relevant environment ${ }^{*}$ \\
\hline TRL 7 & System prototype demonstration in operational environment \\
\hline TRL 8 & System complete and qualified \\
\hline TRL 9 & $\begin{array}{l}\text { Actual system proven in operational environment (competitive manufacturing in the case of key enabling } \\
\text { technologies; or in space) }\end{array}$ \\
\hline $\begin{array}{l}\text { Note: }{ }^{*}-\text { industrially relevant environment in the case of key enabling technologies. } \\
\text { Source: [European Commission, 2014]. }\end{array}$ \\
\hline
\end{tabular}

some cases, the GE3LS and scientific components are completely independent of one another and the teams only come together for meetings with the funding agency. On other occasions, there is greater and greater interaction between the separate research groups over time. When this greater interaction occurs, it is recognized that in order to translate research into practice, this will require more than $10 \%$ of the funding and a wider range of non-technical specialists (i.e., there is anecdotal evidence of scientists looking for more involvement with different types of people in the arts, humanities, and social sciences). However, this small forced interaction provides a useful starting point for addressing a complex problem. While requiring technological projects to have a non-technical component-as is the case with the GE $\mathrm{LS}^{3}$ program-is not always successful, it ensures that there is some consideration and activity related to the interaction between technology and society. This is the preferred starting point. Cross-disciplinary interaction requires academic researchers that are unaccustomed to working with academics from very different fields to interact with one another. It also challenges universities, as these organizations are often ill equipped for developing and building interdisciplinary teams either with a bottom-up or topdown approach. Similarly, the internal university structure is often ill suited for supporting the funding required for the interaction between researchers in different departments and faculties. As Genome Canada contracts involve millions of Canadian dollars in a single contract, a $\mathrm{GE}^{3} \mathrm{LS}$ contract is worth hundreds of thousands of dollars to a Co-Principal Investigator based in an arts, humanities, or social sciences department, making it among the largest grants available to Canadian researchers in these faculties. As the rate of commercialization has been lower than desired and the coordination between technical and $\mathrm{GE}^{3} \mathrm{LS}$ researchers has not been as seamless as hoped, there is interest in improving the current model.

\section{Implications for Policy and Programs to Support Better Value Extraction from Innovation}

Having outlined some programs that offer different approaches to the integration of arts, humanities, and social sciences into the innovation agenda, the implications for encouraging greater levels of innovation are considered.

\begin{tabular}{|c|c|c|c|}
\hline $\begin{array}{l}\text { SAE } \\
\text { Level }\end{array}$ & Name & \multicolumn{2}{|c|}{ Narrative definition } \\
\hline 0 & No Automation & \multicolumn{2}{|c|}{$\begin{array}{l}\text { The full-time performance by the human driver of all aspects of the dynamic driving task, even when } \\
\text { «enhanced by warning or intervention systems» }\end{array}$} \\
\hline 1 & Drive Assistance & $\begin{array}{l}\text { The driving mode-specific execution by a driver assistance } \\
\text { system of «either steering or acceleration/deceleration» }\end{array}$ & \multirow{2}{*}{$\begin{array}{l}\text { using information about the driving } \\
\text { environment and with the expectation } \\
\text { that the human driver performs all } \\
\text { remaining aspects of the dynamic } \\
\text { driving task }\end{array}$} \\
\hline 2 & $\begin{array}{l}\text { Partial } \\
\text { Automation }\end{array}$ & $\begin{array}{l}\text { The driving mode-specific execution by one or more driver } \\
\text { assistance systems of both steering and acceleration/deceleration }\end{array}$ & \\
\hline 3 & $\begin{array}{l}\text { Conditional } \\
\text { Automation }\end{array}$ & \multirow{3}{*}{$\begin{array}{l}\text { The driving mode-specific performance by an automated } \\
\text { driving system of all aspects of the dynamic driving task }\end{array}$} & $\begin{array}{l}\text { with the expectation that the human } \\
\text { driver will respond appropriately to } \\
\text { a request to intervene }\end{array}$ \\
\hline 4 & High Automation & & $\begin{array}{l}\text { even if a human driver does not respond } \\
\text { appropriately to a request to intervene }\end{array}$ \\
\hline 5 & Full Automation & & $\begin{array}{l}\text { under all roadway and environmental } \\
\text { conditions that can be managed by } \\
\text { a human driver }\end{array}$ \\
\hline
\end{tabular}


Table 5. Non-Technological Innovations as Sources of Value Extraction

\begin{tabular}{|l|l|}
\hline \multicolumn{1}{|c|}{ Type of innovation } & \multicolumn{1}{c|}{ Means of value extraction } \\
\hline Social innovation & Allows and/or enhances the possibility of value extraction from technological innovation. \\
\hline Business innovation & Allows one to extract value that would otherwise be lost due to market externalities \\
\hline Administrative innovation & Changes some element of existing business processes and/or systems \\
\hline Organizational innovation & Creates value by changing the structure of social systems such as groups or organizations \\
\hline Source: compiled by the author. & \\
\hline
\end{tabular}

Above all, it is necessary to raise awareness that innovation is most often not technological, by supporting the programs that illustrate the importance of relevant dimensions of innovation. Table 5 summarizes the means of value extraction that are inherent to different types of non-technological innovation.

Further, one should focus on extracting value from a technology as opposed to developing a technology. The UK has been characterized as having excellence in science, but not in technology. However, studies of British technology have shown that the UK is successful in producing innovative technology - such as EMI's CT Scanner. While EMI was the developer of a successful product, they lost market share and eventually the entire market to General Electric (GE). GE's focus was on extracting value from the technology and utilizing business model innovation. This strategy allowed GE to catch up and eventually eliminate EMI from the market [Mitchell, 1994]. Perhaps if EMI had been a leader in both technological and business model innovation, they could have fought off GE's competitive challenge.

Finally, it is viable to force interaction - with patience. Researchers are educated, trained, and rewarded for having an intense interest in one specific field of study. Universities, their departments, and faculties are similarly structured, assessed, and rewarded for narrow specialization. Innovation - technological or otherwise - calls for an interdisciplinary focus on problems and/or opportunities. While incentivizing (forcing) technological researchers to work with arts, humanities, and social sciences researchers may seem inefficient, it is worthwhile if there is interest in exploiting technological innovation. Similarly, it is worth incentivizing other forms of translational research (e.g., those involving arts, humanities, and social sciences) to unleash innovation.

Incentivizing the interaction between different fields and faculties should not be limited to research, it should also be encouraged for undergraduate and graduate education. The association of degree programs with specific departments is a major hindrance to the goal of encouraging different specialties (departments) to work with one another in general.

\section{Conclusions}

Historically, innovation has not been the focus of national laboratories or universities in most countries. If innovation is to be a priority, new incentives and approaches are required as innovation requires a blending of expertise from a variety of fields.

The first barrier is a clear understanding of the existence and nature of different types of innovation and how all types of innovation - even technological innovations - rely heavily upon input from the arts, humanities, and social sciences. There is no clear global leader in innovation for the arts, humanities, and social sciences. However, there is recognition that this area is under-developed and offers excellent opportunities for international cooperation.

The three recommendations offered to advocates of innovation are to:

1. Raise awareness about the fact that innovation is most often not technological

2. Focus on extracting value from technology as opposed to developing technology

3. Force interaction across disciplines - but to do so with patience.

This project was supported by the Innovation Caucus, funded by Innovate UK and the Economic and Social Research Council. This article was prepared within the framework of the Basic Research Program at the National Research University Higher School of Economics (HSE) and supported within the framework of subsidy provided by the Russian Academic Excellence Project '5-100'. Finally, a thank you to Linda Xu for the thorough literature review she conducted on the prior academic work at the interface of innovation the arts, humanities and social sciences.

\section{References}

Barras R. (1986) Towards a Theory of Innovation in Services. Research Policy, vol. 15, pp. 161-173.

Bullen E., Robb S., Kenway J. (2004) 'Creative destruction': Knowledge economy policy and the future of the arts and humanities in the academy. Journal of Education Policy, vol. 19, no 1, pp. 3-22. 
European Commission (2014) HORIZON 2020 - Work Programme 2014-2015 (Annex G. Technology Readiness Levels (TRL) as Defined by the Commission Decision C(2014)4995), Brussels: European Commission. Available at: https://ec.europa.eu/research/participants/data/ref/h2020/wp/2014_2015/annexes/h2020-wp1415-annex-gtrl_en.pdf, accessed 15.05.2018.

Fri R.W., Savitz M.L. (2014) Rethinking energy innovation and social science. Energy Research and Social Science, vol. 1, pp. 183-187.

Gokhberg L., Sokolov A. (2017) Technology foresight in Russia in historical evolutionary perspective. Technological Forecasting and Social Change, vol. 119, pp. 256-267.

Gokhberg L., Sokolov A., Chulok A. (2017) Russian S\&T Foresight 2030: Identifying New Drivers of Growth. Foresight, vol. 19, no 5, pp. 441-456.

Gulbrandsen M., Aanstad S. (2015) Is innovation a useful concept for arts and humanities research? Arts and Humanities in Higher Education, vol. 14, no 1, pp. 9-24.

Hammer M., Champy J. (1993) Reengineering the Corporation, Harper Collins: New York.

Hawkins R., Langford C.H., Saunders C. (2015) Assessing the practical application of social knowledge: A survey of six leading Canadian universities. Research Policy, vol. 44, no 1, pp. 83-95.

Jenkins N. (2015) Alarm over huge cuts to humanities and social science at Japanese universities. Time Magazine, September 16. Available at: http://time.com/4035819/japan-university-liberal-arts-humanities-social-sciencescuts/, accessed 17.07.2018.

Klein K.J., Sorra J.S. (1996) The challenge of innovation implementation. Academy of Management Review, vol. 21, no 4, pp. 1055-1080.

Lavoie M. (2011) The role of social scientists in accelerating innovation in regenerative medicine. Review of Policy Research, vol. 28, no 6, pp. 613-630.

Linton J.D. (2009) De-Babelizing the Language of Innovation. Technovation, vol. 29, no 11, pp. 729-737.

Lundströma A., Zhou C. (2011) Promoting innovation based on social sciences and technologies: The prospect of a social innovation park. Innovation, vol. 24, no 1-2, pp. 133-149.

Mitchell W. (1994) Playing leap-frog with Elephants: EMI, Ltd. and CT scanner competition in the 1970s. A Case Study by the University of Michigan Business School. Available at: http://www-personal.umich.edu/ afuah/cases/case4. html, accessed 11.03.2018.

Murphy J., Parry S., Walls J. (2016) The EPSRC's Policy of Responsible Innovation from a Trading Zones Perspective. Minerva, vol. 54, no 2, pp. 151-174.

NISTEP (2017) Efforts aimed at realizing a sustainable aging society and low carbon society (Part 2 - Study on the ideal way of living in the area) // STI Horizon. Vol. 3. № 1. Available at: http://doi.org/10.15108/stih.00070, accessed 15.02.2018.

Ponomarev A., Dezhina I. (2016) Approaches to the formulation of Russia's technological priorities. Foresight and STI Governance, vol. 10, no 1, pp. 7-15.

Rogers E.M. (1995) The Diffusion of Innovations ( $4^{\text {th }}$ ed), New York: Free Press.

SAE (2014) Taxonomy and Definitions for Terms Related to On-Road Motor Vehicle Automated Driving Systems J3016_201401. Available at: https://www.sae.org/standards/content/j3016_201401/, accessed 15.05.2018.

Teixeira A.A.C., Vieira P.C., Abreu A.P. (2017) Sleeping Beauties and their princes in innovation studies. Scientometrics, vol. 110, no 2, pp. 541-580.

Tornatzky L.G., Fleischer M. (1990) The Process of Technological Innovation, Lexington: Lexington Books.

Turcanu C., Schröder J., Meskens G., Perko T., Rossignol N., Carlé B., Hardeman F. (2016) Like a bridge over troubled water - Opening pathways for integrating social sciences and humanities into nuclear research. Journal of Environmental Radioactivity, vol. 153, no 88-96.

von Hippel E. (2017) Free Innovation, Boston MA: MIT Press.

von Krogh G., Spaeth S. (2007) The open source software phenomenon: Characteristics that promote research. Journal of Strategic Information Systems, vol. 16, no 3, pp. 236-253.

Wise R., Baumgartner P. (2000) Go downstream: The new profit imperative in manufacturing. IEEE Engineering Management Review, vol. 28, pp. 89-96.

Yin R.K. (1978) Changing Urban Bureaucracies: How New Practices Become Routinized, Santa Monica, CA: Rand Corporation.

Yin R.K. (1992) Measuring success in AMT implementation using customer-supplier interaction criteria. International Journal of Operations and Production Management, vol. 12, no 10, pp. 34-55.

Zmud R.W., Apple E. (1992) Measuring Technology Incorporation/Infusion. Journal of Product Innovation Management, vol. 9, no 2, pp. 148-155. 


\title{
Research Programmes that Address Societal Challenges - Aligning Policy, Implementation, and Expected Impact
}

\author{
Irene Ek \\ Senior Analyst, Irene.Ek@tillvaxtanalys.se \\ Swedish Agency for Growth Policy Analysis, Torsgatan 11, Stockholm, Sweden
}

\begin{abstract}
7 his article explores research programs that address societal challenges. In recent years, the rationale for innovation policy has been extended to include support instruments more explicitly designed to address societal challenges. While there are broad agreements that in this rationale research and innovation support can not only stimulate growth and economic activity, but they can also actively be directed towards meeting societal challenges.

However, exploring how societal challenge policy goals can be translated into something that the support instruments can influence, is not yet the focus of challenge-driven innovation policy and a topic that seems to be neglected in the research literature. This article develops a framework for a cross country analysis of how policy, programs, and impact align and highlight what can be learned from selected societal challenge programs.
\end{abstract}

\section{Keywords:}

societal challenges; policy alignment; innovation policy; research programmes; programme design; impact; evaluation
Citation: Ek I. (2018) Research Programmes that Address Societal Challenges - Aligning Policy, Implementation, and Expected Impact. Foresight and STI Governance, vol. 12, no 3, pp. 13-19. DOI: 10.17323/2500-2597.2018.3.13.19 
$\mathrm{T}$ The debate over research and innovation policy that address societal challenges has received increased attention over recent years [Edler, Boon, 2018; Foray et al., 2012; George et al., 2016; Kallerud et al., 2013; Kuhlmann, Rip, 2016; Mazzucato, 2015, 2018; Weber, Stephanie, 2014]. Researchers and policy makers alike are increasingly focusing on the difficulties stemming from the complexity of policy. A growing number of countries turn their attention to societal challenges like climate change, health, and sustainable society [DFiR, 2017; Finnish Government, 2014; Swedish Government, 2016; UK Government, 2015]. Scholars have recognized that the instruments that implement policies directed at societal challenges need to encompass a diverse set of actors and address multiple objectives [Edler, Boon, 2018; Foray et al., 2012; Kuhlmann, Rip, 2016]. It is argued that this complexity calls for a systemic approach.

It is not only individual countries that turn their focus toward societal challenges. Looking at the EU's plans for the new research program Horizon Europe for 2021-2027, it was put forward that the research supported by the program would tackle the major global challenges of our time and contribute to achieving the Sustainable Development Goals [Mazzucato, 2018]. The literature suggests that the role of the state in innovation policy is changing. It is becoming increasingly important for both researchers and policy makers to explore how to use research and innovation to solve the pressing global challenges of our time.

The ability of innovation to drive economic growth has long been recognized [Bloom et al., 2013; OECD, 2015]. Less recognized is the view that innovation also has a direction [Mazzucato, 2018]. By harnessing the directionality of innovation, it is suggested that it is also possible to harness the power of research and innovation in order to achieve wider social and policy aims as well as economic goals. Rather than supporting traditional research and innovation programs that deliver incremental results, the state is increasingly seen as an actor that can shape the directionality of innovation, i.e., create the conditions for systemic transformation [Geels et al., 2017]. This shift is most clearly expressed in "challenge"-oriented policies that seek to define areas of societal concern and tackle defined societal challenges.

The present article analyzes the experience of working with national research programs in selected countries. These case studies provide empirical descriptions of existing practices, with conclusions about important factors to consider in the design and implementation of such national research programs.

Case studies of the following five programs have been carried out:

- Denmark - Grand Solutions

- United Kingdom - Prime Minister's Challenge on Dementia

- Canada - NRC-CNRC, Arctic Program

- Finland - Strategic Research Council (SRC), focus on Climate Neutral Finland

- EU - JPI, focus on climate change

In Sweden, research programs that address societal challenges are a relatively new phenomenon [Swedish Government, 2016]. They differ from more "traditional" programs in the following ways [FORMAS, 2017]. First, they are longer as they extend beyond the time span of two research bills. Second, they are more ambitious in scope. Third, they aim to achieve a strategic overall coordination of research funding and other activities in Sweden, and are expected to create synergies between different actors. Fourth, rather than focusing on creating a project portfolio in line with program objectives (as in the case of "traditional" research programs), they also aim to function as a platform for new and ongoing research and to be a link to international programs and EU Joint Programming Initiatives. Finally, they aim to contribute to an increased impact in society in terms of development, knowledge building, evidence-based policies and management, and ultimately to contribute to national policy goals. The need for an international scanning report was articulated by the Swedish Research Council for Sustainable Development and the lessons learned have been presented to the Swedish Research Councils [Tillväxtanalys, 2017].

\section{Method}

Several properties make the study of research and innovation programs that address societal challenges particularly demanding from a methodological perspective. First, these are complex programs embedded in different national contexts. The need to gather and conduct a cross country comparative analysis is recognized in the literature. Intensified globalization requires public administration research to embrace a comparative perspective [Fitzpatrick et al., 2011]. In addition, several countries face the same challenges increasing the need for coordination. Second, in some sense it is an ex-ante exploration as some of the selected programs are still ongoing. While the budget and governance structures are fixed, the program design can, to some extent, still be developed and undergo changes, thus it remains somewhat flexible.

To mitigate these constraints, this paper presents five qualitative case studies about research and innovation programs that address societal challenges in selected countries. These case studies allow for an in-depth study of emerging programs that address societal challenges. Case studies allow the researcher to deal with a variety of material such as documents and interviews [Yin, 2003]. In this article, data has been collected and analyzed from a diverse set of sources including program documents and 15 semi-structured interviews with program experts from each respective country. 
The semi-structured interviews were focused on program design, implementation, and covered the following questions:

- Can you describe the process for program design and setting the research agenda? Which actors participated? What helped that happen?

- Can you describe the support instruments that were used?

- Can you describe the governance structure of the program? Does the governance structure allow for flexibility and if so how?

- Can you describe how collaboration takes place? How does it happen?

- Is the program evaluated, if so, what were the results?

\section{Theoretical Framework}

This article attempts to address the problem of developing and implementing policies that seek to alleviate the pressing global challenges of our time. A framework was introduced that sets out the elements and illustrates the flow from policy goal to the instrument deployed, and finally to the impacts that the selected instrument can deliver. In other words, it shows how the nested relations between policy, instrument, and impact align. The framework expands upon existing literature as it highlights a new form of policy coherence that is compatible with a more sophisticated, multi-actor, and dynamic understanding of the processes by which policies that address societal challenges are implemented and can deliver societal impact.

Policy makers and researchers alike are increasingly focusing upon challenges that demand a complex policy approach. This shift in emphasis is exemplified by the adoption of the term "policy mix", which implies a focus on coherence, i.e., the interactions and interdependencies between different support instruments as they affect the extent to which policy goals are realized [Flanagan et al., 2011]. In addition, the literature emphasizes the fact that support instruments are not intended to (and cannot) influence the ultimate policy objectives (e.g., system transformation) in an immediate sense because these instruments can only influence the innovation and industrial development processes. This implies that the ultimate policy objectives must be "translated" into concrete problems that can be influenced directly by support instruments [Borrás, Edquist, 2013].

Thus far, there have been a number of more theoretical studies that address societal challenges. This article expands upon this previous literature [Cejudo, Michel, 2017; Edler, Boon, 2018; Koff, 2017; Mazzucato, 2018] and it introduces a new framework that is used to analyze empirical examples from a number of programs that address societal challenges. The research question is, "How coherent are the policies for the implementation of these transformative objectives that characterize societal challenges?" Any progress in addressing complex problems such as societal challenges requires empirically clarifying these policy initiatives and showing their implications for policy design and implementation.

This article explores the problem of developing and implementing policies that address societal challenges. It offers new recommendations regarding new support instruments by introducing the idea of describing the choice and formulation of the support instruments that make up the implementation of societal challenges. There may be serious consequences, if the choices of support instrument for such complex programs as societal challenges are not specifically addressed.

To this end, Figure 1 proposes a new framework that set out the elements necessary to illustrate the flow from the policies that address societal challenges, to the instruments deployed, and finally to the impacts that the selected instruments can have. In other words, how the nested relationships between policy, instrument, and impact align. This new framework is designed to highlight a new type of policy coherence that is compatible with a more sophisticated, multi-actor, and dynamic understanding of the processes from which policy that aims for system transformation emerges, how it is implemented, and what impact can be expected.

The framework presented here is used to conduct a coherence analysis of how the nested relationships between policy, support instrument, and impact align. High coherence indicates that the political objective can be implemented. Low coherence indicates that that the selected support instruments cannot fully implement the policy objectives.

The present results indicate that the political objectives and the support instruments do not fully align. The policy objective to address societal challenges has been followed by the launch of research programs. Following the flow from the policy objectives, the choice of support instruments was fairly traditional and could not fully implement the transformation necessary to address the societal challenge.

There is a gap in the literature when it comes to theories that are used to understand the implementation of policies that address societal challenges and require system transformation. Societal challenges are an area of policy-making that is characterized by the need for coordination between policy domains [Trein, 2017]. OECD innovation strategy highlights the need for vertical as well as horizontal governance [OECD, 2015], which implies that the public authorities in charge belong to various levels of authority and policy competences. Effective policies for system transformation might need to be joined up, across 

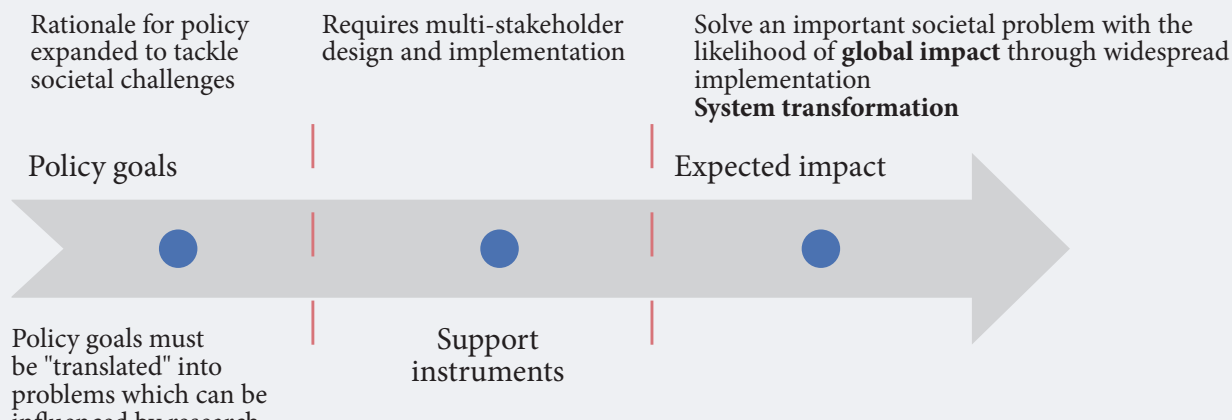

problems which can be

programs

Source: compiled by the author.

Alignment/coherence

a broad set of policy areas, including research policy, industrial policy, environmental policy, and public sector policy. This increases the number of actors and agendas that need to be coordinated in order to achieve coherent policies.

\section{Case Findings}

The case description below is a summary of an international review of research programs that focus on societal challenges performed by the Swedish Agency for Growth Policy Analysis [Tillväxtanalys, 2017]. The five case studies show certain differences and some similarities. This section summarizes these findings and explores practices for such programs.

The cases present some common features. They all address societal challenges as this was part of the selection criteria. Still, there are differences in how specific or generic these programs are. Some address more universally agreed upon societal challenge topics (e.g., climate change) and some are more targeted or local in scope, such as the dementia challenge in the UK or the challenges of living and conducting business in the Arctic in Canada.

Some of the case studies, such as the Danish Grand Solutions and A Climate-Neutral and ResourceScarce Finland, broadly define the challenge or challenges to be addressed, but leave it to the applicant to define how and what part of the challenge to tackle. The UK Dementia challenge and Canada Arctic Program are much more specific in the issues they address.

The scope of the programs, in terms of budget and time limit, varies. The Danish Grand Solutions program funds projects that have a life span of three to five years; the UK and Finnish cases run from 2015 to 2020; the Canadian Arctic Program case is an eight-year program, whereas the Climate JPI has no fixed end date. The annual budgets are difficult to compare, but those of the Danish and UK cases are larger than the others.

All the case study programs involve a higher degree of stakeholder consultation than what is normally seen in research and innovation programs, although the nature of the interaction of different types of stakeholders varies between the programs. They are all explicitly "top down", in the sense that government sets the policy objectives to be implemented in the program. However, there is then variation in how the policy objective is translated into a specific research program. The UK Dementia challenge has a detailed program design that considers the correlation between individual activities and therefore involves the development of infrastructure as well as research. Canada's Arctic Program is designed within the NRC and presumably is in line with the NRC's larger research program and its implementation.

The other three cases do not involve mutually consistent, programmed activities that together build towards a predetermined goal. Thus, the Danish Grand Solutions are selected from the bottom-up within the government's thematic priorities. Similarly, Finland's Strategic Research Programmes select the proposals that meet the thematic and quality criteria but do not have a collective architecture. Finally, the JPIs fund bottom-up research within the thematic priorities agreed upon among the participating states. The five cases show different mechanisms for providing input in the decision-making process. For example, decisions on funding allocations for challenge areas in Denmark are taken up by policy makers (topdown) but these decisions refer to a non-binding "catalogue" of priority areas developed in consultation 
Table 1. Similarities and Differences among National Research Programs

\begin{tabular}{|l|l|l|l|l|l|}
\hline \multicolumn{1}{|c|}{ Features } & \multicolumn{1}{|c|}{ UK } & \multicolumn{1}{c|}{ Denmark } & \multicolumn{1}{c|}{ Finland } & \multicolumn{1}{c|}{ Canada } & \multicolumn{1}{c|}{ Japan } \\
\hline Budget & $>£ 300 \mathrm{mln}$ & $600 \mathrm{~m}$ DKK/year & $€ 17 \mathrm{mln}$ & \$ CAN $86 \mathrm{mln}$ & Not defined \\
\hline Time & $2015-2020$ & $3-5$ years & $2015-2020$ & 8 years & Not defined \\
\hline Focus & Dementia & $\begin{array}{l}\text { Several, i.e., energy } \\
\text { and health }\end{array}$ & Climate change & $\begin{array}{l}\text { Business development } \\
\text { in an Arctic climate }\end{array}$ & Climate change \\
\hline Governance & $\begin{array}{l}\text { Partnership both top- } \\
\text { down and bottom-up }\end{array}$ & $\begin{array}{l}\text { Theme: mostly top- } \\
\text { down } \\
\text { Choice of program: } \\
\text { bottom-up }\end{array}$ & $\begin{array}{l}\text { Formulation: top-down } \\
\text { Selection: bottom-up }\end{array}$ & $\begin{array}{l}\text { Top-down selection } \\
\text { of four areas, bottom- } \\
\text { up selection of } \\
\text { technologies }\end{array}$ & Bottom-up \\
\hline Participants & $\begin{array}{l}\text { Public and private sector, } \\
\text { health sector, NGOs, } \\
\text { researchers, patients, } \\
\text { care-givers, public }\end{array}$ & $\begin{array}{l}\text { Public and private } \\
\text { sector, researchers } \\
\text { and users }\end{array}$ & $\begin{array}{l}\text { University, institutes, } \\
\text { companies and } \\
\text { some international } \\
\text { participants }\end{array}$ & $\begin{array}{l}\text { Public and private } \\
\text { sector }\end{array}$ & $\begin{array}{l}17 \text { member } \\
\text { countries }\end{array}$ \\
\hline
\end{tabular}

with the sector. A similar catalogue is used in Finland, which is prepared by the research council. This means that although this process is formally top-down from the policy-makers, it still permits input from stakeholders. How these themes are expressed in the actual proposals and partnerships is usually decided upon through a bottom-up process in which the applicants describe the issues to be tackled and chose them according to certain pre-set criteria. These criteria can be tilted more towards innovation (as in the case of the Danish Grand Solutions, in which value creation is a decisive factor) or more towards research (as in A Climate-Neutral and Resource-Scarce Finland, in which certain guiding principles and research issues are decisive).

It seems reasonable to suppose that the UK Dementia challenge and Canada's Arctic Program will make progress towards the practical implementation of goals while the other three cases are more likely to produce knowledge that may or may not turn out to be useful in setting agendas and developing policy. The style of governance follows the same pattern, with the UK Dementia challenge and presumably the Canadian Arctic Program, being closely monitored and governed. A rather strong vertical coordination emerges in the Danish and Finnish cases, in which central government plays an active role in defining priorities and budgets. The UK Dementia case is more about horizontal coordination, with collaboration between sector agencies and ministries. The Board of the UK Dementia Programme comprises senior leaders from many partner organizations involved in the challenge and is chaired by the Parliamentary Under Secretary of State. Major individual initiatives under the program have their own governance structures. In the case of the Danish Grand Solutions, IFD is led by a Board of Directors comprising nine politically-appointed members with research and industry expertise. The Fund reports to the Ministry for Education and Research but functions at arm's length from the government. Unlike the Fund's other schemes, all decisions concerning investments in Grand Solutions are taken directly by the Board. The other three cases follow a more traditional research council model of defining thematic priorities, selecting projects, and then allowing nature to take its course.

The Joint Programming Initiative was evaluated in 2016 and is the only one of the cases studied that has been formally evaluated thus far. Most of the other programs have been scheduled for such analyses in the near future. An internal Progress Review Group continually monitors the key performance indicators of the UK Dementia Programme, which in this respect stands out as more detailed and, possibly, more ambitious than the other programs. The program's approach of discussing beforehand what must be done to achieve the desired outcomes and impact in the short, medium, and long term, and what success will look like at each stage, could be a lessons learned for challenge-led research programs elsewhere.

\section{Results}

All the cases studied are top-down in the sense that they stem from a political decision. It seems clear that the aim to align the program with national priorities is a common feature. The inclusion of a broad spectrum of stakeholders in designing the programs is common and, in turn, favors networking with new stakeholders and decision-makers.

Public-private partnerships (PPPs) such as the UK Dementia Challenge involve a transfer of programming activity and research agenda setting from the funding organization to the partnership. This may create a principal-agent problem, providing an incentive to the partnership to follow its own narrower goals rather than those of the funder. Therefore, this type of program may require close monitoring and supervision by the funder, which is to some extent reflected in the governance structure of the Dementia challenge, with multiple checks and balances.

A program that draws on a national strength is more likely to be perceived by the respondents as being successful. This is highlighted in all of the case studies. 
Although the overarching initiative, and possibly even its objectives or goals, are set from the beginning, deciding on the actual program design and content through a flexible, interactive, and inclusive process would seem to increase the likelihood of a successful program.

All the case study programs involve a higher degree of stakeholder consultation than is normally seen in research and innovation programs. Early dialogue with stakeholders about priorities seems to favor inclusion and commitment. The respondents all describe a dialogue that strives to include all relevant partners from the outset through planning to delivery.

\section{Concluding Remarks}

The traditional focus on the research and innovation processes has served us well in the past, when a central policy aim was to promote excellent research and economic growth. Now, policymakers are more concerned about complex societal challenges. These concerns are transforming much of research and innovation policy.

Policymakers have already begun to take a more systemic view than before on innovation, growth, and development. They are now trying to put policies into place that help address the societal challenges. This article provides further empirical nuances that support Arnold et al.s [Arnold et al. 2018] view that these policy initiatives involves greater coordination across different parts of society including stakeholders well outside of what we have historically regarded as the research and innovation community, creating larger-scale and longer-term programs that span more actors than before - both horizontally across different sectors of society and also vertically, with activities taking place at international, national, and regional levels. As policy interventions become larger and more complicated, involving greater numbers of actors, coordination becomes increasingly important. The cases highlight a move towards what Edler and Boon [Edler, Boon, 2018] describe as a demand-driven process for identifying the research priorities and program design.

This article also provides a coherence analysis of how the nested relationships between policy, instrument, and impact align. High coherence indicates that the political objective of addressing societal challenges can be implemented. Low coherence indicates that that the selected instrument cannot fully implement the changes needed to address societal challenges. The present results indicate that the political objectives and the selected support instruments do not fully align. Following the flow from the policy objectives to the implementation, it becomes clear that some parts of the policy to address societal challenges are still waiting to be implemented. Although the programs studied here have a somewhat new dimension, a large part of their design is still more traditional. Delivering the system transformation required to address societal challenges with programs that remain traditional is problematic. System transformations are important as many of the societal challenges seem likely to require them. Still the literature provides few examples of how these new types of complex programs can be designed, implemented, and evaluated.

The text in this article is the writer's own view and not that of the Swedish Agency for Growth Policy Analysis.

\section{References}

Arnold E., Åström T., Glass C., de Scalzi, M. (2018) How should we evaluate complex innovation programmes and sustainability transitions? Stockholm: Technopolis Group.

Bloom N., Schankerman M., van Reenen J. (2013) Identifying Technology Spillovers and Product Market Rivalry. Econometrica, vol. 81, no 4, pp. 1347-1393. DOI: 10.3982/ECTA9466.

Borrás S., Edquist C. (2013) The choice of innovation policy instruments. Technological Forecasting and Social Change, vol. 80, pp. 1513-1522. Available at: https://doi.org/10.1016/j.techfore.2013.03.002, accessed 15.02.2017.

Cejudo G.M., Michel C.L. (2017) Addressing fragmented government action: Coordination, coherence, and integration. Policy Sciences, vol. 50, no 4, pp. 745-767. DOI:10.1007/s11077-017-9281-5.

DFiR (2017) Danish Research Bill. RESEARCH2025, Copenhagen: Danish Council for Research and Innovation Policy (DfiR).

Edler J., Boon W.P. (2018) The next generation of innovation policy: Directionality and the role of demand-oriented instruments' - Introduction to the special section. Science and Public Policy (forthcoming). DOI: 10.1093/scipol/ scy026.

Finnish Government (2014) Government Proposal for a New Climate Change Act to Parliament (HE 82/2014, 5 June 2014), Helsinki: Finnish Government.

Fitzpatrick J., Goggin M., Heikkila T., Klingner D., Machado J., Martell C. (2011) A New Look at Comparative Public Administration: Trends in Research and an Agenda for the Future. Public Administration Review, vol. 71, no 6, pp. 821-830. 
Flanagan K., Uyarra E., Laranja M. (2011) Reconceptualising the 'policy mix' for innovation. Research Policy, vol. 40, no 5, pp. 702-713. Available at: https://doi.org/10.1016/j.respol.2011.02.005, accessed 27.11.2017.

Foray D., Mowery D.C., Nelson R.R. (2012) Public R\&D and social challenges: What lessons from mission R\&D programs? Research Policy, vol. 41, no 10, pp. 1697-1702. Available at: http://dx.doi.org/10.1016/j. respol.2012.07.011, accessed 14.03.2018.

Geels F.W., Sovacool B.K., Schwanen T., Sorrell S. (2017) Sociotechnical transitions for deep decarbonization. Science, no 357(6357), pp. 1242-1244. DOI:10.1126/science.aao3760.

George G., Howard-Grenville J., Joshi A., Tihanyi L. (2016) Understanding and Tackling Societal Grand Challenges through Management Research. Academy of Management Journal, vol. 59, no 6, pp. 1880-1895. DOI: 10.5465/ amj.2016.4007.

Kallerud E., Amanatidou E., Upham P., Nieminen M., Klitkou A., Sutherland Olsen D., Toivanen M.L., Oksanen J., Scordato L. (2013) Dimensions of research and innovation policies to address grand and global challenges (Working Paper 13/2013), Oslo: NIFU.

Koff H. (2017) Diaspora Philanthropy in the Context of Policy Coherence for Development: Implications for the post2015 Sustainable Development Agenda. International Migration, vol. 55, no 1, pp. 5-19. DOI: 10.1111/imig.12277.

Kuhlmann S., Rip A. (2016) The challenge of addressing Grand Challenges. A think piece on how innovation can be driven towards the "Grand Challenges" as defined under the prospective European Union Framework Programme Horizon 2020, Brussels: European Commission.

Mazzucato M. (2015) A mission-oriented apporach to building the entrepreneurial state (Report commissioned by the UK Government), London: UK Government.

Mazzucato M. (2018) Mission-oriented Research \& Innovation in the European Union. A Problem-solving Approach to Fuel Innovation-led Growth, Brussels: European Commission.

OECD (2015) OECD Innovation Strategy 2015. An Agenda for Policy Action, Paris: OECD.

FORMAS (2017) Report to the Swedish Government on how the work with the natonal programmes evolves, Stockholm: Swedish Research Council for Sustainable Development (FORMAS).

Swedish Government (2016) Swedish Research Bill. Collaborating for knowledge - for society's challenges and strengthened competitiveness, Stockholm: Swedish Government.

Tillväxtanalys (2017) International scanning of research programmes that focus on societal challenges (vol. PM 2017:18), Stockholm: The Swedish Agency for Growth Policy Analysis (Tillväxtanalys).

Trein P. (2017) Coevolution of policy sectors: A comparative analysis of healthcare and public health. Public Administration, vol. 95, no 3, pp. 744-758. DOI: 10.1111/padm.12323.

UK Government (2015) Prime Minister's Challenge on Dementia 2020, London: UK Government.

Weber M., Stephanie D. (2014) Exploring transformative research and innovation futures and their embedding in the ERA. Paper presented at the 5th concerence on the Future-Oriented Technology Analysis (FTA) 2014 "Engage today to shape tomorrow", Brussels, November 2014.

Yin R.K. (2003) Case study research: Design and methods, Thousand Oaks: Sage Publications. 


\title{
The Future of the Italian Electricity Generation Sector. An Analysis of the Possible Strategic Models
}

\author{
Vincenzo Bianco \\ Associate Professor, vincenzo.bianco@unige.it \\ University of Genoa, Via All'Opera Pia 15/A, 16145 Genova, Italy
}

\begin{abstract}
7 he present paper investigates the possible future evolution of the Italian power system. In particular, the generation sector is considered by analyzing its recent development, which has been pushed forward by EU regulations that support the deployment of renewablesbased power plants. These radical changes will determine the restructuring of the system. It is therefore critical to try
\end{abstract}

Abstract

\section{Keywords:}

electricity generation; renewable energy sources; development strategies; roadmap; scenarios; Italy to understand which trajectories its possible evolution could take according to different market and economic conditions. To this aim, a scenario analysis was implemented in order to determine the strategic implications that the various situations can yield for generators. As a result, four strategic models are envisaged, namely Traditional Generator, Innovative Generator, Green Generator, and Energy Service Provider.
Citation: Bianco V. (2018) The Future of the Italian Electricity Generation Sector. An Analysis of the Possible Strategic Models. Foresight and STI Governance, vol. 12, no 3, pp. 20-28. DOI: 10.17323/2500-2597.2018.3.20.28 
$\mathrm{T}$ he European energy strategy attributes pivotal importance to the development of renewable energy sources [European Commission, 2018]. In this regard, the aim of European Union (EU) is twofold, namely to reduce the environmental impact of the energy sector and to increase the energy security of the EU system. In particular, an increase in the share of renewables leads to a decrease in the consumption of fossil fuels, which are massively imported by the EU, especially natural gas [Smith, 2013]. By reducing this consumption, the EU will reduce its energy dependence on third countries, such as the Russian Federation (which is the leading supplier of natural gas to the EU), Middle Eastern countries, and other third countries. A reduction in this dependence will ensure an increase in European energy security as it decouples the EU from geopolitical issues affecting these areas [Richter and Holz, 2015].

In order to achieve this goal, each EU country has committed itself to fulfilling legally binding agreements in terms of the development of renewables, the reduction of carbon emissions, and the increase of energy efficiency. Among the different production sectors, the power generation sector has been particularly affected by these policies as it represents one of the most energy intensive segments and is a principal consumer of fossil fuels. In light of this, European directives have pushed the sector to reshape itself by promoting the massive deployment of renewable energy sources, in particular, solar, photovoltaic (PV), and wind. This has led to a drastic reduction in the utilization of fossil fuels and natural gas in particular, which represented a marginal technology on many EU markets.

The present paper focuses on an analysis of the Italian market, which is relevant as it represents the fourth largest EU market in terms of electricity consumption after France, Germany, and the UK. Therefore, several authors have studied the Italian power system, however, most studies are focused on forecasting electricity prices or an analysis of energy related topics.

For example, Vespucci et al. modelled the finding of equilibrium on a market where a large producer can exert market power, as is the case of Italy [Vespucci et al., 2013]. Gianfreda and Grossi analyzed the Italian spot market with a focus on price dynamics by taking into account technologies, market concentration, the overloading of networks, and volumes. They employed a statistical and econometric approach [Gianfreda, Grossi, 2012]. Other authors investigated the impact that the introduction of nuclear power plants may have had on the Italian electricity market [Guerci, Fontini, 2014].

On the contrary, Franco and Salza developed an analysis of the Italian power system from an energy point of view. They analyzed the energy balances according to different scenarios of renewables penetration [Franco, Salza, 2011].

The analysis of the reviewed literature highlights that the available studies on the Italian power system are quite specific and focus on the analysis of concrete characteristics. This is important because detailed studies have been performed, but, on the other hand, there are very few strategic assessments of the market. The present paper attempts to analyze the strategic implications that various economic factors can have on the power generation sector. In particular, the reduction of natural gas consumption has a significant impact upon the country's energy strategy and infrastructure planning, furthermore the prioritization of investments can strongly change as a result of modified energy balances (e.g. an increase in the construction of infrastructure for electricity storage and the reinforcement of power grids vs. natural gas pipelines, which increase import capacity). Furthermore, the reduced demand for natural gas may lead to changes in the sourcing strategy and in the relationships with the current supplying countries. In particular, new routes of supply may be established via LNG terminals available in Italy that are currently underutilized. This will contribute to a further increase of the country's energy security, since it moves Italy towards a reduction of its energy dependence upon a limited groups of countries (e.g., Algeria, Libya, and the Russian Federation). The current analysis elaborates upon the "Ten Years Network Development Plan" (TYNDP) published by the European Network of Electric Transmission System Operators [ENTSOE, 2018], in order to come up with strategic insights concerning the Italian power system. In particular, the focus is on the analysis of the strategic implications deriving from the four scenarios proposed in the TYNDP. On the basis of this, it will be possible to develop strategic visions, which can be defined as possible future goals and play an important role in the decision making process.

\section{The Italian Power System in Brief}

Over the last several years the Italian power sector has been subjected to radical modifications, which have reshaped its configuration. If the last ten years are taken into account, these changes are clearly highlighted, as reported in Figure 1.

Figure 1(a) shows that approximately ten years ago the electricity generation sector was dominated by the utilization of fossil fuels, primarily coal and natural gas with fuel oil representing a limited share. Renewables were represented by hydro power plants which are quite developed in Italy. It seems like most of the hydro potential of the country has been exploited. Only minor margins exist to increase the use of hydro power.

From a strategic point of view, power generators must be able to guarantee a competitive and continuous supply of natural gas and coal for their power plants. On the other hand, it should be noted that coal is much simpler to handle than natural gas because it can be easily transported and stored without necessitating 
(a) Dynamics of Generation and Consumption

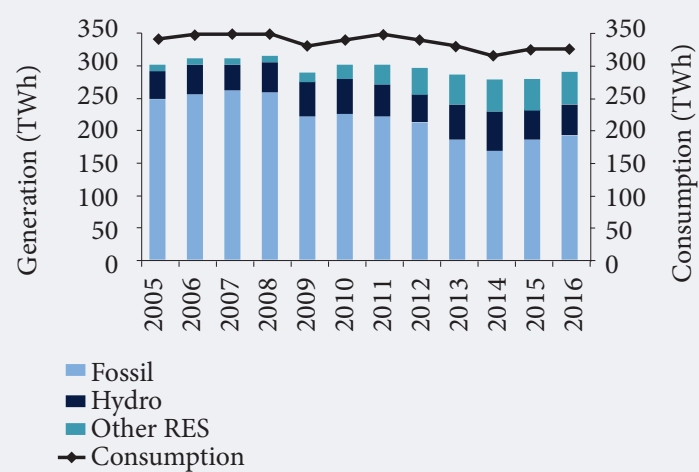

(c) Evolution of RES Capacity

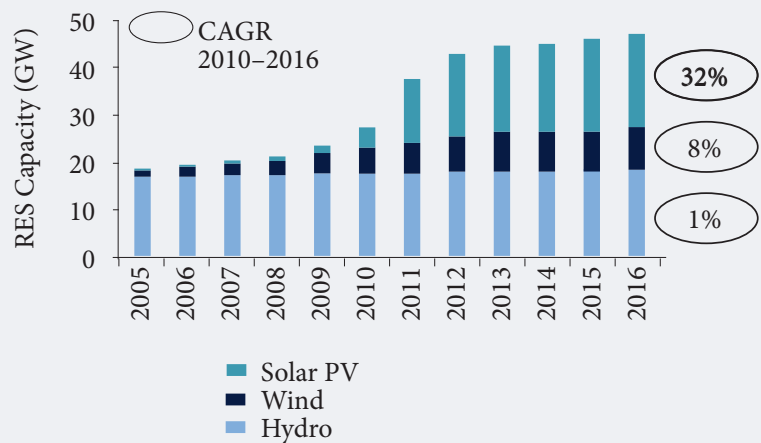

(b) Analysis of Fossil Fuel Generation

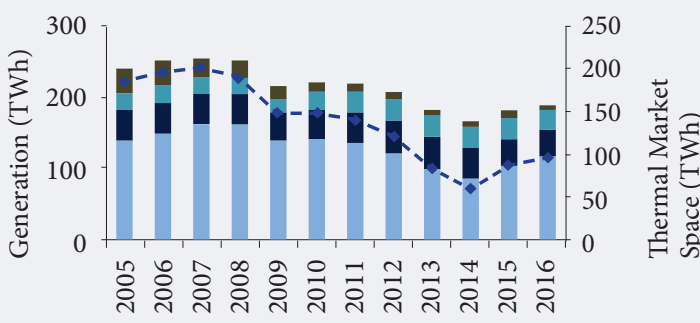

-Oil Products Other Fuels

- Coal Natural Gas

$\rightarrow$-Thermal Market Space

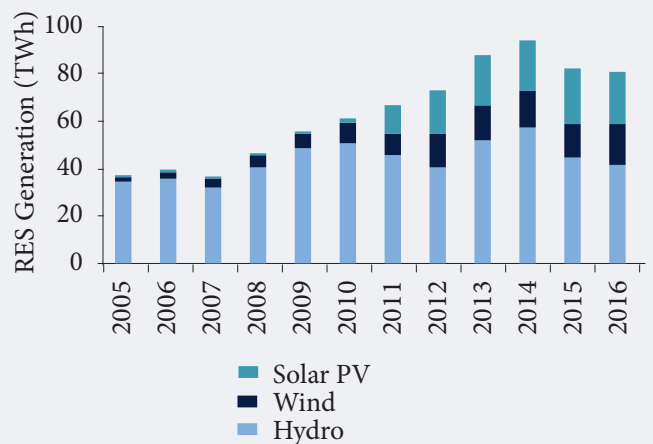

Source: compiled by the author.

particular types of infrastructure. Natural gas is very difficult to store and complicated to transport, pipelines or LNG ships are necessary.

Transportation via pipeline implies a point to point connection between the importing and exporting countries along with the likely presence of "transit" countries. In light of this, it is evident that the geopolitical context and international relations are fundamental in order to support business. The deterioration of the geopolitical situation has a substantial impact upon business operations, as shown by the Russian-Ukrainian dispute [Lochner, 2011] and the unstable political situation in Libya [Lochner, Dieckhöner, 2012].

Italy is particularly sensitive to such issues (e.g. the political instabilities in Libya are a clear example), because has scarce fossil fuel resources, therefore it is critical for the country to diversify its sources of supply, support the implementation of energy efficiency measures, and stimulate the utilization of renewable sources of energy.

As illustrated in Figure 1(a), from the 2007 onward, an increase in the development of renewable energy has been observed. Furthermore, it can be also noted that during the same years there was a reduction of consumption due to an economic downturn, as well as the implementation of energy efficiency policies.

The increased amount of renewable energy on the power market displaced fossil fuel-based technologies, as shown in Figure 1(b), where a noticeable decrease of natural gas generation is detected. A substantial reduction of oil-based generation from 2005 to 2016 was also observed. This phenomenon is due to the closure of many oil power plants since they were no longer competitive in the new market context.

On the contrary, coal-based generation continued to be quite stable, as coal power plants provide a base load and exploit their infra-marginal position. All this led to a decrease of the market potential for thermal generation, which determined weak profitability conditions for fossil fuel generation [Bianco et al., 2015].

At the same time, the implementation of $\mathrm{EU}$ regulations has led to the deployment of a significant amount of renewables-based power plants, especially solar PV and wind. Installed power increased from approximately $0 \mathrm{GW}$ in 2007 to $19 \mathrm{GW}$ of solar PV and from $3 \mathrm{GW}$ to $9 \mathrm{GW}$ of wind in 2017, with an average growth rate of $32 \%$ and $8 \%$, Figure 1 (c). This impressive development has caused a decrease in natural gas consumption, which has been substituted by renewable energy generation, reported in Figure 1(d). 
The increase of renewables-based generation has caused a decrease in both fossil fuel generation and prices on the market, which negatively affects the profitability of thermal power plants.

This phenomenon can be also ascribed to the fall in consumption due to the economic downturn of the period 2008-2015. In fact, due to the slowdown of economic activities, there was a decrease in electricity consumption and, therefore, of thermal power generation.

On the basis of this, it is critical to ascertain whether this represents a transient condition or a new equilibrium point for the market and, consequently, whether power generators have to change their business strategies that have been in place until now.

In this new context, the role of fossil fuel power generators, in particular natural gas, seem radically changed. In fact, until ten years ago, they provided most of the electricity to the system, whereas now their role is more similar to a "strategic reserve" in order to balance the variability of renewables. Therefore, their future role could be more focused on providing services to the system, rather than working as main generators.

Such a change of position will have an impact upon the fuel market as well. For example, if natural gas is not used any longer for massive power generation, its consumption will decrease, therefore the plans to build large pieces of infrastructure should be reviewed.

\section{Scenario Analysis}

A scenario is an example of a probabilistic future, departing from a single point: the present [Horner et al., 2016]. On the other hand, a scenario only represents a single vision of the future, which does not result in anything very helpful to policy makers in situations of high uncertainty. An approach to tackle this issue is represented by the "scenario planning", which is a framework where a limited number of scenarios are defined as the results of the most relevant strategic and planning options [Peterson et al., 2003]. In this way, it is possible to scrutinize the consequences on the future of some important decisions being made now. Comprehensive overviews of the scenario planning methodology can be found in the literature [Bradfield et al., 2005].

In the field of energy, it is quite common to use scenario analysis, as the sector is affected by relevant drivers such as the geopolitical context, which are quite uncertain in the short, medium, and long term. On the other hand, the strategic decisions taken in the energy sector often imply the investment of a huge amount of capital, therefore it is necessary to have an outlook on the possible future situations.

To this aim, different organizations (e.g. the International Energy Agency, Energy Information Agency, etc.) release various scenarios for the energy sector. It can be said that often these international forecasts could be defined as largely conventional in the sense that they are based upon the assumption that the current or emerging socioeconomic and science and technology trends are going to remain relevant in the long term [Kuzminov et al., 2017].

Furthermore, the scenarios published by outstanding international organizations, even though they are independent, are often under the political influence of different interest groups. On the other hand, taking into account all the limitations, these scenarios are based upon the most comprehensive energy databases and up-to-date information, thus they can be taken as a reliable foundation upon which to develop further studies [Kuzminov et al., 2017].

In the present paper, the scenarios provided by the European Network of Electricity Transmission System Operators (ENTSO-E) are considered. In particular, ENTSO-E issues a document called "Ten Years Network Development Plan" where development scenarios, called Visions, are reported for all EU countries in reference to their power sector.

The methodology applied in the present paper is based upon the development of four strategic options starting with the construction of four economic scenarios proposed in the TYNDP developed by ENTSO-E. The economic scenarios provide the context for the analysis, which focuses upon the strategic choices to be made on the basis of different boundary conditions.

The main parameters considered in the economic scenarios are expected fuel price, expected electricity consumption, renewable development, and fossil fuel-based power generation.

Figure 2 reports the main market data associated with the four considered scenarios, called "visions" within the ENTSO-E TYNDP. Figures 2(a) and 2(b) report the natural gas and carbon prices, Figure 2(c) highlights the expected renewable development, and Figure 2(d) reports on the capacity trend of natural gas (mainly CCGTs) and coal power plants.

These data are the result of the hypothesis associated with the outlooks of each vision. In particular, the visions are developed along three dimensions, namely "economy and market", "demand", and "generation". The proposed visions are representative of the four situations, see Figure 3, determined by the consolidation or not of a European framework for the development of the electricity system and on the fulfillment or not of the European Energy Roadmap for the 2050. Table 1 presents a detailed description of the proposed visions.

In terms of the fuel market, two different scenarios are depicted. One with higher natural gas market prices and lower carbon prices and the other with lower natural gas prices and higher carbon prices. Basically, 
(a) Natural Gas Price

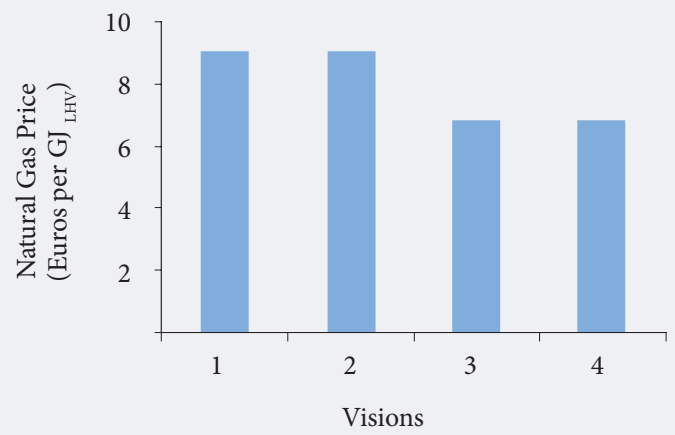

(c) Renewables Capacity

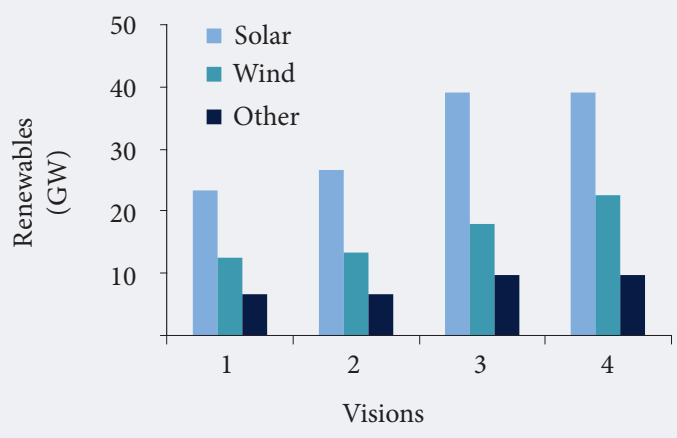

(b) Coal Price

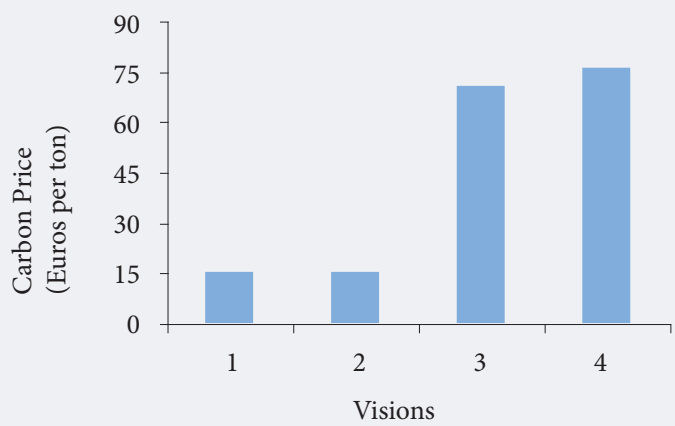

(d) Fossil Fuel Capacity

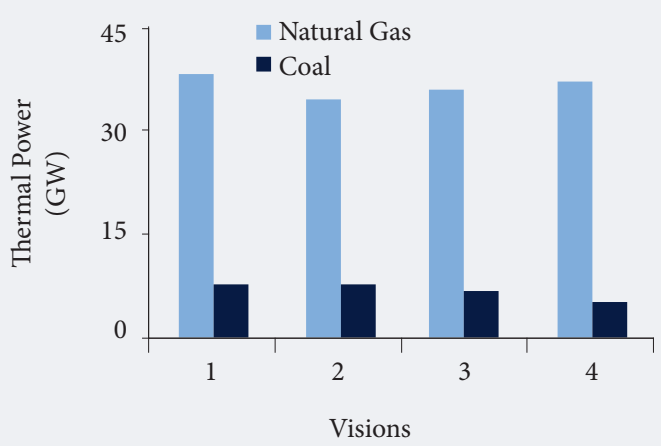

Source: compiled by the author using [ENTSOE, 2018].

they are representative of two market conditions, namely a market equilibrium context, i.e., Visions 1 and 2, where the natural gas price is sustained by supply and demand, which also determine the level of the carbon price. On the contrary, Visions 3 and 4 depict a scenario where there is an oversupply of natural gas, which determines a relevant decrease in price (-30\%). In such a context, regulatory intervention regarding the carbon price (e.g., the introduction of a "carbon floor") is possible in order to stimulate the adoption of clean technologies and avoid the massive utilization of natural gas (or coal). These measures are supported by sustained economic growth, which allow for the implementation of energy policies focused on the "decarbonization" of the sector.

Accordingly, Figure 2(c) highlights the expected development of renewable energy sources. In Visions 1 and 2 a moderate increase of renewables is detected with respect to Visions 3 and 4, where a significant push for renewables development is foreseen. This is due to the different economic conditions. In fact, in Visions 1 and 2, modest economic growth is foreseen, therefore the resources to support a massive deployment of RES are limited. On the other hand, Visions 3 and 4 report better economic conditions, which permit the large-scale development of RES.

Finally, Figure 2(d) reports the capacity trend of natural gas (mainly CCGTs) and coal power plants. It can be noticed that it does not vary significantly between the scenarios. Coal power plants fall from $7.9 \mathrm{GW}$ of Vision 1 and 2 to $5.4 \mathrm{GW}$ of Vision 4. It can be also noted that natural gas power plants in Vision 2 are fewer than in Vision 1. This is due to the fact that in Vision 2, solar power plants increase with respect to Vision 1, therefore they displace natural gas power plants from the merit order. This can also be attributed to the fact that the number of coal power plants do not decline between Vision 1 and 2. Visions 3 and 4 highlight a slight increase in natural gas capacity with respect to Vision 2, since the more favorable economic conditions allow for the development of more back-up capacity to complement the massive development of renewables. The expected evolution of electricity consumption is reported in Figure 4. It can be observed that consumption steadily decreases in Visions 1 to 3, whereas there is an increase in Vision 4. The decrease of electricity consumption is due to the implementation of aggressive energy efficiency measures in the power sector (e.g., the widespread utilization of LED lamps).

The increase detected in Vision 4 is due to the switching of different end-user sectors (e.g., transportation, heating, etc.) from the fossil fuel market to the electricity market.

The fuel switching is supported by the fact that power generation becomes "RES-dominated", therefore its carbon intensity decreases and it becomes more sustainable to use electricity rather than fossil fuels for the 


\section{Table 1. Specific Features of the Considered Visions}

\begin{tabular}{|c|c|c|}
\hline \multirow[t]{3}{*}{$\begin{array}{l}\text { Vision } 1 \\
\text { "Slowest, } \\
\text { Progress" }\end{array}$} & $\begin{array}{l}\text { Economy } \\
\text { and Market }\end{array}$ & $\begin{array}{l}\text { Each EU country has its own framework for the reduction of carbon emissions and increase of the } \\
\text { use of RES. Economic growth is modest. Old power plants are kept on line and coal represents the } \\
\text { baseload technology. }\end{array}$ \\
\hline & Demand & $\begin{array}{l}\text { There are no major energy efficiency developments. The modest economic growth determines a } \\
\text { limited increase of demand. }\end{array}$ \\
\hline & Generation & $\begin{array}{l}\text { The generation mix is determined by national policy schemes. A lack of EU coordination, which } \\
\text { determines an evolutionary trajectory far from the } 2050 \text { objectives. Policies for further development } \\
\text { of RES are only established at the local level. }\end{array}$ \\
\hline \multirow[t]{3}{*}{$\begin{array}{l}\text { Vision } 2 \\
\text { "Constrained } \\
\text { Progress" }\end{array}$} & $\begin{array}{l}\text { Economy } \\
\text { and Market }\end{array}$ & $\begin{array}{l}\text { Economic conditions are a little bit better with respect to Vision 1, therefore some more resources } \\
\text { are allocated for energy efficiency and RES. On the other hand, there are still uncertainties related } \\
\text { to the EU "carbon policy", therefore the willingness to invest is limited. Coal still represents the } \\
\text { baseload technology. }\end{array}$ \\
\hline & Demand & $\begin{array}{l}\text { Energy efficiency investments are slightly higher with respect to Vision 1, therefore lower demand is } \\
\text { expected. }\end{array}$ \\
\hline & Generation & $\begin{array}{l}\text { The development of the energy mix is coordinated at the EU level, however, the resources in which } \\
\text { to invest are limited. This encourages the extension of the operating life of existing thermal power } \\
\text { plants and a slight increase of renewable capacity with respect to Vision } 1 .\end{array}$ \\
\hline \multirow[t]{3}{*}{$\begin{array}{l}\text { Vision } 3 \\
\text { "National Green } \\
\text { Revolution" }\end{array}$} & $\begin{array}{l}\text { Economy } \\
\text { and Market }\end{array}$ & $\begin{array}{l}\text { Economic growth is more favorable with respect to Vision } 2 \text {. There is a lack of coordination at the } \\
\text { EU level, but each country has more resources to invest. "Carbon policies" are implemented with the } \\
\text { results that natural gas becomes the baseload technology. }\end{array}$ \\
\hline & Demand & $\begin{array}{l}\text { More significant development in energy efficiency measures with respect to Vision } 2 \text { determines a } \\
\text { decrease in demand for electricity. }\end{array}$ \\
\hline & Generation & $\begin{array}{l}\text { The greater development of RES makes them competitive, but the lack of a coordinated EU } \\
\text { framework does not allow them to be exploited to the full extent. The good economic conditions } \\
\text { allow for the implementation of a capacity market and the installation of new back-up capacity. }\end{array}$ \\
\hline \multirow{3}{*}{$\begin{array}{l}\text { Vision } 4 \\
\text { "European Green } \\
\text { Revolution" }\end{array}$} & $\begin{array}{l}\text { Economy } \\
\text { and Market }\end{array}$ & $\begin{array}{l}\text { Better economic conditions with respect to all the other visions. Strong coordination at the EU level. } \\
\text { Implementation of coordinated "carbon policies". }\end{array}$ \\
\hline & Demand & $\begin{array}{l}\text { Substantial effort in the implementation of energy measures. Massive development of e-mobility and } \\
\text { electrification of heat and cooling sectors. }\end{array}$ \\
\hline & Generation & $\begin{array}{l}\text { Strong EU vision, which allows countries to be on track to fulfill the } 2050 \text { objectives. Large scale } \\
\text { expansion of RES and the adequate development of back-up capacity. Phase-out of old nuclear } \\
\text { power plants and corresponding replacement with RES. Natural gas represents the baseload } \\
\text { technology. }\end{array}$ \\
\hline
\end{tabular}

heating of buildings [Bianco et al., 2017] by using heat pumps, or for transportation. Building heating and transportation are the two end users where a major penetration of electricity as the main source of energy is expected.

\section{Discussion}

The visions described in the previous section represent four possible scenarios for the Italian generation sector. Despite their differences, they have a relevant common principle, which is the unprecedented transition the sector is undergoing. This transformation presents many challenges, but also a great number of opportunities for power generation sector. In the past, the sector was able to guarantee stable returns for investors and it presented a very low risk profile, but the policies implemented over the last ten years aimed at the reduction of the carbon intensity of the power sector has reshaped the generation business.

Electricity generation operators, often large utilities, need to look for new business models in order to secure the margins that guaranteed the stability of the business. In order to do this, it is critical that they gain a clear vision of the possible future scenarios in order to implement an optimal strategy in relation to the possible changes of the situation.

In all the four scenarios reported in Figure 4, thermal power plants still represent the majority of the power capacity. There will be a mix of centralized and non-centralized generation, but the risk profile of centralized generators is changing due to the merit order effect of renewables [Sensfuß et al., 2008; Cludius et al., 2014] and the consequent "missing money problem" [Hogan, 2017; Da Silva, Figueiredo, 2017]. Furthermore, the implementation of energy efficiency measures, with the corresponding decrease in expected demand for electricty, makes the situation more unpredictable and complex. Therefore, the intervention of policy makers with instruments able to provide clear market signals is necessary in order to provide stability for the system. On the other hand, generators should target the optimization of their generation mix in order to remain competitive and ready for new investments.

"Optimization" appears to be the key word for the future strategies of power generators, with specific reference to the optimization of energy sources (e.g., thermal power vs. renewables). 
Figure 3. Matrix of the Economic and Market Scenarios Proposed in the TYNDP 2016

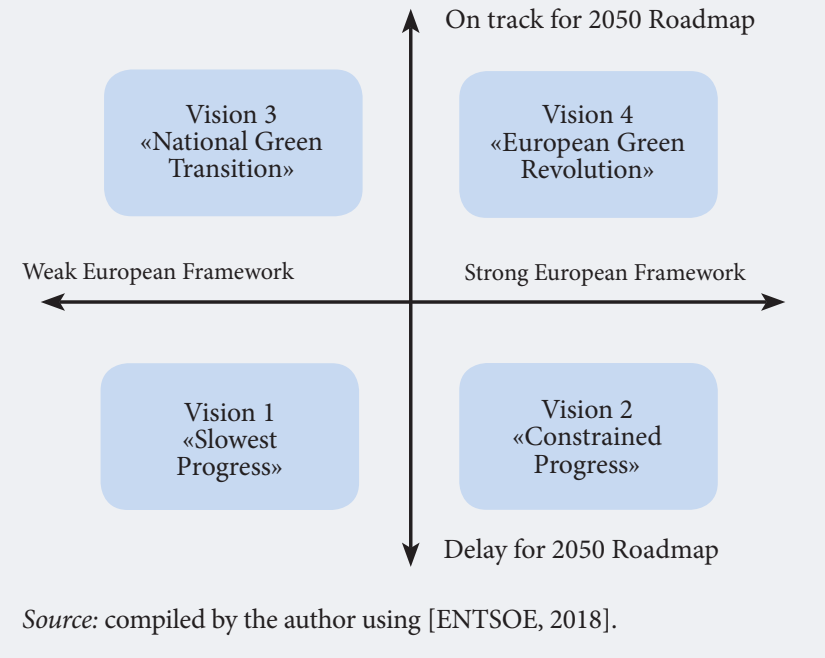

Figure 4. Expected Electricity Demand in the Considered Market Visions

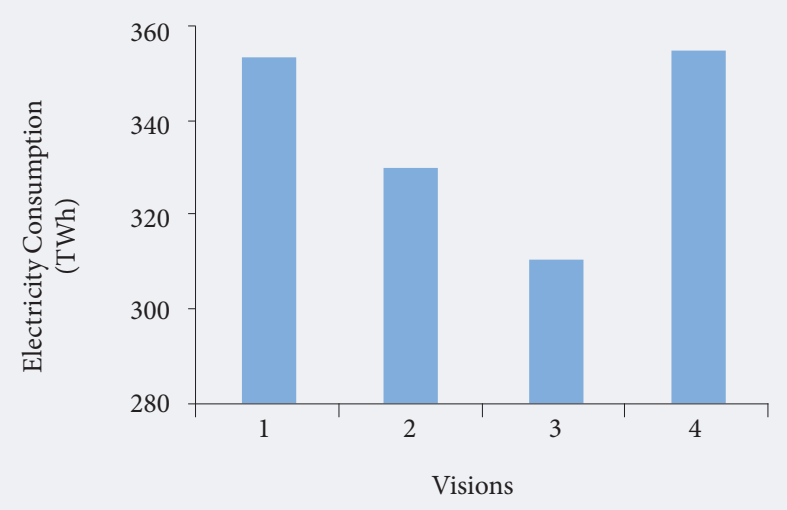

Source: compiled by the author.

According to the aforementioned visions, different strategic models for generators are envisaged, namely:

- Vision 1 "Slowest Progress", corresponding strategic model: "Traditional Generator"

- Vision 2 "Constrained Progress", corresponding strategic model: "Innovative Generator"

- Vision 3 "National Green Revolution", corresponding strategic model: "Green Generator"

- Vision 4 "European Green Revolution", corresponding strategic model: "Energy Service Provider"

Each strategic model is tailored to the corresponding business context in order to maximize the generator results, irrespective of policy makers' expectations. In the following, there is the detailed description of the aforementioned strategic options.

\section{Traditional Generator}

In the scenario characterized by weak economic growth, operators should opt for a "conservative" strategy that leaves no room for large investments due to the many unknowns affecting the future development of the sector, which is further exacerbated by the lack of a common EU agreement. In this situation, generators can opt for the optimization of their existing thermal power plants, such as the increasing the flexibility of CCGTs, in order to benefit from possible extra revenues on the ancillary services market. Furthermore, infra-marginal capacity (e.g., coal power plants) guarantees most of these revenues, therefore even old coal power plants should be kept online (except for the inefficient ones) despite their carbon intensity. There is no possibility of developing renewables unless they have already reached grid parity and, therefore, the investment is profitable. On the contrary, operators can improve the management of their existing renewable power plants, for example by massively implementing Virtual Power Plants (VPPs).

The combined management of the power and gas markets appears necessary in a limited economic growth scenario, as generators can secure more margin by trading part of their natural gas on the EU integrated market or on the international market by benefiting from the commissioning of new infrastructure previously under construction (e.g. pipelines, LNG terminals, etc.).

This strategy aims at the consolidation of large operators with a diversified fuel mix in their generation portfolio, which may have many opportunities for the merger and acquisition (M\&A) of smaller operators, such as those with natural gas and some renewables in their portfolios. This period may end with a significant concentration of the power market among a few operators on the basis of the "survival" of the fittest principle.

\section{Innovative Generator}

In a situation characterized by limited economic growth, energy generators are not incentivized to invest and implement growth strategies. Rather, they try to keep their positions safe. The conditions of uncertainty are significant, especially with respect to a possible "carbon strategy", therefore it is not possible to assume clear positioning on the generating market. On the other hand, there is agreement at the EU level upon the willingness to pursue the de-carbonization of the power generation system by fulfilling the 2050 objectives, therefore it is necessary to monitor $\mathrm{R} \& \mathrm{D}$, pursue innovative business practices, and organizational models, etc., related to a "RES-dominated" market. Pursuing such a market is necessary given that it is reasonable to assume that a push for renewables would be imminent once the economic situation improves. Therefore, it is necessary to be ready for such a situation by focusing on the "innovative" strategies to be put in place. 
During this period of limited growth, some operators, especially those with an unbalanced amount of natural gas in their mix, could move into critical condition due to the unsatisfactory level of revenues. In such a situation, they can be the possible targets of M\&A strategies of larger operators with a more balanced generation mix, for whom revenue issues are not a concern.

Therefore, also in this case, it is possible to have market concentration, which reduces the number of players active in the power generation sector.

Furthermore, operators can invest in optimizing the management of their power fleet in order to capture the opportunities available on all markets, namely the ancillary services, natural gas market, and VPPs.

\section{Green Generator}

In the context of sustained economic growth with local willingness to develop renewables, operators are pushed to invest massively in renewable capacity, but, at the same time, according to the policy signals, they also need to optimize their thermal power fleet. In particular, if clear indications are given concerning the carbon policy with a push for de-carbonization, coal power plants will be phased out and only the newest ones will be kept online. In such a context, it is possible that CCGTs will displace coal power plants and become an infra-marginal technology, therefore they will begin to generate revenues. Such a condition is advantageous for operators, usually the smaller ones, with an unbalanced presence of natural gas and some renewables in their mix.

The market will be very competitive and therefore a large range of generators will be active.

Given the lack of agreement at the EU level, it will be possible for the larger operators to exploit international strategies only to a small extent, since each country will develop its own regulations. This turns into an advantage for smaller and, usually, more flexible operators which can exploit all the opportunities available on the local market, and, furthermore, for smaller scale investments, which are usually not attractive for larger operators.

The strategy depicted here will aim at increasing the share of renewables in the power portfolio of all the operators, independent of their size. No critical modifications of the business model, services, and organizations are expected.

\section{Energy Service Provider}

In the context of sustained economic growth and strong agreement on the fulfillment of EU objectives for 2050, operators will be pressed to change their traditional approach to power generation and new business models may be adopted. In this new context, the massive development of renewables, e-mobility, etc., are expected. Therefore, clients' needs are completely changed. Customers will look for innovative solutions in order to support them in the efficient management of energy in their homes and businesses. Services such as storage, control, and monitoring will be fundamental in a context where consumers actively participate in the market.

Electric utilities will play a pivotal role in marketing new technologies. For example, they can finance, install, and run charging stations for e-mobility, as well as provide storage services, etc. In this new context, larger utilities can exploit large-scale synergies, whereas small operators may offer very customized services. Small or very small companies offering very innovative services can appear on the market and gain significant market shares, especially in the field of remote control and monitoring systems. There will be a highly competitive market situation, where the most innovative companies will be the winners, irrespective of their size.

\section{Figure 5. Positioning with Respect to Innovation Level and Market Competitiveness} of the Analyzed Strategic Options

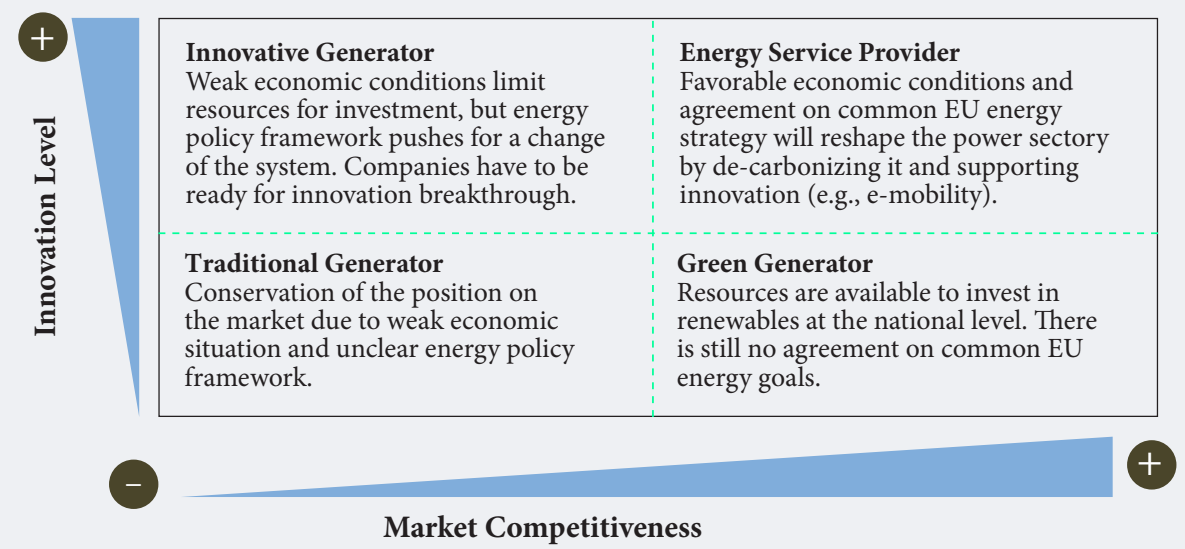

Source: compiled by the author. 


\section{Conclusion}

The present paper provides an overview of the Italian generation system by highlighting its main features deriving from the radical changes experienced over the last ten years, namely the substantial development of renewables.

Power generators need to plan their future well in advance as the sector is capital intensive and, usually, a long execution time is necessary in order to build infrastructure and develop investments (authorization and permit phases can take years), therefore it critical to perform scenarios analysis in order to discuss the various strategic implications.

On the basis of the economic visions developed by ENTSOE in the TYNDP 2016, four strategic scenarios are envisaged, namely: Traditional Generator, Innovative Generator, Green Generator, and Energy Service Provider. Their positioning in terms of innovation level and market competitiveness is reported in Figure 5. It can be said that the Traditional Generator and Innovative Generator are two defensive positions, determined by limited economic growth and the uncertainties concerning future policies on renewables and carbon emissions. The Green Generator strategic scenario describes a situation where all the operators will increase the share of renewables in their mix and where there is a moderate advantage for generators with an unbalanced mix in favor of natural gas and renewables. Finally, the Energy Service Provider strategic scenario represents a change in the paradigm for the power generation sector, as companies will turn themselves in providers of advanced energy services, such as storage, e-mobility, control, and monitoring. Such a context will be very competitive, irrespective of the size of the competitors.

\section{References}

Bianco V., Scarpa F., Tagliafico L.A. (2017) Estimation of primary energy savings by using heat pumps for heating purposes in the residential sector. Applied Thermal Engineering, vol. 114, pp. 938-947.

Bianco V., Scarpa F., Tagliafico L.A. (2015) Long term outlook of primary energy consumption of the Italian thermoelectric sector: Impact of fuel and carbon prices. Energy, vol. 87, pp. 153-164.

Bradfield R., Wright G., Burt G., Cairns G., Heijden K. (2005) The origins and evolution of scenario techniques in long range business planning. Futures, vol. 37, no 8, pp. 795-812.

Cludius J., Hermann H., Matthes F.C., Graichen V. (2014) The merit order effect of wind and photovoltaic electricity generation in Germany 2008-2016: Estimation and distributional implications. Energy Economics, vol. 44, pp. 302-313.

Da Silva P., Figueiredo N. (2017) Renewables optimization in energy-only markets. Analysis of Energy Systems. Management, Planning and Policy (ed. V. Bianco), Boca Raton: CRC Press, pp. 149-169.

ENTSO-E (2018) Ten Years Network Development Plan. Available at: https://www.entsoe.eu/major-projects/tenyear-network-development-plan/planning-studies/Pages/default.aspx, accessed 03.03.2018.

European Commission (2018) Energy Strategy and Energy Union. Secure, Competitive, and Sustainable Energy. Available at: https://ec.europa.eu/energy/en/topics/energy-strategy-and-energy-union, accessed 05.03.2018.

Franco A., Salza P. (2011) Strategies for optimal penetration of intermittent renewables in complex energy systems based on techno-operational objectives. Renewable Energy, vol. 36, no 2, pp. 743-753.

Gianfreda A., Grossi L. (2012) Forecasting Italian electricity zonal prices with exogenous variables. Energy Economics, vol. 34, no 6, pp. 2228-2239.

Guerci E., Fontini F. (2014) The impact of the introduction of nuclear power on electricity prices in a power exchangebased liberalised market. Progress in Nuclear Energy, vol. 71, pp. 52-60.

Hogan M. (2017) Follow the missing money: Ensuring reliability at least cost to consumers in the transition to a lowcarbon power system. The Electricity Journal, vol. 30, no 1, pp. 55-61.

Horner N., de Paula Oliveira A.G., Silberglitt R., Poppe M.K., Bressan Rocha B. (2016) Energy foresight, scenarios and sustainable energy policy in Brazil. Foresight, vol. 18, no 5, pp. 535-550.

Kuzminov I., Bereznoy A., Bakhtin P. (2017) Global energy challenges and the national economy: Stress scenarios for Russia. Foresight, vol. 19, no 2, pp. 174-197.

Lochner S. (2011) Modeling the European natural gas market during the 2009 Russian-Ukrainian gas conflict: Expost simulation and analysis. Journal of Natural Gas Science and Engineering, vol. 3, no 1, pp. 341-348.

Lochner S., Dieckhöner C. (2012) Civil unrest in North Africa - Risks for natural gas supply? Energy Policy, vol. 45, pp. 167-175.

Peterson G.D., Cumming G.S., Carpenter S.R. (2003) Scenario planning: A tool for conservation in an uncertain world. Conservation Biology, vol. 17, no 2, pp. 358-366.

Richter P.M., Holz F. (2015) All quiet on the eastern front? Disruption scenarios of Russian natural gas supply to Europe. Energy Policy, vol. 80, pp. 177-189.

Sensfuß F., Ragwitz M., Genoese M. (2008) The merit-order effect: A detailed analysis of the price effect of renewable electricity generation on spot market prices in Germany. Energy Policy, vol. 36, no 8, pp. 3086-3094.

Smith W.J. (2013) Projecting EU demand for natural gas to 2030: A meta-analysis. Energy Policy, vol. 58, pp. $163-176$.

Vespucci M.T., Innorta M., Cervigni G. (2013) A Mixed Integer Linear Programming Model of a Zonal Electricity Market with a Dominant Producer. Energy Economics, vol. 35, pp. 35-41. 


\section{INNOVATION IN COMPANIES}

$i$
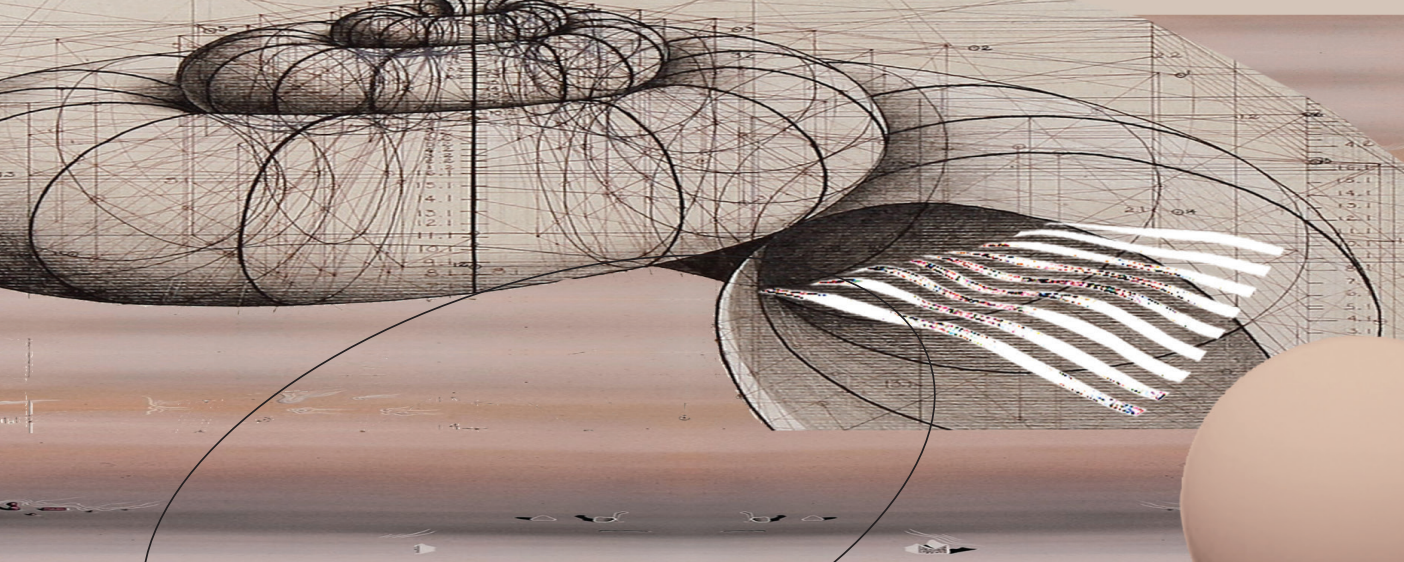


\title{
Enhancing Innovation Performance in Companies
}

\author{
Jonathan Calof \\ Full Professor a ; Extraordinary Professor ${ }^{\mathrm{b}}$; Leading Research Fellow ${ }^{\mathrm{c}}$, calof@telfer.uottawa.ca \\ a Telfer School of Management, University of Ottawa, 55 Laurier Ave E, Ottawa, ON K1N 6N5, Canada \\ b North West University, Potchefstroom, South Africa \\ ${ }^{c}$ Research Laboratory for Science and Technology Studies of the Institute for Statistical Studies and Economics \\ of Knowledge (ISSEK) of the National Research University Higher School of Economics (NRU HSE), 11 \\ Myasnitskaya str., Moscow 101000, Russian Federation
}

\begin{abstract}
$\mathrm{T}$ his introductory article to the special section «Innovation at Companies» focuses on how to enhance innovation performance at companies. It looks at the factors that define innovative activities at companies as well as the various kinds of corporate innovations. The
\end{abstract}

Abstract

Keywords:

inovation performance;

innovation strategies;

training programs author stresses importance of special training programs for managers, and suggests the need to take the specifics of local economic, cultural, and other factors into account when implementing relevant educational and policy initiatives aimed at fostering innovation.
Citation: Calof J. (2018) Enhancing Innovation

Performance in Companies. Foresight and

STI Governance, vol. 12, no 3, pp. 30-33.

DOI: 10.17323/2500-2597.2018.3.30.33

I nnovation, in particular open innovation, are becoming increasingly recognized by companies and governments alike as being important for both national and corporate growth and performance. This is so critical that countries around the world have launched programs and policies designed to enhance their countries' innovation performance and companies have focused efforts in this area as well. The latest such initiative being the appointment of senior-level open innovation executives in the "C" suite by leading companies around the world. For governments, it is generally about developing policy and programs that will improve their countries' rankings in innovation publications such as the Global Innovation Index. For companies, it is about increasing revenues, reducing costs, and enhancing competitive advantages.

How one helps grow innovation has been a subject of intense interest not only for government and industry but for academia as well. A recent search on ABI ProQuest for peer reviewed articles with innovation in their title resulted in 24,532 articles, including 13,933 published since 2010, with many studies looking at activities related to innovation. The literature is so deep that many meta-analysis and literature review articles have emerged that are not just about the generic innovation field but subdomains within innovation, for example:

- a meta-analysis of success factors for service innovation [Storey et al., 2015];

- a bibliometric review of the open innovation literature [Randhawa et al., 2016]; 
- a review of the literature on accelerating the speed of innovation [Ellwood et al., 2016];

- a review of the literature on culture's impact on innovation [Tian et al., 2018].

These articles have provided readers with a multitude of both hard and soft factors that can result in corporate innovation. Hard factors such as the appropriate competitive environment, government assistance and policies, financial resources, and firm size have been linked to innovation. Soft factors such as organizational culture, in particular openness, have also been linked to innovation. There have also been a host of studies that have identified organizational structural elements, as well as appropriate knowledge and human capital.

Clearly, based on the depth of research in innovation and its recognized importance to corporate performance, it is critical to ensure that today's managers are equipped with the knowledge necessary to create and carry out appropriate innovation strategies. Recent research looking at the influence of firms management on innovation in emerging economies [Crowley, Bourke, 2018; Terzic, 2017] makes the need for this kind of management development program even more important in such economies. For example, a review of research on innovation in Russia by Filippov noted:

"The main conclusion of these studies on Russia's innovative performance is that while the country possesses a strong science base, a well-developed education system and devotes substantial resources to R\&D; its actual innovation activity remains disappointing... The main problem, as stated, is that the S\&T system does not produce nearly as much innovation as expected, and even more so, the private sector" [Filippov, 2011, p. 187].

Given these problems, the Russian government has developed extensive policy and programs around innovation. Gokhberg and Roud [Gokhberg, Roud, 2015] examined various government initiatives in this area with mixed results.

Further, from a country perspective, given the mass of literature linking innovation to regional and national economic performance, this kind of knowledge development and training for government officials who develop innovation programs is also important. This suggests that those designing policies and programs meant to improve their regions' or countries' innovation should do so based on research that clearly identifies the factors linked with innovation.

It is not only this explosive recent growth in research and knowledge about innovation best practices that fuels the need for management and government officer innovation development programs, it is also the expansion of our understanding about where innovation can be applied, call this "corporate innovation breadth". Innovation used to be talked about from the perspective of product/service innovation, the development of new products and services that would provide an organization with an economic advantage. The OECD in defining innovation [OECD, 2018] broadens this traditional view describing four types of innovation: product innovation, process innovation, marketing innovation, and organizational innovation.

- Product innovation: A good or service that is new or significantly improved. This includes significant improvements in technical specifications, components and materials, software in the product, user friendliness, or other functional characteristics.

- Process innovation: A new or significantly improved production or delivery method. This includes significant changes in techniques, equipment, and/or software.

- Marketing innovation: A new marketing method involving significant changes in product design or packaging, product placement, product promotion, or pricing.

- Organizational innovation: A new organizational method in business practices, workplace organization, or external relations."

Keeley et al. [Keeley et al., 2013] in their best-selling book on innovation identified ten types of innovation that they broke into three categories:

- Configuration: Profit model (the way in which you make money); Network (connections with others to create value), Structure (Alignment of your talent assets); Process (unique best practices for doing your work)

- Offering: Product performance (distinguishing features and functionality); Product system (complementary products and services)

- Experience: Service (support and enhancements that surround your offerings); Channel (how your offerings are delivered to customers and users); Brand (representation of your offerings and business); Customer engagement (distinctive interactions you foster)

The book offers the 10 types of innovation mentioned above and then over 100 tactics surrounding each of these innovations. For example, under process innovation (under configuration), the authors offer 
the following tactics: crowdsourcing, flexible manufacturing, intellectual property, lean production, localization, logistics systems, on-demand production, predictive analytics, process automation, process efficiency, process standardization, strategic design, and user-generated design.

In short, the growth in our knowledge of what leads to innovation and the understanding of where innovation can be applied has led to the need for and the development of programs to bring these best practices to today's managers. Top universities have developed these kinds of programs. Stanford, for example, has developed an innovation and entrepreneurship certificate program to help participants develop innovative organizations. MIT created a professional certificate program in innovation and technology. Harvard Business School has developed several innovation leadership and management programs including: Leading and Building a Culture of Innovation and Leading Product Innovation and Disruptive Innovation.

This special issue of Foresight and STI Governance adds to this growing body of innovation knowledge and innovation best practices by looking specifically at innovation within Russia and China. The articles look at drivers of corporate innovation as well as various roles that government policy can play in enhancing Innovation.

Roelfsema and Zhang look at the choice of product innovation (R\&D and product development) and internationalization (market innovation) at 13,874 Chinese firms. In examining various factors, the authors point to the need for a differentiated government policy that recognizes the need for different incentives to encourage innovation depending on a firm's productivity. In this case, the authors note a complex relationship that needs to be understood to create a capability-based series of government support programs.

The paper by Zavyalova et al. looks at the innovation ecosystem in China and examines the various tools, programs, and mechanisms that are designed to enhance innovation activity in companies. The study uses broad innovation measurements that capture several elements of the OECD innovation definition and several innovation dimensions from Keeley et al. According to the results of detailed interviews with 60 companies, the role of training and personnel development as a means to enhance innovative activities is confirmed with those lagging behind in innovation exhibiting low staff training and development.

The Nissen et al paper looks at the role of IT management in another kind of innovation activity - digital transformation. In adopting a case-based approach (interviews at five Russian companies), the paper develops deep insight into the role that IT can play in enhancing innovation at Russian companies. In terms of improving innovation, the authors identified two companies in their study for which IT played a role in business innovation, another company at which IT was an enabler, and two at which it provided more of a support function. The lack of qualified personnel (human capital) was seen as a key challenge once again suggesting the need for appropriate training. The study also points to the need for senior management of a firm to be trained to understand how innovations can be developed. Call this innovation literacy training, the need for senior management to understand different approaches for innovation management including, in this case, IT management.

The hypothesis in the Davidson et al. paper is that companies' willingness to innovate is largely determined by the external environment, although internal factors were also considered. The study looks at one kind of innovation, new products or services, and notes that this kind of innovation is linked to both firm and regional factors such as state support, institutional environment, state support, corruption, and human capital (trained staff) as well as firm size. Based on the factors linked with corporate innovation, the authors recommend regional innovation policy that takes into account the identified factors. The need for appropriate human capital supports some of the training initiatives mentioned in this paper while the identification of factors linked with corporate innovation in Russia supports the need for government policy-makers to similarly understand critical success factors of corporate innovation in order to design appropriate programs. It also points to a number of unique Russian environmental factors that would need to be reflected in innovation-related government policy.

Taken together, the four studies in this special issue suggest that governments considering innovation programs need to understand the factors that lead to corporate innovation if they are to effectively design programs that will enhance innovation. Three of the papers point to the need for developing appropriate corporate knowledge and human capital for innovation. They point also to the need for management training programs. There is even within the two Russian studies an indication that training programs and policy will have to include factors that are unique to the local environment.

This paper concludes with a lesson from Canada in innovation policy and programs. In 1970, the Canadian Senate Special Committee on Science Policy in support of Canada's economic performance concluded 
with the following statement "Since 1916...the main objective of Canada's science policy has been to promote technological innovation by industry... Almost every decade since the 1920's has witnessed renewed attempts by successive governments to achieve it but on the whole they have all failed" (cited from [CCA, 2013]). In examining Canada's innovation efforts since then, Peter Nicholson, President of the Council of Canadian Economies wrote "In the more than four decades since this report, nothing has changed to alter the essential truth of its conclusions" [Nicholson, 2016, p. S39]. In a presentation about the lack of innovation improvement in Canada given to Canadian technology executives, Calof and Sedivy noted that Canadian innovation policy did not always reflect current best innovation practices nor respond to Canadian cultural factors [Calof, Sedivy, 2017]. Based on this experience, perhaps in recommending both training for managers and government policy-makers which will result in innovation policy that reflects research identified by best practices, this should be supplemented based upon research that identifies any local economic, cultural, or other factors that need to be integrated into training and policy.

This article was prepared within the framework of the Basic Research Program at the National Research University Higher School of Economics (HSE) and supported within the framework of the subsidy granted to the HSE by the Government of the Russian Federation for the implementation of the Global Competitiveness Program.

\section{References}

Calof J., Sedivy J. (2017) Tools and techniques for better innovation. Paper presented at tech-Tuesday, November 7, 2017, Ottawa, Ontario, Canada.

CCA (2013) Paradox Lost: Explaining Canada's Research Strengths and Innovation Weakness, Ottawa: The Council of Canadian Academies.

Crowley F., Bourke J. (2018) The Influence of the Manager on Firm Innovation in Emerging Economies. International Journal of Innovation Management, vol. 22, no 3. Available at: https://doi.org/10.1142/S1363919618500287, accessed 05.08.2018.

Ellwood P., Grimshaw P., Pandza K. (2016) Accelerating the Innovation Process: A Systematic Review and Realist Synthesis of the Research Literature. International Journal of Management Reviews, vol. 19, no 4, pp. 510-530.

Filippov S. (2011) Emerging Russian Multinationals: Innovation, Technology, and Internationalization. Journal of East-West Business, vol. 17, no 2-3, pp. 184-194.

Gokhberg L., Roud V. (2015) Structural changes in the national innovation system: Longitudinal study of innovation modes in the Russian industry. Economic Change and Restructuring, vol. 49, no 2-3, pp. 269-288.

Keeley L., Pikkel R., Quinn B., Walters H. (2013) Ten types of innovation, Hoboken, N.J: Wiley.

Nicholson P. (2016) Canada's Low-Innovation Equilibrium: Why It Has Been Sustained and How It Will Be Disrupted. Canadian Public Policy, vol. 42(S1), pp. S39-S45.

OECD (2018) Defining Innovation. Available at: https://www.oecd.org/site/innovationstrategy/defininginnovation. htm, accessed 07.09.2018.

Randhawa K., Wilden R., Hohberger J. (2016) A Bibliometric Review of Open Innovation: Setting a Research Agenda. Journal of Product Innovation Management, vol. 33, no 6, pp. 750-772.

Storey C., Cankurtaran P., Papastathopoulou P., Hultink E. (2015) Success Factors for Service Innovation: A MetaAnalysis. Journal of Product Innovation Management, vol. 33, no 5, pp. 527-548.

Terzić L. (2017). The Role of Innovation in Fostering Competitiveness and Economic Growth: Evidence from Developing Economies. Comparative Economic Research, vol. 20, no 4, pp. 65-81.

Tian M., Deng P., Zhang Y., Salmador M. (2018) How does culture influence innovation? A systematic literature review. Management Decision. DOI: 10.1108/MD-05-2017-0462. Available at: https://www.researchgate.net/ publication/323020818_How_does_culture_influence_innovation_A_systematic_literature_review, accessed 07.09.2018. 


\title{
Internationalization and Innovation in Emerging Markets
}

\author{
Hein Roelfsema \\ Chair of International Macroeconomics, h.j.roelfsema@uu.nl \\ Utrecht University School of Economics, Kriekenpitplein 21-22 3584 EC, Utrecht, the Netherlands
}

\section{Yi Zhang}

Assistant Professor, Jinhe Center for Economic Research, zhangyi.econ@mail.xjtu.edu.cn

Xian Jiaotong University, Xi'an, Shaanxi, P.R. China

\begin{abstract}
$\mathrm{W}$

ith high growth on domestic markets, many firms in emerging economies face a tradeoff between using their competitive advantages in foreign markets or innovating in domestic markets. By analyzing export and innovation data for a large dataset of Chinese firms, we uncover a specific productivity sorting pattern of firms over exporting and innovation. As expected, high

productivity firms both export and innovate and low productivity firms do not export or innovate. Interestingly, low-medium productivity firms export more than they innovate, whereas high-medium productivity firms innovate more than they export. Clearly, these findings have important implications for the new trade literature that stresses the primacy of high productivity for entry into export markets.
\end{abstract}

Keywords: internationalization; innovation; emerging markets; strategic choice; new trade theory; profits/ productivity linkage
Citation: Roelfsema H., Zhang Y. (2018) Internationalization and Innovation in Emerging Markets. Foresight and STI Governance, vol. 12, no 3, pp. 34-42.

DOI: 10.17323/2500-2597.2018.3.34.42 
$\mathrm{O}$ ver the past few decades, firms from China and to a lesser extent Russia, Brazil, and India (the BRICs) have internationalized and become major players in the world economy. For China, its entry into the World Trade Organization (WTO) in 2001 has brought a spectacular increase in exports both to developed and developing countries. India has become an important player in trade in services, especially in the information and technology (IT) sector. Russia is confronting international diversification challenges to move it away from oil and gas and into technology-led exports and foreign direct investment (FDI). For firms from emerging markets, entry into the global economy includes an important role for international alliances and acquisitions, mostly with the goal of strategic asset seeking to improve competitiveness. Originally the term emerging markets refers to the increased importance of consumers in these countries for multinational firms. With the dramatic increase in purchasing power of consumers, domestic markets have become more important for home-grown firms as well. However, domestic markets have become fiercely competitive because of the presence of productive native firms together with foreign multinationals and thus require substantial innovation for sustainable long-term competitive advantages. For firms in China, India, and Russia, this creates a strategic challenge. Should the focus be on maintaining and gaining market share in the domestic market and should the firms invest in innovation, or should the firm leverage capabilities abroad with considerable investments in distribution and learning?

In this article we analyze the choice between internationalization and innovation for 13,874 Chinese firms included in the National Bureau of Statistics Annual Database. Based on our conceptual model founded in the new trade theory [Melitz, 2003] and developed in the next section, we hypothesize that this tradeoff will be especially relevant for firms with medium productivity. In the conceptual model, managers struggle of allocating limited (financial) resources over competing strategies. The most common tradeoff is between product innovation ( $R \& D$, product development) and organizational scope expansion like starting to export. Our conceptual model provides a theoretical lens for such innovation management that is contingent of firm conditions. The regression results indeed show a complex relationship of the factors that define the investment trade-off between exporting and innovation. In line with theory, we show that the most productive firms sort into exporting and innovation and the least productive firms do not export or innovate. The middle segment of productivity where firms are financially constrained and must choose between export and innovative activity is the most interesting. We show that high-medium productivity firms choose innovation on the domestic market over internationalization. By contrast, lowmedium productivity firms choose exporting over innovation.

The statistical findings have potentially important theoretical, managerial, as well as policy implications. From a theoretical perspective, to the best of our knowledge, this is the first paper that connects firm heterogeneity to simultaneous moves toward exporting and innovation under resource constraints. Other papers focus either on exporting or innovation, some analyze the sequential process of exporting and innovation. By looking only at internationalization and innovation separately, current theory shows why the more productive firms are exporters [Bernard, Jensen, 1999, 2004] and are engaged in quality improvement [Fan et al., 2015]. In addition, there is a substantial literature that stresses that internationalization may result in innovation [De Loecker, 2007] and that there is complementarity between exporting and innovation [Ferguson, 2009].

The empirical findings also have potentially important policy implications for emerging markets and transition economies. Most policy makers are well-aware of the Solow implications that in the long run, economic growth and prosperity are determined by innovation [Solow, 1956]. However, innovation has many faces including new products and services, using new technologies, new organizational forms, and entering new markets. In the presence of imperfect information, policy makers have to nudge firms towards the correct strategy by providing incentives and business facilitation. This paper provides policy guidance about where to focus for which type of firms. We argue that very low and very high productivity firms do not need innovation policy as their choices are predetermined. However, on large domestic markets like China, Russia, and Brazil, contrary to popular perception, the high-medium segment maybe best pushed toward R\&D and product innovation and not into export. By contrast, low-medium productivity firms should be nudged towards exporting and not innovation. In practice, many policies are designed to achieve the opposite at high cost to the taxpayer.

\section{Demand and Innovation in Emerging Markets}

One of the most important features, probably the most important feature, of the last 30 years is the political and economic liberalization of China, Russia, and India, which together account for slightly less than half of the global population. Economic liberalization has led to social transformation and impressive economic growth and development. The internationalization of business has been an important driver for growth. In the case of China, global demand in the supply chain of labor-intensive goods has led to the massive relocation of workers from the agricultural sector into manufacturing. Russia has made use of its technological advantages to support its exporting manufacturing industry, whereas India with its strong IT skills tapped into the globalization of the services industry. As is well documented elsewhere, in these markets this process led to an inflow of foreign investments and substantial increases in productivity. 
Over time, economic dynamics in emerging markets closely follow the predictions of the classical Solow growth model [Solow, 1956]. This approach stresses two engines of economic growth: increases in inputs of labor and capital and increases in productivity. In the short run, high growth rates mainly come from the increases in inputs (labor from agriculture to manufacturing and foreign direct investment), whereas technology catch-up and spill-over effects shape productivity increases. The speed of technology catch-up is shaped by public investments in education, which improves the absorption capacity of firms. The Solow model predicts that in the long run, the economy returns to steady state growth driven by productivity increases only, for the aforementioned normal increases in inputs die out. However, as stressed by the new growth models, reviewed by Syverson [Syverson, 2011], productivity growth is endogenously determined by three dominant factors. First, with respect to institutional elements, in order to keep growing, emerging markets have to improve their business climate in terms of legal restrictions, property rights, and ease of doing business. Second, with respect to business culture, improvements in management practices play an important role in shaping productivity [Bloom, van Reenen, 2007]. Third, with respect to spatial economic development, industrialization has led to large scale urbanization. For productivity to keep increasing, this move to the city has to be accompanied by a rise in ambitious entrepreneurship in the service industry and at creative start-ups [Glaeser et al., 2016].

Table 1 provides some general statistics on demand and productivity in China, Russia, and India. The top part of the table focuses on changing demand factors in these emerging economies. The main stylized fact demonstrated here is the relative decline in the importance over time of export demand, as measured by the fall in export growth rates. By contrast, rising domestic demand has become a more important driver of growth. For example, in the recent period for China, consumption growth has overtaken the role of export growth. Another example is the increased overall importance of domestic investments (net of FDI) as a driver of demand in Russia and China. The lower part of Table 1 shows aggregate scores on innovation coming from the Global Competitiveness Index [WEF, 2017]. As an overall conclusion, emerging markets have substantially increased their internal engines of innovation in the recent period, as can be observed in several overall innovation scores. Overall, China, India, and Russia have improved R\&D spending, patent applications, and public funding for innovation. In addition, substantial improvements have been made on the soft elements of innovation like technology transfer, retaining talent, and entrepreneurship.

To dig one level deeper, in Table 2 we use our dataset to show the overall statistics for the exports and innovation of Chinese firms over time. The data, to be discussed in more detail below, are from the annual surveys of manufacturing enterprises from 1998 to 2009 conducted by the National Bureau of Statistics (NBS) of China and include all state-owned firms and non-state-owned firms with annual sales of more than RMB 5 million. In Columns (2) to (5), we show (i) the share of firms with no exports or new products sales in the total number of firms, (ii) the share of firms exporting traditional products, (iii) the share of firms with new product sales but no exports, and (iv) the share of firms with exports and innovation, respectively. Looking at the time pattern of these statistics, we have some interesting observations. In Column (3), the share of firms exporting traditional products first increases over time, probably due to China's entry into the WTO in 2001. However, in recent years this share has begun to decrease. In Column (4), it can be observed that there has been a mild increasing trend in the share of firms focusing on innovation in domestic markets over years. Again, this table provides evidence of the increased importance of the Domestic Demand - Innovation locus for economic development.

\section{Theoretical Background and Conceptual Model}

The cornerstones of the new trade models are monopolistic competition and firm heterogeneity with respect to productivity. Together these assumptions imply that in each industry there is a cut-off productivity level for the firm with zero profits and the rest of the firms make a profit. Expanding the firm with an export unit and selling in foreign markets are costly because this strategy has fixed costs and the marginal costs are higher for exporters than for producers on the domestic market. Melitz's [Melitz, 2003] seminal paper shows that trade liberalization in the form of lower marginal trade costs induces a selection effect among domestic producers. Trade liberalization causes an expansion of the export sector and increases labor demand. When labor relocates, this also increases the wage costs in equilibrium for domestic firms, raising the cut-off productivity level.

The position that exporting firms are more productive than non-exporting firms has deep roots in the international business literature, which stresses that internationally oriented firms have (technological) ownership advantages that they leverage on foreign markets [Dunning, 1988]. However, firms from emerging markets often lack these advantages and build them through international alliances [Mathews, 2009; Mathews, Zander, 2007]. In addition, there are older studies investigating the interaction between internationalization and product improvement through quality ladders [Grossman, Helpman, 1991]. This has given rise to a substantial empirical literature on the spillback effect of internationalization on innovation in emerging markets [Damijan, Kostevc, 2006; Damijan et al., 2010; De Loecker, 2007, 2011]. In this literature, innovation is often modelled as R\&D expenditures to increase productivity by reducing the marginal costs of production. When analyzing the effects of productivity on the sorting pattern into exporting and innovation, account should be taken of other factors that influence these decisions. Clearly, 
Table 1. Exports, Domestic Consumption, and Innovation for Major Emerging Markets

\begin{tabular}{|c|c|c|c|c|c|c|}
\hline \multirow{2}{*}{ Indicators } & \multicolumn{2}{|c|}{ China } & \multicolumn{2}{|c|}{ India } & \multicolumn{2}{|c|}{ Russia } \\
\hline & $2001-2011$ & 2012-2017 & 2001-2011 & 2012-2017 & 2001-2011 & 2012-2017 \\
\hline \multicolumn{7}{|c|}{ International Orientation } \\
\hline Exports of goods - growth & 24.2 & 3.2 & 22.7 & 0.2 & 22.3 & -4.7 \\
\hline High-tech exports (\%) & 27.0 & 25.9 & 6.7 & 7.6 & 11.0 & 10.9 \\
\hline Trade to GDP ratio & 29.5 & 22.7 & 20.8 & 24.9 & 26.9 & 23.7 \\
\hline \multicolumn{7}{|c|}{ Domestic market } \\
\hline Gross fixed capital formation (\%) & 38.9 & 44.5 & 30.5 & 30.1 & 18.7 & 20.1 \\
\hline Gross fixed capital formation (change) & 20.9 & 5.6 & 18.5 & 3.5 & 30.6 & 16.2 \\
\hline Household consumption expenditure (\%) & 40.3 & 37.9 & 61.4 & 58.2 & 49.3 & 49.6 \\
\hline Household consumption expenditure (\$bn) & 946.9 & 3863.2 & 487.9 & 1243.1 & 394.3 & 881.8 \\
\hline Household consumption expenditure (change) & 15.0 & 8.8 & 12.3 & 7.6 & 27.1 & -2.3 \\
\hline \multicolumn{7}{|c|}{ Innovation } \\
\hline Patent applications per capita & 14.3 & 64.2 & 0.9 & 1.7 & 20.4 & 22.5 \\
\hline Total R\&D personnel in business per capita & 0.9 & 2.1 & 0.1 & 0.1 & 3.6 & 2.9 \\
\hline Researchers in $\mathrm{R} \& \mathrm{D}$ per capita & 1.0 & 1.1 & 0.2 & 0.2 & 3.2 & 3.1 \\
\hline Business expenditure on R\&D (\%) & 1.0 & 1.5 & 0.2 & 0.3 & 0.7 & 0.6 \\
\hline Attracting and retaining talent ${ }^{*}$ & 6.5 & 6.9 & 7.6 & 6.9 & 5.2 & 5.4 \\
\hline Brain drain* & 3.4 & 3.8 & 5.7 & 5.4 & 2.6 & 3.0 \\
\hline Entrepreneurship ${ }^{*}$ & 5.5 & 6.4 & 6.0 & 5.6 & 5.7 & 5.1 \\
\hline Funding for technological development ${ }^{*}$ & 4.2 & 5.6 & 5.2 & 5.5 & 3.2 & 4.4 \\
\hline Innovative capacity* & 4.7 & 5.3 & 5.3 & 5.0 & 4.1 & 3.8 \\
\hline Knowledge transfer ${ }^{\star}$ & 3.8 & 4.6 & 4.4 & 4.1 & 3.2 & 3.4 \\
\hline
\end{tabular}

industry context matters as well as firms' characteristics such as size and location. The stage model of international learning argues that it takes time for firms to internationalize, so that firm age potentially is an important factor to control for [Johanson, Vahlne, 1977]. Access to capital is another crucial factor to finance exports and innovation [Feenstra et al., 2014; Manova et al., 2015].

We use the above theoretical insights to construct a conceptual model that guides the empirical analysis. The basic intuitions of the approach are highlighted in Figure 1. On the axes we have firm productivity (x-axis) and firm profits (y-axis). The intuition behind the new trade theory is that firms within a single industry differ in productivity, which under monopolistic competition results in higher profits for the higher productivity firms. Firms serve a domestic market and potentially a foreign market by exporting. Firms with constant returns to scale can evenly split production into serving the domestic and the foreign markets. As exporting has some fixed costs (so the profit curves start below zero) and higher marginal costs than serving the domestic market (so exporting profit curves are flatter), only firms with higher productivity than the cut-off point A make a profit in the export market. Firms that serve only the domestic market are depicted by the profit curve D and exporting firms have the profit curve E.

For innovation, we follow the Aghion-Chaney setup in which innovation raises the marginal costs of production. More simply put, producing higher quality products does not come free [Aghion et al., 2001; Chaney, Ossa, 2013]. Firms that only sell domestically but are innovative are captured by the profit curve DI. The convex shape of the curve comes from the following. Higher quality products can be sold at a premium price because of lower substitutability. Innovation comes at a cost that is equal for all firms, however, it comes from a trade-off that is different for high and low productivity firms. Higher productivity firms have larger market shares (lower marginal costs) which at the margin means that quality increases have a larger impact on profitability for high productivity firms than they have for low productivity firms. Hence, the profit functions for innovators are convex. We draw two profit curves: DI is for innovators that produce for the domestic market, whereas EI are for exporters that innovate.

In the new trade models, firms first evaluate their productivity and after that decide on their business choices. In our model, there are four options: domestic traditional production only, domestic innovator, export traditional production, and export innovator. Using Figure 1, the choices for the outer segments 


\section{Figure 1. The Conceptual Model of Companies and the Level of Productivity}

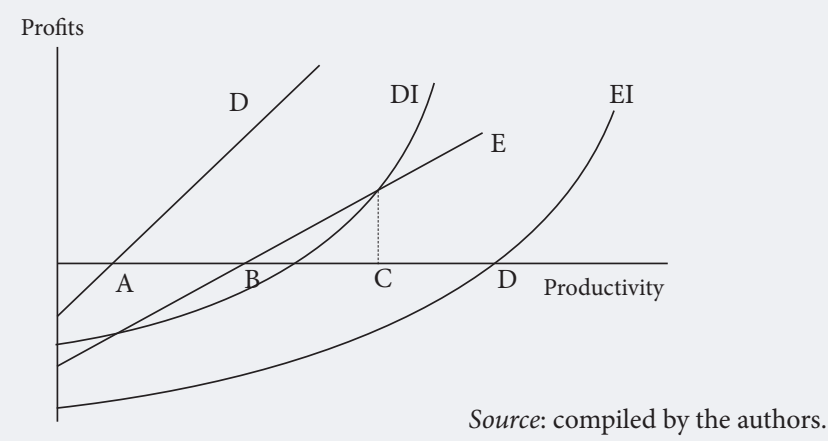

of the productivity distribution are pretty straightforward: low productivity firms choose traditional domestic production methods to maximize profits, whereas high productivity firms choose to produce innovative exports. In-between the choices depend upon the cost structures of exporting and innovation. In our setup, low-medium productivity firms choose exporting over innovation. The reason is that although the fixed costs of innovation for firms are lower than those of exports, for low productivity firms, the effect of innovation is that it raises marginal costs without substantially increasing market shares and prices, so the DI curve for low-medium productivity firms is rather flat. Hence, as the benefits of innovation on the domestic market are low for low-medium productivity firms, traditional production together with paying the fixed costs of exporting produces higher payoffs for these firms than innovation. By contrast, for high-medium productivity firms, taking on the higher marginal costs associated with innovation on the domestic market has a higher payoff than traditional low quality production on export markets. However, doing both innovation and the exporting would produce lower profits than restricting it to domestic innovation. Only firms with very high productivity can bare the combined costs of exporting and innovation.

Figure 1 shows the structure of the distribution of companies according to productivity. In line with the new trade theory concepts, the story is best told by assuming that all firm owners observe a productivity draw for their firms and then decide on strategy. Firms that observe a productivity below A will not start production as they expect to be loss making, thus saving on sunk costs. Low productivity firms in the segment $\mathrm{AB}$ will become domestic producers that do not engage in exporting and innovation, as these firms given their market shares will not be able to earn back the higher fixed and variable costs of these strategies. In the BC segment, firms make profits on the exporting and innovation strategy, however, combining these would mean very high fixed costs. These firms choose exporting traditional goods

\section{Table 2. Exports and Innovation in China in the Period of Study}

\begin{tabular}{|c|c|c|c|c|c|}
\hline \multirow[b]{2}{*}{ Year } & \multirow{2}{*}{$\begin{array}{c}(1) \\
\text { Number of } \\
\text { firms }\end{array}$} & \multicolumn{4}{|c|}{ Share in total number of firms (\%) } \\
\hline & & $\begin{array}{l}\text { (2) } \\
\text { Focus on the Domestic Market }\end{array}$ & $\begin{array}{l}\text { (3) } \\
\text { Focus on Exports }\end{array}$ & Domestic Innovator & $\begin{array}{l}(5) \\
\text { Export Innovator }\end{array}$ \\
\hline 1998 & 165135 & 75.02 & 18.28 & 3.52 & 3.18 \\
\hline 1999 & 162033 & 74.78 & 18.35 & 3.81 & 3.07 \\
\hline 2000 & 162883 & 73.45 & 19.67 & 3.72 & 3.17 \\
\hline 2001 & 171256 & 72.54 & 20.51 & 3.64 & 3.32 \\
\hline 2002 & 181557 & 71.50 & 21.93 & 3.54 & 3.03 \\
\hline 2003 & 196220 & 70.83 & 23.05 & 3.23 & 2.89 \\
\hline 2004 & 276475 & 68.11 & 24.95 & 3.72 & 3.22 \\
\hline 2005 & 271834 & 68.41 & 22.00 & 3.77 & 5.82 \\
\hline 2006 & 301958 & 69.59 & 20.53 & 4.14 & 5.74 \\
\hline 2007 & 336765 & 72.11 & 19.44 & 4.39 & 4.05 \\
\hline 2008 & 412285 & 74.34 & 18.12 & 4.08 & 3.46 \\
\hline 2009 & 434673 & 76.42 & 15.64 & 4.41 & 3.52 \\
\hline
\end{tabular}




\section{Table 3. Firm Divide by Groups: 1998-2009}

\begin{tabular}{|l|l|l|}
\hline Group & \multicolumn{1}{|c|}{ Name } & \multicolumn{1}{c|}{ Description } \\
\hline G1 & Domestic traditional producer & Company has not exported nor sold any new products \\
\hline G2 & Export traditional producer & $\begin{array}{l}\text { Company has exported but not engaged in innovation and created } \\
\text { new products }\end{array}$ \\
\hline G3 & Domestic innovator & $\begin{array}{l}\text { Company has engaged in innovation and created new products but } \\
\text { not exported }\end{array}$ \\
\hline G4 & Export innovator & Company has exported and engaged in innovation \\
\hline \multicolumn{2}{|l}{ Source: compiled by the authors. } & \\
\hline
\end{tabular}

over innovation as their market shares are too low for domestic innovation to be more profitable than exporting. In the CD segment, firms have higher market shares and benefit more from innovation on the domestic market than they do by entering foreign markets. Firms with productivity levels higher than D sell innovative products on both the domestic and foreign markets.

\section{Empirical Analysis}

Our data are taken from the annual surveys of manufacturing enterprises from 1998 to 2009 conducted by the National Bureau of Statistics (NBS) of China. We clean the data by dropping observations with missing values on key variables and firms with employment of less than eight people. ${ }^{1}$ To allow a consistent comparison of firms with different strategies over the sample period, we restrict our data sample to firms

\section{Table 4. Firm Distribution across Groups and Industries}

\begin{tabular}{|c|c|c|c|c|c|}
\hline Industry & G1 & G2 & G3 & G4 & Total \\
\hline Processing and Food from Agricultural Products & 465 & 108 & 124 & 99 & 796 \\
\hline Foods & 184 & 62 & 66 & 49 & 361 \\
\hline Beverages & 181 & 53 & 90 & 40 & 364 \\
\hline Tobacco & 20 & 8 & 6 & 6 & 40 \\
\hline Textile & 287 & 275 & 197 & 121 & 880 \\
\hline Textile Wearing Apparel, Footwear and Caps & 75 & 130 & 129 & 43 & 377 \\
\hline Leather, Fur, Feather and Related Products & 30 & 64 & 67 & 35 & 196 \\
\hline Processing of Timber, Wood, Bamboo and Others & 59 & 28 & 31 & 32 & 150 \\
\hline Furniture & 36 & 19 & 19 & 28 & 102 \\
\hline Paper and Paper Products & 373 & 74 & 80 & 54 & 581 \\
\hline Printing, Reproduction of Recording Media & 267 & 46 & 43 & 36 & 392 \\
\hline Articles for Culture, Education and Sport Activities & 7 & 22 & 49 & 13 & 91 \\
\hline Processing of Petroleum, Coking, Processing of Nuclear Fuel & 93 & 22 & 13 & 10 & 138 \\
\hline Raw Chemical Materials and Chemical Products & 639 & 244 & 284 & 185 & 1352 \\
\hline Medicines & 33 & 11 & 25 & 5 & 74 \\
\hline Chemical Fibers & 39 & 17 & 20 & 11 & 87 \\
\hline Rubber & 82 & 43 & 48 & 37 & 210 \\
\hline Plastics & 255 & 139 & 143 & 86 & 623 \\
\hline Non-metallic Mineral Products & 1284 & 157 & 249 & 179 & 1869 \\
\hline Smelting and Pressing of Ferrous Metals & 181 & 65 & 46 & 39 & 331 \\
\hline Smelting and Pressing of Non-ferrous Metals & 30 & 11 & 11 & 10 & 62 \\
\hline Metal Products & 378 & 211 & 255 & 110 & 954 \\
\hline General Purpose Machinery & 527 & 235 & 312 & 188 & 1262 \\
\hline Special Purpose Machinery & 273 & 153 & 153 & 135 & 714 \\
\hline Transport Equipment & 120 & 71 & 77 & 51 & 319 \\
\hline Communication Equipment, Computers and Other Electronic Equipment & 401 & 199 & 295 & 162 & 1057 \\
\hline Machinery for Cultural Activity and Office Work & 66 & 95 & 131 & 51 & 343 \\
\hline Artwork and Other Manufacturing & 43 & 25 & 53 & 28 & 149 \\
\hline Total & 6428 & 2587 & 3016 & 1843 & 13874 \\
\hline \multicolumn{6}{|c|}{$\begin{array}{l}\text { Note: Here and in the following tables the sample is restricted to firms that are active for all the } 12 \text { years between 1998-2009. } \\
\text { For the definitions of firm groups (G1 to G4) see Table } 3 \text {. } \\
\text { Source: compiled by the authors. }\end{array}$} \\
\hline
\end{tabular}

\footnotetext{
${ }^{1}$ In China, firms with fewer than eight employees are regarded as being under a different legal regime.
} 
Table 5. Data Summary for Different Groups

\begin{tabular}{|l|c|c|c|c|}
\hline \multirow{2}{*}{ Variables } & \multicolumn{2}{|c|}{ Non-innovator } & \multicolumn{2}{c|}{ Innovator } \\
\cline { 2 - 5 } & G1: Non-exporter & G2: Exporter & G3: Non-exporter & G4: Exporter \\
\hline$T_{F P}$ & $5.434(0.783)$ & $5.561(0.881)$ & $5.639(0.874)$ & $5.647(0.860)$ \\
\hline Age $_{1}$ & $13.664(9.987)$ & $10.265(9.368)$ & $11.681(9.573)$ & $10.474(9.289)$ \\
\hline Employment $_{1}$ & $258.312(194.273)$ & $250.110(201.569)$ & $288.472(205.708)$ & $255.316(203.276)$ \\
\hline Leverage $_{1}$ & $0.609(0.247)$ & $0.606(0.234)$ & $0.613(0.222)$ & $0.589(0.233)$ \\
\hline $\begin{array}{l}\text { Note: } \text { Standard deviations are reported in parentheses. } \\
\text { Source: compiled by the authors. }\end{array}$
\end{tabular}

that are observed in each of the 12 years. We end up with 13,874 firms in 28 industries and 31 provinces. The data are cut at 5th and 95th percentiles so as to drop outliers.

To check whether the pattern depicted in Figure 1 is consistent with the data, we classify firms into four groups (see Table 3). The ranking order of the four groups is therefore consistent with the sorting pattern predicted in the conceptual model. Table 4 reports the breakdown of firms across groups and industries. The main dependent variable is an ordinal variable with four levels from 1 to 4 corresponding to the four groups of firms' exporter and innovator status (Group). For robustness, we also use several dummy dependent variables to make comparisons between separate groups. These dummy variables take on the value 1 if a firm is in a higher group and 0 if it is in a lower group. For example, Group takes on the value 1 if a firm is in Group 2 and 0 if in Group 1. The main explanatory variable is the initial productivity level of firms $\left(T F P_{1}\right)$. To alleviate potential simultaneity bias and selection bias, we use the Olley and Parkes [Olley, Parkes, 1996] method to estimate the production function and construct the total factor productivity. We estimate the production function separately for each 2-digit industry so as to capture variations in production across industries. We also control for initial firm age $\left(A g e_{1}\right)$, employment

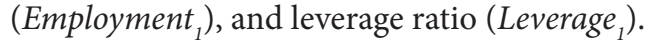

Table 5 reports on the descriptive statistics for the main variables based on firms' exporter and innovator classification. We find that the mean of the initial firm productivity level increases with the ordering of the groups, which provides some evidence for the pattern predicted in our conceptual model. It is worth noting that compared with firms exporting traditional products (G2), firms focusing on innovation on domestic markets (G3) have higher levels of initial productivity. The mean difference tests results in Table 6 show that the mean differences in the initial level of productivity across groups are statistically significant.

We then employ rigorous econometric regression analysis to control for some confounding factors in order to better identify the effect of the initial productivity on firms' export and innovation decisions. The econometric model is set up as follows:

$\operatorname{Group}_{i}=\alpha+\beta \operatorname{TFP}_{1 i}+X^{\gamma} \gamma+u_{j}+u_{p}+u_{o}+e$

where the subscript $i, j, p, o$ denote firm, industry, province, and firm ownership type, respectively. Group refers to dependent variables on firm classification including the ordinal variable Group and several dummy variables for separate comparisons; $T F P_{1}$ denotes the main explanatory variable of the initial productivity; $X$ is a vector of the control variables. In the model we incorporate industry $\left(u_{i}\right)$, province $\left(u_{p}\right)$, and ownership type $\left(u_{o}\right)$ fixed effects. It is noted that we use a cross-sectional data set as a firm enters into a group only once in the sample period. We employ the ordered probit estimation method for modelling the ordinal dependent variable and the probit regressions for the dummy dependent variables. Compared with the OLS method, the ordered probit and probit models can better deal with heteroscedasticity and nonnormality. ${ }^{2}$

Table 6. Mean-Difference Test on Initial TFP between Groups

\begin{tabular}{|l|c|c|c|c|c|c|}
\hline TFP, & G2-G1 & G3-G1 & G4-G1 & G3-G2 & G4-G2 & G4-G3 \\
\hline Mean difference & $0.127^{* * *}$ & $0.205^{* * *}$ & $0.213^{\star * *}$ & $0.078^{* * *}$ & $0.086^{* * *}$ & $0.008^{\star * *}$ \\
\hline t-value & 6.439 & 11.131 & 8.738 & 3.387 & 2.534 & 2.245 \\
\hline $\begin{array}{l}\text { Note: Here and in the following table } \\
\text { Source: compiled by the authors. }\end{array}$ \\
Sout and indicate statistical significance at the $1 \%, 5 \%$ and $10 \%$ levels, respectively. \\
\hline
\end{tabular}

\footnotetext{
We also use the OLS method to estimate the econometric model. The OLS results are consistent with the results of the ordered
} probit and probit regressions. 
Table 7. Effects of Initial TFP on Firm Export/Innovation Decisions

\begin{tabular}{|c|c|c|c|c|c|c|c|}
\hline Variables & $\begin{array}{c}(1) \\
\text { Group } \\
\mathrm{G} 1=1, \mathrm{G} 2=2, \\
\mathrm{G} 3=3, \mathrm{G} 4=4\end{array}$ & $\begin{array}{c}(2) \\
\text { Group_12 } \\
\text { G2=1, } \\
\text { G1=0 }\end{array}$ & $\begin{array}{c}(3) \\
\text { Group_13 } \\
\text { G3=1, } \\
\text { G1=0 }\end{array}$ & $\begin{array}{c}(4) \\
\text { Group_14 } \\
\text { G4=1, } \\
\text { G1=0 }\end{array}$ & $\begin{array}{c}(5) \\
\text { Group_23 } \\
\text { G3=1, } \\
\text { G2=0 }\end{array}$ & $\begin{array}{c}(6) \\
\text { Group_24 } \\
\text { G4=1, } \\
\text { G2=0 }\end{array}$ & $\begin{array}{c}(7) \\
\text { Group }_{34} \\
\text { G4=1, } \\
\text { G3=0 }\end{array}$ \\
\hline $\operatorname{TFP}_{1}$ & $\begin{array}{c}0.115^{\star * *} \\
(0.014)\end{array}$ & $\begin{array}{c}0.023^{* * *} \\
(0.006)\end{array}$ & $\begin{array}{c}0.037^{\star * *} \\
(0.006)\end{array}$ & $\begin{array}{c}0.040^{* * *} \\
(0.006)\end{array}$ & $\begin{array}{l}0.017^{* *} \\
(0.008)\end{array}$ & $\begin{array}{c}0.033^{\star * *} \\
(0.009)\end{array}$ & $\begin{array}{l}0.021^{* *} \\
(0.009)\end{array}$ \\
\hline$A G E_{1}$ & $\begin{array}{c}-0.006^{\star * *} \\
(0.001)\end{array}$ & $\begin{array}{c}-0.003^{* * *} \\
(0.001)\end{array}$ & $\begin{array}{c}0.000 \\
(0.001)\end{array}$ & $\begin{array}{c}-0.003^{* * *} \\
(0.001)\end{array}$ & $\begin{array}{l}0.004^{\star * \star} \\
(0.001)\end{array}$ & $\begin{array}{l}-0.001 \\
(0.001)\end{array}$ & $\begin{array}{c}-0.005^{\star * *} \\
(0.001)\end{array}$ \\
\hline Employment $_{1}$ & $\begin{array}{c}0.196^{\star * *} \\
(0.013)\end{array}$ & $\begin{array}{l}0.064^{\star * *} \\
(0.006)\end{array}$ & $\begin{array}{l}0.091^{\star * *} \\
(0.005)\end{array}$ & $\begin{array}{l}0.060^{\star * *} \\
(0.005)\end{array}$ & $\begin{array}{l}0.052^{\star * *} \\
(0.008)\end{array}$ & $\begin{array}{l}0.026^{* * *} \\
(0.008)\end{array}$ & $\begin{array}{c}-0.017^{\star *} \\
(0.008)\end{array}$ \\
\hline Leverage $_{1}$ & $\begin{array}{l}-0.024 \\
(0.044) \\
\end{array}$ & $\begin{array}{l}-0.026 \\
(0.019) \\
\end{array}$ & $\begin{array}{l}-0.006 \\
(0.019) \\
\end{array}$ & $\begin{array}{l}-0.001 \\
(0.017) \\
\end{array}$ & $\begin{array}{l}0.049^{*} \\
(0.029) \\
\end{array}$ & $\begin{array}{c}-0.002 \\
(0.030) \\
\end{array}$ & $\begin{array}{l}-0.045 \\
(0.029) \\
\end{array}$ \\
\hline Province dummy & Yes & Yes & Yes & Yes & Yes & Yes & Yes \\
\hline Sector dummy & Yes & Yes & Yes & Yes & Yes & Yes & Yes \\
\hline Ownership dummy & Yes & Yes & Yes & Yes & Yes & Yes & Yes \\
\hline Number of observations & 13873 & 9016 & 9445 & 8272 & 5601 & 4428 & 4857 \\
\hline \multicolumn{8}{|c|}{$\begin{array}{l}\text { Note: Robust standard errors are reported in parentheses. Columns (2-7) contain values of the marginal effects and the } \\
\text { dependent dummy variables which take on the value } 1 \text { if firms are in a higher group and } 0 \text { if they are in a lower group. }\end{array}$} \\
\hline
\end{tabular}

Table 7 reports the main estimation results. The dependent variable in Column (1) is the ordinal variable Group with value 1 if the firm is a domestic traditional producer (G1), 2 if it is an export traditional producer (G2), 3 if it is domestic innovator (G3), and 4 if it is export innovator (G4), respectively. We then use the dummy dependent variables for separate group comparisons in the rest columns. For example, in Column (2) we compare the effect of the initial productivity level on the choice between traditional domestic production (Group ${ }_{12}$ takes on the value 0 ) and exports with traditional production (Group ${ }_{12}$ takes on the value 1). The same way of constructing the dummy dependent variables applies to Columns (3) to (7) with different comparisons between groups. The ordered probit results in Column (1) shows that the initial productivity level of firms, as expected, has a significantly positive impact on the probability of firms located in a higher exporter and innovator classifications, which supports the pattern illustrated in our conceptual model, and which is confirmed by the probit results in the rest columns. Again, we find that firms with relatively low productivity choose to export traditional products (G2), while those with relatively high productivity choose domestic innovation over exporting (G3). As for control variables, the results show that young and large firms are more likely to end up in the higher groups.

\section{Conclusion and Policy Implications}

Transforming economic growth from input-based to innovation-driven is the most important objective for policy makers in emerging markets. Russia is probably the most outspoken in stating that digitalization and scientific capabilities are the key to its future success. Guided by a conceptual model, the analysis conducted for this article shows that on emerging markets, the connections between firm productivity and internationalization and innovation are quite multi-faceted. When firms face constraints in financing and resources, they may have to choose between exporting and innovating on the domestic market. We provide evidence for China that the increased importance of the domestic market raises the incentives for productive firms to choose innovation over internationalization.

The analysis has potentially important policy implications. When policy incentives are there to nudge firms towards their first best choice, our analysis argues that policies should take a great amount of care in differentiating incentives for firms with differing levels of productivity. As a thought experiment, often it is assumed that a close connection exists between productivity and firm size. In that case, and in contrast to popular policy opinion, internationalization should be promoted among smaller firms. The reason is that these firms can leverage their low costs capabilities internationally. By contrast, larger firms may better concentrate on gaining market share on the rapidly growing domestic market. Hence, policies that support access to technology and access to financing for innovation may better be aimed at larger and more productive companies.

In addition, our analysis has important strategic managerial implications. The most important one may be for the high productivity firms that face a trade-off between internationalization and innovation. Often, these firms connect with foreign firms in order to learn and leverage their capabilities for operational efficiency and excellence. The long run strategy is access to strategic assets that would complement existing capabilities. However, in the minds of senior management, such linking strategies often have the strategic goal of opening foreign markets. Our analysis highlights the fact that linking internationally may serve the goal of gaining access to capabilities that are to be leveraged on the domestic market more than internationally. 


\section{References}

Aghion P., Harris C., Howitt P., Vickers J. (2001) Competition, imitation and growth with step-by-step innovation. The Review of Economic Studies, vol. 68, no 3, pp. 467-492.

Bernard A.B., Jensen J.B. (2004) Why some firms export. Review of Economics and Statistics, vol. 86, no 2, pp. 561-569.

Bernard A.B., Jensen J.B. (1999) Exceptional exporter performance: Cause, effect, or both? Journal of International Economics, vol. 47, no 1, pp. 1-25.

Bloom N., Van Reenen J. (2007) Measuring and explaining management practices across firms and countries. Quarterly Journal of Economics, vol. 122, no 4, pp. 1341-1408.

Chaney T., Ossa R. (2013) Market size, division of labor, and firm productivity. Journal of International Economics, vol. 90, no 1, pp. 177-180.

Damijan J.P., Kostevc C. (2006) Learning-by-exporting: Continuous productivity improvements or capacity utilization effects? Evidence from Slovenian firms. Review of World Economics, vol. 142, no 3, pp. 599-614.

Damijan J.P., Kostevc Č., Polanec S. (2010) From innovation to exporting or vice versa? The World Economy, vol. 33, no 3, pp. 374-398.

De Loecker J. (2007) Do exports generate higher productivity? Evidence from Slovenia. Journal of International Economics, vol. 73, no 1, pp. 69-98.

De Loecker J. (2011) Product differentiation, multiproduct firms, and estimating the impact of trade liberalization on productivity. Econometrica, vol. 79, no 5, pp. 1407-1451.

Dunning J.H. (1988) The Eclectic Paradigm of International Production: A Restatement and Some Possible Extensions. Journal of International Business Studies, vol. 19, no 1, pp. 1-31.

Fan H., Lai E.L., Li Y. (2015) Credit constraints, quality, and export prices: Theory and evidence from China. Journal of Comparative Economics, vol. 43, no 2, pp. 390-416.

Feenstra R.C., Li Z., Yu M. (2014) Exports and credit constraints under incomplete information: Theory and evidence from China. Review of Economics and Statistics, vol. 96, no 4, pp. 729-744.

Ferguson S.M. (2009) Exporting and Quality Complementarity with Heterogeneous Firms. Paper presented at the ETSG 2009 Conference, Rome. Available at: http://www.etsg.org/ETSG2009/papers/ferguson.pdf, accessed 12.02.2018.

Grossman G.M., Helpman E. (1991) Quality Ladders and Product Cycles. Quarterly Journal of Economics, vol. 106, no 2, pp. 557-586.

Glaeser E.L., Ponzetto G.A., Zou Y. (2016) Urban networks: Connecting markets, people, and ideas. Papers in Regional Science, vol. 95, no 1, pp. 17-59.

Johanson J., Vahlne J.E. (1977) The internationalization process of the firm-a model of knowledge development and increasing foreign market commitments. Journal of International Business Studies, vol. 8, no 1, pp. 23-32.

Manova K., Wei S., Zhang Z. (2015) Firm exports and multinational activity under credit constraints. Review of Economics and Statistics, vol. 97, no 3, pp. 574-588.

Mathews J. (2009) China, India and Brazil: Tiger technologies, dragon multinationals and the building of national systems of economic learning. Asian Business \& Management, vol. 8, no 1, pp. 5-32.

Mathews J., Zander I. (2007) The international entrepreneurial dynamics of accelerated internationalisation. Journal of International Business Studies, vol. 38, no 3, pp. 387-403.

Melitz M.J. (2003) The impact of trade on intra-industry reallocations and aggregate industry productivity. Econometrica, vol. 71, no 6, pp. 1695-1725.

Olley S., Pakes A. (1996) The dynamics of productivity in the telecommunications equipment industry. Econometrica, vol. 64, no 6, pp. 1263-1298.

Solow R.M. (1956) A Contribution to the Theory of Economic Growth. The Quarterly Journal of Economics, vol. 70, no 1, pp. 65-94.

Syverson C. (2011) What determines productivity? Journal of Economic Literature, vol. 49, no 2, pp. 326-365.

WEF (2017) The Global Competitiveness Report 2017-2018, Geneva: World Economic Forum. 


\title{
Personnel Development in Chinese Innovation-Active Companies
}

\author{
Elena Zavyalova \\ Head of Organizational Behavior and HR Management Department, zavyalova@gsom.pu.ru
}

Artem Alsufyev

Assistant Professor of Organizational Behavior and HR Management Department, E-mail: alsufyev@gsom.pu.ru

School of Management of the St. Petersburg University, 3 Volkhovskiy Lane, St. Petersburg 199004, Russian Federation

Inna Krakovetskaya

Associate Professor of Strategic Management and Marking Department, inna_krakov@mail.ru

National Research Tomsk State University, 36 Lenina Str., 634050, Tomsk, Russian Federation

\author{
Wan Lijun \\ Head, sitlily@aliyun.com
}

Chinese-Russian Institute at the Shenyang Polythechnical University, 6 Nanpingzhong Rd Hunnan New District of Shenyang City, Liaoning Province, China

Jessica Li

Associate Professor, Education Policy, Organization and Leadership Department, jli2011@illinois.edu

University of Illinois Urbana Champaign, USA, 61820, Champaign, 354 Education Bldg 1310 S. Sixth St.

\begin{abstract}
$\mathrm{T}$ This article is devoted to an analysis of the mechanisms and tools that promote innovative activity at Chinese companies. We describe and evaluate the model of the Chinese innovation ecosystem with its major subsystems and their interconnections. Personnel training and development are considered an element of the subsystem "Education" within the innovation ecosystem, which serve as tools for the formation of human resources to ensure the transformation of the national economy into a global center of innovation. The authors analyze the main challenges connected with the level of development of the environment and the socioeconomic institutions that may impede the effective management of human resources and the various practices for training personnel at innovative companies in China.

The data analyzed for this empirical study on training and development practices includes structured interviews at 60 medium and large innovative companies in China. Objective economic indicators of innovative activity were taken as measures. The analysis results allow one to identify four clusters of companies: "Innovators," "Leader in Training," "Stars," and "Lagging Behind," which describe the different company approaches to providing personnel training and development. Clusters vary in quantitative and qualitative indicators for personnel training and development processes, as well as economic indicators of innovation activity. The results prove that a relationship exists between approaches to personnel training and development and innovative activity results and suggest that training and development initiatives are effective tools for managing innovative companies.
\end{abstract}

\section{Keywords:}

innovation-active companies; the innovation ecosystem; state regulation of innovation activity; China; personnel training and development

Citation: Zavyalova E., Alsufyev A., Krakovetskaya I., Lijun W., Li J. (2018) Personnel Development in Chinese Innovation-Active Companies. Foresight and STI Governance, vol. 12, no 3, pp. 43-52. DOI: 10.17323/25002597.2018.3.43.52 
$\mathrm{T}$ he principles of designing and developing China's innovation system in the context of the national economy's transition "from imitating to independent innovation and development of high technologies" $[L i, 2010]$ were declared officially by the Chinese government. Chinese national innovation policy serves as the basis for the gradual construction of such a system, which in turn is based upon Deng Xiaoping's theory of technological progress [Chang, 1996]. Leonov and Domnich [Leonov, Domnich, 2010] identify five stages of innovation policy implementation in China, each accomplishing important objectives for the national economy such as setting industry-specific priorities, creating conditions for generating new knowledge in breakthrough areas of science, developing mechanisms for their practical implementation, and so on. According to the "Strategic S\&T Development Plan 20062020" [Chinese Academy of Sciences, 2014], the country is expected to take a qualitative leap forward in terms of increasing the number of high-tech companies, the share of information and communication technologies (ICT) in national exports, $\backslash$ and extending the range of telecommunication services' users (mobile and landline telephones, the internet, etc.). This has kicked off the fifth stage of implementing China's innovation policy, the goal of which is to achieve long-term sustainable development by modernizing all industries of the economy and turning the country into an innovation leader.

The objectives set by the Chinese government required a review of the principles of human resources management. Successful modernization and technological upgrading of production facilities revealed a number of problems in this area, in particular, shortages of skilled professionals (specialists and managers alike), the lack of an overall human resources management strategy, and competition between global and local businesses, state-owned and commercial companies, and Western and domestic business practices. It takes decades to acquire the unique engineering and managerial competences and experience that make staff training and development for innovative activities possible. Apart from the practical relevance, studying the existing approaches to dealing with it also has a theoretical dimension connected with conceptualizing human capital development in the corporate sector of emerging countries.

The objective of this paper is to analyze staff training practices of medium and large innovative Chinese companies in order to study their approaches to it, keeping in mind that such techniques are seen as components of the "Education" subsystem of the Chinese national innovation ecosystem, and are employed as human capital management tools to accomplish strategic objectives of the country's innovation-based development.

\section{The Emergence and Development of China's Innovation Ecosystem}

The first steps towards creating the national innovation system were taken by the Chinese authorities in 1975, when the course towards "openness" was announced. This process was officially complete in 2010. As a component, or a subsystem of the global system, the national innovation system in its turn exceeds the sum of its elements; a systemic approach is required to describe and model it [Chistiakova, 2007].

The "black box" model we have used in this study analyzes a system's inputs and outputs and allows one to describe the system in terms of how it transforms them. The classic black, grey, and white box schemes, in addition to analyzing systems through their inputs and outputs, also involve studying the actual mechanism that transforms the former (resources) into the latter (products) (see Figure 1). The main components of the Chinese innovation system, and their functions, are presented in Table 1. Each functional subsystem affects the overall national potential, and its innovation environment.

The "Education" subsystem plays a key role in stepping up the country's innovation-based development, since the national innovation ecosystem and all its components require highly skilled personnel with unique competences and professional experience sufficient to generate and disseminate innovations and create new technological paradigms.

\section{Government Regulation of Innovative Activities in China}

At the initiative of the Ministry of Science and Technology of the People's Republic of China, more than 1,500 business incubators were established in the country, providing comprehensive support to innovative and high-tech companies. Eighty thousand firms use the incubators' services every year. The ministry also administers a 3.5-billion-yuan investment fund (about 440 million euros) to support innovative projects. According to the European Commission, in 2012 the Chinese Innovation Fund for Small Technology-Based Firms (InnoFund) provided subsidies in the amount of about 520 million euros [European Commission, 2015].

One of the mechanisms for providing indirect support to innovative Chinese businesses is a preferential taxation regime. For example, just in the first three quarters of 2015, Chinese innovative firms received tax breaks in the amount of 237.5 billion yuan ( $\$ 37.2$ billion) [Xinhua, 2015]. Also, the state helps companies patent and license their designs. All innovations created on Chinese territory are recorded in special product catalogues, and subsequently receive preferential treatment when they take part in tenders or public procurement procedures. 


\section{Figure 1. Model of the Chinese National Innovation Ecosystem}

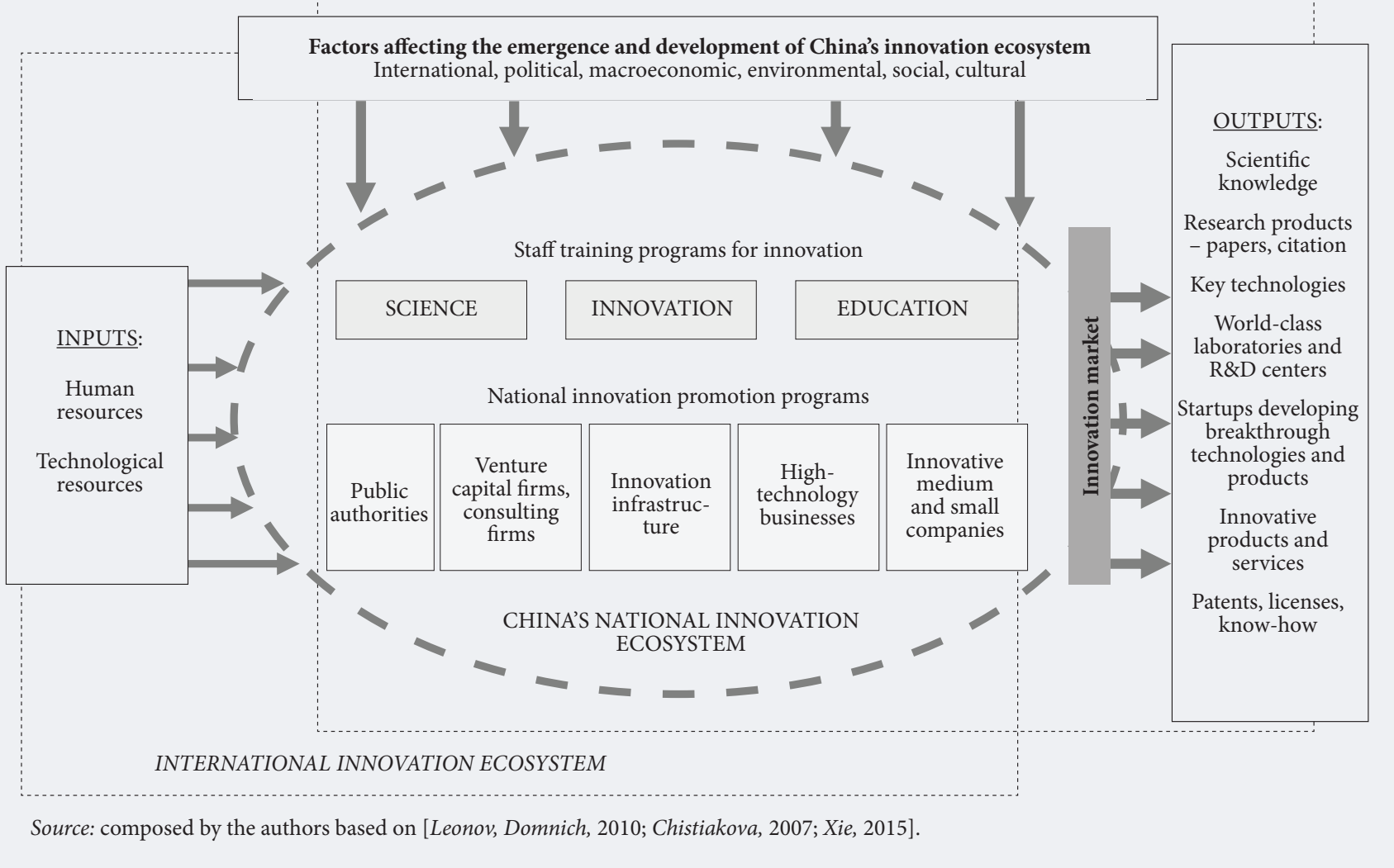

The state controls all interactions between the participants of various subsystems of the national innovation ecosystem, in particular those within the scope of the various national innovation support programs (Table 1).

\section{Approaches to Innovative Companies' Human Resources Management}

The re-orientation of Chinese businesses towards the application of knowledge and innovative technologies created demand for highly skilled professionals [Simon, Cao, 2009]. To address this issue, the Chinese government designed a set of measures to support and aid technological university graduates in job placement (Table 2). In particular, in the scope of the Thousand Talents Program, steps are being taken to repatriate more successful managers and scientists from abroad. Companies, especially innovative ones, also work on improving the quality of their human capital [Simon, Cao, 2009]. One of the tools they use for this purpose is improving their human resources management systems - an issue to which businesses used to pay insufficient attention. The first labor code adopted in the country that strongly protects workers' rights has served as the mechanism regulating labor relations since 2008.

By the beginning of the $21^{\text {st }}$ century, companies were only starting to move on from the personnel management concept to the human resources management principle [Soltitskaya, Bo, 2005]. Personnel managers tended to have a rather low status, and their functions normally were administrative and based on control. However, innovative companies have always been somewhat different in this respect. A recent study of the correlation between the level of firms' R\&D activities and their personnel management practices identified the following practices: setting up cross-functional project groups; systematically arranging training events and workshops to upgrade employees' qualifications; sharing experiences with other companies in the industry; and providing financial incentives to encourage employees' participation in R\&D [Eriksson et al., 2014].

Certain authors point to China's national features as the reason for different approaches to managing human resources. The first such specific feature is connected with companies' ownership. Malcolm Warner [Warner, 2008] notes that state-owned companies in the country frequently bear the burden of the traditionally established personnel management practices [Child, David, 2001; Warner, 1996]. Quite natural for large, old enterprises, this organizational inertia comes at odds with the economic reforms 
Table 1. The Components of the Chinese Innovation System, and their Functions

\begin{tabular}{|c|c|}
\hline Subsystem & Function \\
\hline Public authorities & $\begin{array}{l}\text { - Government regulation and promotion of innovation activities in the country, directly and indirectly } \\
\text { - Funding research and development (R\&D) } \\
\text { - Development of legal basis for innovation activities } \\
\text { Development and modernization of innovation infrastructure }\end{array}$ \\
\hline $\mathrm{R} \& \mathrm{D}$ sector & $\begin{array}{l}\text { - Creating new knowledge and radical innovations } \\
\text { - Conducting R\&D in priority science and technology (S\&T) areas } \\
\text { - Training R\&D personnel }\end{array}$ \\
\hline $\begin{array}{l}\text { High-technology } \\
\text { businesses }\end{array}$ & $\begin{array}{l}\text { - Production of high-technology products and services } \\
\text { - Job creation } \\
\text { - Funding R\&D from their own sources } \\
\text { Integration of large companies, leading R\&D organizations, and universities }\end{array}$ \\
\hline $\begin{array}{l}\text { Small and medium } \\
\text { innovative businesses }\end{array}$ & $\begin{array}{l}\text { - Production of innovative products and services } \\
\text { - Job creation in the innovative business sector } \\
\text { - Funding R\&D from their own sources }\end{array}$ \\
\hline $\begin{array}{l}\text { Innovation } \\
\text { infrastructure }\end{array}$ & $\begin{array}{l}\text { - Commercialization of R\&D results } \\
\text { - Promoting creation of small research-intensive companies } \\
\text { - Pob creation }\end{array}$ \\
\hline Education sector & $\begin{array}{l}\text { - Training and upgrading personnel to create innovations } \\
\text { - Conducting basic and applied research at universities } \\
\text { - Achieving "critical mass" of talented people } \\
\text { - Promotion of innovative culture in the business environment } \\
\text { - Development of innovative education technologies } \\
\text { - Development of innovation infrastructure } \\
\text { - Increasing overall intelligence level of the population }\end{array}$ \\
\hline
\end{tabular}

aimed at encouraging companies in the non-public sector to promote the development of human capital [Ding, Akhtar, 2001].

Another feature is evident in the problems Chinese companies encounter when they try to apply Western human resources management standards. Values shared by the local staff include harmony and a complex system of informal connections - the so-called guanxi [Verburg et al., 1999]. Chinese workers are more inclined to accept their superior's opinion and obey rather than initiate change [Zhao, 1994]. In the context of unequal, hierarchic relations, changes at the workplace are seen as undermining stability [Hofstede, 1991]. This contradiction becomes particularly apparent when rewards and incentives programs are implemented [Sumelius, 2009]. Despite the higher compensation, Chinese citizens are not very keen on working for foreign companies: they do not like the high intensity of work, the rigid bureaucratic subordination, strict discipline, and lack of flexible working hours [Nyrovba, 2009]. There is no standing in for one another on a traditional Chinese team: areas of responsibility at companies are delineated so strictly that employees in the same division frequently have no idea what their colleagues who report to a different boss actually do. It is a Confucian tenet: to bring harmony into the world, everybody must do their job as best they can, and pay no heed to others. The sources of strict division of work responsibilities can be traced all the way back to the ancient institute of apprentices [Marchenko, 2013].

Warner proposes that human resources management systems in China may develop towards hybrid forms, including various combinations of local managerial features and Western or East Asian practices [Warner, 1996]. The authors of another study [Ding et al., 1997] come to a similar conclusion: they link the degree of integration of various approaches to human resources management to organizations' characteristics, and their chosen strategies for achieving competitive advantages.

\section{Staff Training at Chinese Companies}

Human resources management strategies and practices employed by innovative companies depend upon their approach to staff training and development as tools to acquire more relevant competences. Very few companies have resources to design and implement staff training systems on their own. Following the Western example, the well-known Lenovo Group established its own corporate. State-owned companies very much lag behind private firms in this area [Warner, 1993, 1996], which among other things is confirmed by the data published in a study of human resources management practices at various Chinese companies [Lu, Bjorkman, 1997]. Most of the studies stress that such training programs remain less than perfect [Lu, Bjorkman, 1997, 1998]; they are mostly focused on developing technical skills, as opposed to managerial competences [Child, 1996].

Training programs in technical and managerial skills are quite common in the corporate sector, but stateowned companies implement them much more rarely. Joint ventures typically provide training of both these types, with priority given to technical skills. A larger-scale study [Zhu, 1998] based on a sample comprising 440 enterprises with different ownership statuses in Shanghai revealed that joint ventures 


\section{Table 2. National Chinese S\&T and Innovative Activity Support Programs}

\begin{tabular}{|c|c|}
\hline Program & Brief description \\
\hline 863 Program & $\begin{array}{l}\text { A government program to promote S\&T research and development of high technologies; the goal of which } \\
\text { is to eliminate the country's dependency on high technology imports and to achieve breakthroughs in key } \\
\text { technology areas. A strategy for researching and developing high technologies was designed in the scope } \\
\text { of the program, along with a set of measures aimed at raising a new generation of personnel to work in the } \\
\text { high-technology sectors of the economy. }\end{array}$ \\
\hline 973 Program & $\begin{array}{l}\text { This is a national basic S\&T research plan which among other things envisages mobilizing research talent } \\
\text { to promote such areas as agriculture, energy, ICT, natural resources and environment, demography, and } \\
\text { health. The program makes provisions for training research personnel to conduct innovative research } \\
\text { in breakthrough areas, with the potential to contribute to the country's economic, social, and S\&T } \\
\text { development. }\end{array}$ \\
\hline Key Technologies Program & $\begin{array}{l}\text { This program is designed to support research aimed at achieving breakthroughs in developing key } \\
\text { technologies, technological modernization, restructuring traditional and promoting the emergence of new } \\
\text { industries to implement domestic innovation. The program allocates public funding to universities and } \\
\text { research institutes, whose productivity is assessed on the basis of their research results (i.e., publications } \\
\text { and patents). }\end{array}$ \\
\hline $\begin{array}{l}\text { Excellent Engineers Training } \\
\text { Program }\end{array}$ & $\begin{array}{l}\text { A project of the Ministry of Education of the People's Republic of China to implement medium- and long- } \\
\text { term programs for reforming the education system and providing support for Chinese talent in 2010-2020, } \\
\text { to improve the quality of enrollment, education, and training of talented engineers. }\end{array}$ \\
\hline $\begin{array}{l}\text { New Century Excellent } \\
\text { Talents }\end{array}$ & $\begin{array}{l}\text { The program's objective is to create a platform for training of and to provide support for research leaders } \\
\text { with great innovative potential. For this purpose, about } 1,000 \text { outstanding young scientists are annually } \\
\text { selected across the country, to receive subsequent support. }\end{array}$ \\
\hline Hundred Talents Program & $\begin{array}{l}\text { The program is aimed at encouraging talented professionals aged under } 45 \text { to come and work in China. } \\
\text { Subsidies are offered of up to } \$ 240,000 \text { per scientist, for a period of up to three years. The money can } \\
\text { be spent on funding research, paying researchers' rents and salaries. The program strives to deepen the } \\
\text { integration of the Chinese Academy of Sciences (CAS) into the global context. About } 81 \% \text { of the CAS } \\
\text { members, and } 54 \% \text { of the Chinese Academy of Engineering members are repatriated scientists. }\end{array}$ \\
\hline Thousand Talents Program & $\begin{array}{l}\text { The objective of the program is to encourage top-level foreign researchers to come and work in China on } \\
\text { a long-term basis (starting from three years), and fund their research. By the middle of 2012, 2,263 high- } \\
\text { level international scientists took part in the program. }\end{array}$ \\
\hline $\begin{array}{c}\text { Innovation } 2020 \text { Personnel } \\
\text { Development Strategy }\end{array}$ & $\begin{array}{l}\text { The implementation of this medium- to long-term strategy (2010-2020) is the responsibility of the CAS. } \\
\text { The objective is to train more than 3,000 young talented researchers in the S\&T area, and more than } \\
2,000 \text { innovation team leaders for industrial application of S\&T achievements. }\end{array}$ \\
\hline 211 Project and 985 Project & $\begin{array}{l}\text { The projects envisaged that leading Chinese universities would be included in the global top } 100 \text { by } \\
\text { the beginning of the } 21 \text { st century. Nine universities were initially selected to receive priority funding; } \\
\text { subsequently the list was expanded. Now several elite Chinese research universities are indeed included } \\
\text { in the top } 100 \text { ranking, that is, they are becoming competitive in the global educational services market. }\end{array}$ \\
\hline
\end{tabular}

usually offer additional training to their staff, including technical and managerial skills. The author divided staff training and development objectives into three groups:

1) correcting employees' shortcomings, upgrading their technical knowledge and skills;

2) increasing employees' ability to adapt;

3) strengthening employees' loyalty.

The companies in the sample were asked to rate each element in these three groups on a five-point scale in relation to the current and expected situation. Contrary to previous studies, this one's results revealed that state-owned companies offer more training programs than firms of other ownership do, and the training they offer is focused on developing professional skills needed to increase productivity. Technical training is seen as a standard practice, while training in behavioral skills such as team work or interpersonal communication remains at low or moderate levels. Also, a modest amount of training aimed at increasing employees' understanding of the company's business and values is offered. Generally, all of the above tools are believed to be effective in terms of helping one to accomplish business objectives. Another Chinese study based on a sample of 156 companies with foreign participation revealed that training played an important role in accomplishing the following six objectives [Tang et al., 1996]:

1) advancing managers' administrative competencies;

2) increasing productivity;

3) extending the range of employees' skills;

4) increasing employees' readiness for technological innovations;

5) increasing adaptability to changing production processes;

6) strengthening employees' morale.

The authors of the study also noted that high labor turnover at foreign-owned companies hindered investments in staff training. Other studies made similar conclusions [Tsang, 1994; Ding, Akhtar, 2001]. An analysis of staff training's impact upon Chinese production companies' performance [ $\mathrm{Ng}$, Siu, 2004] shows that non-state companies see this tool as more important than state-owned firms do. Staff training 
is conducted to improve work relationships, deal with skill shortcomings, and develop necessary professional competences. State-owned companies give priority to technical skills, while non-state firms seem to be more interested in improving employees' relations and developing their communication skills. Expectations and actual results of training do not significantly vary between companies of different ownership status, while its perceived efficiency is equally high. Expenditures on staff training are directly connected to companies' performance. On the whole, the existing staff training programs in the Chinese corporate sector tend to be hybrid, combining national personnel management traditions with Western approaches.

Strikingly different assessments of approaches to staff training, and of relevant techniques applied by Chinese companies, lead us to the main research question of this study: what are the specific features of staff training by innovative Chinese companies, in terms of its organization and content?

\section{Methodology}

A qualitative, or descriptive, analysis of staff training and development practices applied by innovative Chinese companies (which are very different in terms of the numerous contextual and organizational characteristics) is not solely limited to revealing relevant causal relationships; it also implies studying the behavior of specific individual players. A variety of qualitative analyses, namely cluster analysis, was chosen for the purposes of this study. Data collected in the scope of the survey conducted by the Graduate School of Management of the St. Petersburg State University and the University of Illinois in 2011-2013 served as the empirical basis of the study. To assess the human capital development practices (including staff training), employees' efficiency, compensation, and career paths, members of the latter university applied special in-house tools [Bartlett et al., 2002], which subsequently have been used in other international surveys including in Russia [Ardichvili, Dirani, 2005]. The toolset comprises a series of structured interviews based on John Lawler's questionnaire [Lawler et al., 1995]; the answers are given using a seven-point Likert scale where scores 1 to 5 indicate the degree of the respondents' agreement with suggested statements $(1=$ totally disagree, $5=$ completely agree $) ; 6=$ not applicable to the company, and 7 = cannot say. Several questions were aimed at collecting data about the company (number of employees) and the respondent (position). The sample comprised 60 innovative Chinese firms selected using the methodology described in the Oslo Manual [OECD, Eurostat, 2005] which offers guidance for collecting and interpreting innovation data. Due to the difficulties with identifying such activities in China, the "snowball" technique was used to collect relevant data.

Cluster analysis is well suited for building classifications, i.e. dividing the initial array of observed objects into clusters. Their characteristics allow one to assess groups' similarities and differences, including individual comparisons. Classifying observations in the sample implies distributing the objects into groups in such a way that the similarities within each group are stronger than those between objects in different clusters. In other words, cluster (hierarchical) analysis is a statistical technique for organizing objects into relatively homogenous groups (or clusters) on the basis of their individual comparison using certain criteria set in advance. In our case, seven staff training and development practices applied by innovative Chinese companies served as such criteria. The survey was conducted among two types of respondents: managers and professionals; their reactions to the following statements were used as variables:

1. "Our company spends significant amounts of money on staff training and development" (training expenditures);

2. "We see training expenditures more like long-term investments rather than production costs" (training as investment)

3. "Training is primarily directed at providing workers with more and broader knowledge, as opposed to training them for their current jobs" (broad approach to training)

4. "Our company pays considerable attention to training to help employees acquire various skills, so they would be able to stand in for each other if need be" (cross-functional training)

5. "Our company's employees frequently work in autonomous groups" (team work)

6. "New employees undergo serious training aimed at learning company values and traditions" (adaptation programs)

7. “Our training is aimed at improving employees' interpersonal communication skills" (communication training).

Innovative activity indicators applied in our study included the following variables: share of innovations in total volume of shipped products; share of innovations in total exports; number of patents received in two previous years; number of patent applications submitted during the same period. The share of innovative products was measured using a five-point Likert scale, the patents and patent applications indicators - using a binary scale.

The cluster analysis of innovative Chinese companies allowed us to group them on the basis of similarity of their staff training and development practices. Comparing the mean values helped us identify certain 


\section{Table 3. Size of Chinese Companies Included in the Sample (Number of Employees)}

\begin{tabular}{|c|c|c|}
\hline Number of employees & Number of observations & Share in the sample (\%) \\
\hline $100-249$ & 14 & 23.3 \\
\hline $250-499$ & 5 & 8.3 \\
\hline $500-749$ & 22 & 36.7 \\
\hline $750-1500$ & 19 & 31.7 \\
\hline Bcero & 60 & 100.0 \\
\hline Source: composed by the authors.
\end{tabular}

patterns in the groups regarding the share of innovations in the total output and exports, the number of patents and patent applications, which can be interpreted as business behavior patterns.

The survey's respondents were top managers and members of HR departments of medium (100-500 employees) and large (>500 employees) companies. The distribution of companies in the sample by number of employees is presented in Table 3.

\section{Discussion of Results}

The results of the analysis include the mean values for staff training and development practices applied by companies in each of the four constructed clusters (Table 4). Since the variables were measured using a five-point Likert scale, a mean value above three allows one to describe a staff training practice as actively used, and a value below three - as rarely applied.

The mean values of companies' innovation activity indicators for each of the four clusters are presented in Table 5 .

The cluster analysis of innovative Chinese companies' staff training and development practices allowed us to break the companies down into the following four groups:

1) Staff training leaders (the largest group, comprises 52 companies): lower innovative activity indicators but high staff training and development figures;

2) Innovators (comprises two firms): the highest innovative activity indicators, and moderate staff training and development expenditures;

3) Laggers (comprises five companies): low staff training and development and innovative activity indicators alike;

4) Stars (a single firm): top staff training and development indicators, with no data available about the level of innovative activity.

The largest cluster ( 52 firms) has average innovative activity values, both in terms of products and patents. These companies invest serious money in staff training and development (the mean indicator value is 3.81) and see it as a long-term investment aimed at expanding the range of employees' competences, cross-functional training, adaptation, and development of communication and team work skills. Companies in this group can be seen as staff training and development leaders of Chinese businesses. Their predominance in our sample allows us to profile a typical national innovative firm as follows: an average level of innovative activity against the background of large-scale staff training and development programs.

Table 4. Staff Training and Development by Innovative Chinese Companies (mean values of assessments made using a five-point Likert scale)

\begin{tabular}{|l|c|c|c|c|}
\hline \multirow{2}{*}{ Parameters } & \multicolumn{3}{c|}{ Company clusters } \\
\cline { 2 - 5 } & Innovators & Staff training leaders & Laggers & Stars \\
\hline Number of observations & 2 & 52 & 5 & 1 \\
\hline Training expenditures & 2.75 & 3.81 & 2.20 & 5.00 \\
\hline Training as an investment & 1.00 & 1.88 & 3.10 & 5.00 \\
\hline Broad approach to training & 2.50 & 3.26 & 2.90 & 5.00 \\
\hline Cross-functional training & 4.25 & 3.98 & 2.00 & - \\
\hline Team work & 4.00 & 3.14 & 3.40 & 5.00 \\
\hline Adaptation programs & 2.25 & 4.10 & 3.70 & 5.00 \\
\hline Communication training & 4.00 & 3.07 & \multicolumn{5}{|}{} \\
\hline Source: composed by the authors. & & & & \\
\hline
\end{tabular}


Table 5. Innovative Activities of Chinese Companies (mean values of assessments made using a five-point Likert scale)

\begin{tabular}{|c|c|c|c|c|}
\hline \multirow{2}{*}{ Parameters } & \multicolumn{4}{|c|}{ Company clusters } \\
\hline & Innovators & Staff training leaders & Laggers & Stars \\
\hline Number of observations & 2 & 52 & 5 & 1 \\
\hline Share of innovative products & 3.50 & 2.87 & 2.00 & - \\
\hline Share of innovative products in exports & 3.00 & 1.89 & 1.00 & - \\
\hline Number of patents & 2.00 & 1.85 & 1.33 & - \\
\hline Number of patent applications & 2.00 & 1.82 & 1.00 & - \\
\hline Average value for innovative products & 3.25 & 2.41 & 1.67 & - \\
\hline Average value for patents and patent applications & 2.00 & 1.83 & 1.17 & - \\
\hline
\end{tabular}

The second group is represented by just two examples of very high innovative activity, in terms of the share of innovative products (the mean value of 3.25) and patents (2.00) alike. The companies in this group are not inclined to spend a lot on staff training and development (the average value is 2.75) since they do not see the long-term potential of such programs. The training programs they do implement are designed to enable workers to do their jobs better; no personnel adaptation courses are offered, but there is cross-functional training and the development of communication and team work skills. In other words, Chinese innovators pay the least attention to staff training and development among all domestic companies, and the programs they do offer mostly provide cross-functional and team work training.

The third group (comprises 5 companies) displays the lowest innovative activity values and staff training and development expenditures (the average value is 2.20), but these firms do see such costs as long-term investments. Companies in this group are interested in expanding employees' knowledge and giving them cross-functional training; they offer adaptation and communication skills programs, but do not set up autonomous teams. These are the least innovative companies, but they make the biggest effort to develop their human capital - and tend to have problems with funding relevant programs.

The fourth group is limited to a single example displaying the highest staff training and development expenditures (the value is 5.00). Indicators for all training programs are seen as long-term investments at the top level, while training areas include expanding knowledge, cross-functional training, adaptation, and the development of communication skills. No data is available about the firm's innovative activities, so in effect the latter amount to just training programs.

\section{Conclusion}

To identify the specific features of staff training and development arrangements of innovative Chinese companies, keeping in mind the significant disparities in assessments of the approaches they apply, we conducted cluster analysis of 60 national companies. The relevant data was used to analyze links between staff training practices and the level of innovative activities. Most of the firms in the sample (52) funded various forms of staff training while displaying average innovative activity regardless of how it was measured (as a share of innovative products or the number of patents). The two companies in the sample with the highest performance indicators offered only a limited range of staff training programs and invested in this area moderately. Companies which had no resources to fund staff training programs despite being willing to do so displayed the lowest innovative activity indicators. Unfortunately, the firm that adopted the most solid approach to staff training and development did not provide data about its innovative activities, but what data we had was sufficient to suggest that investments in human capital development have a significant impact on the results of companies' innovative activities.

Summarizing the obtained results allows us to draw several important conclusions. The first concerns the development of staff training practices and approaches to making relevant arrangements. As was noted in [Soltitskaya, Bo, 2005], human resources management in the Chinese corporate sector is in its infancy - at the transition stage from the administrative approach. The same applies to the staff training and development system. Over the last 12 years, Chinese firms, including innovative ones, made significant progress both in terms of funding staff training programs and applying specific practices. The empirical study showed that "staff training leaders" invested significant resources in various forms of staff training and development, including cross-functional training, broad general training, team work, adaptation, and company values programs. All this helps the companies in this group achieve average innovative activity indicators for the sample.

The results of the study also reveal that existing staff training programs tend to take hybrid forms combining Chinese personnel management traditions with relevant Western approaches. Innovative domestic companies have largely overcome the legacy of guanxi tied to the Confucian values, which 
gives priority to personal responsibility. In the scope of that archaic culture, workers are not expected to know what their colleagues do, and the scope for standing in for each other is extremely limited. Crossfunctional training practices borrowed from the Western human resources management experience are widely employed by innovative companies in countries with developed and emerging markets.

The transformation of innovative Chinese companies' approaches to staff training and retraining is taking place in the framework of the "Education" subsystem of the national innovation ecosystem. The state's close attention to relevant programs, their prioritization, and implementation ultimately are embodied in the approaches and training techniques innovative firms apply to their human resources and in the results of their activities. Further studies of staff training and development practices that promote the innovative activity of Chinese businesses should focus on analysing the experience of specific firms. This could help innovative players in other emerging markets build more efficient staff training systems.

The paper was supported with the grant "Human resources development and training as a factor affecting competitiveness of companies operating in emerging markets" (16.23.1842.2015) provided by the Graduate School of Management of the St. Petersburg State University.

\section{References}

Ardichvili A., Dirani K. (2005) Human Capital Practices of Russian Enterprises. Human Resource Development International, vol. 8, no 4, pp. 403-418.

Bartlett K. R., Lawler J. J., Bae J., Chen S., Wan D. (2002) Differences in International Human Resource Development Among Indigenous Firms and Multinational Affiliates in East and Southeast Asia. Human Resource Development Quarterly, vol. 13, no 4, pp. 383-405.

Chang M. (1996) The Thought of Deng Xiaoping. Communist and Post-Communist Studies, vol. 29, no 4, pp. 377-394.

Child J. (1996) Management issues in China, New York: Routledge.

Child J., David K.T. (2001) China's transition and its implications for international business. Journal of International Business Studies, vol. 32, no 1, pp. 5-21.

Chinese Academy of Sciences (2014) China’s Strategic Options for S\&T Development Toward 2020. Bulletin of the Chinese Academy of Sciences, vol. 28, no 1, pp. 107-113.

Chistyakova N.O. (2007) Regional'naya innovatsionnaya sistema: sushchnost', struktura, spetsifika [Regional innovation system: Essence, structure, specificity]. Innovatsii [Innovation], no 4, pp. 56-59 (in Russian).

Ding D., Fields D., Akhtar S. (1997) An empirical study of human resource management policies and practices in foreign-invested enterprises in China: The case of Shenzen Special Economic Zone. International Journal of Human Resource Management, vol. 8, no 5, pp. 595-613.

Ding D.Z., Akhtar S. (2001) The organizational choice of human resource management practices: A study of Chinese enterprises in three cities in the PRC. International Journal of Human Resource Management, vol. 12, no 6, pp. 946-964.

Eriksson T., Qin Z., Wang W. (2014) Firm-level Innovation Activity, Employee Turnover and HRM Practices Evidence from Chinese Firms (Economics Working Papers 2014-09), Aarhus: Aarhus University. Available at: http://econ.au.dk/fileadmin/site_files/filer_oekonomi/Working_Papers/Economics/2014/wp14_09.pdf, accessed on 01.11.2017.

European Commission (2015) Evolution of China's Innovation Performance: 2000-2013. Brussels: European Commission, Available at: https://ec.europa.eu/research/innovation-union/pdf/evolution_of_china_innovation_ performance.pdf, accessed on 01.11.2017.

Haour G., von Zedwitz M. (2016) Created in China: How China is becoming a global innovator, London: Bloomsbury Publishing.

Hofstede G. (1991) Cultures and organizations. Intercultural cooperation and its importance for survival. Software of the mind, London: McGraw-Hill.

Lawler J.J., Jain H., Ratnam C., Atmiyanandana V. (1995) Employment practices in developing countries: A comparison of India and Thailand. International Journal of Human Resource Management, vol. 6, no 2, pp. 319-346.

Leonov S.N., Domnich E.L. (2010) Gosudarstvennaya innovatsionnaya politika poreformennogo Kitaya: soderzhanie, periodizatsiya, masshtaby [State innovation policy of post-reform China: Content, periodization, scale]. Vestnik TOGU [Bulletin of the Pacific National University], vol. 2, no 17, pp. 168-176 (in Russian).

Li Y. (2010) Imitation to Innovation in China. The Role of Patents in Biotechnology and Pharmaceutical Industries, Cheltenham: Edward Elgar.

Lu Y., Bjorkman I. (1997) HRM practices in China-Western joint ventures: MNC standardization versus localization. International Journal of Human Resource Management, vol. 8, no 5, pp. 614-628.

Lu Y., Björkman I. (1998) Human resource management in international joint ventures in China. Journal of General Management, no 23, pp. 63-79.

Marchenko V. (2013) Kak upravlyayut personalom v Kitae: osobennosti kitaiskogo mentaliteta [How the personnel in China are managed: The characteristics of the Chinese mentality]. General'nyi director [General Director]. Available at: http://www.gd.ru/articles/2819-red-kak-upravlyayut-personalom-v-kitae-osobennosti-kitayskogomentaliteta, accessed on 01.11.2017 (in Russian). 
Ng Y.C., Siu N.Y. (2004) Training and Enterprise Performance in Transition: Evidence from China. The International Journal of Human Resource Management, vol. 15, no 4-5, pp. 878-894.

Nyrova N.N. (2009) Podvodnye kamni upravleniya personalom v Kitae [Underwater Stones of Personnel Management in China]. Rossiiskii vneshneekonomicheskii vestnik [Russian Foreign Economic Journal], no 4, pp. 62-67 (in Russian).

OECD, Eurostat (2005) Oslo Manual. Guidelines for Collecting and Interpreting Innovation Data (3 ${ }^{\text {rd }}$ ed.), Paris: OECD, Eurostat.

Simon D., Cao C. (2009) Creating an Innovative Talent Pool. China Business Review. Available at: http://www. chinabusinessreview.com/creating-an-innovative-talent-pool/, accessed on 01.11.2017.

Soltitskaya T.A., Bo Z. (2005) Osobennosti sistemy upravleniya personalom v kitaiskikh kompaniyakh [The Personnel Management System in Modern China Companies]. Vestnik Sankt-Peterburgskogo universiteta. Seriya 8. Menedzhment [Vestnik of Saint Petersburg University. Management], no 2, pp. 90-104 (in Russian).

Sumelius J. (2009) Social networks and subsidiary HRM capabilities: The case of Nordic MNC subsidiaries in China. Personnel Review, vol. 38, no 4, pp. 380-397.

Tang S.F.Y., Lai E.W.K., Cheng L.Z., Zhang S.Q. (1996) Human Resource Management Strategies and Practices in Foreign Invested Enterprises in the PRC, Hong Kong: Hong Kong Institute of HRM.

Tsang E.W. (1994) Human resource management problems in Sino-foreign Joint Ventures. International Journal of Manpower, vol. 15, no 9, pp. 4-21.

Verburg R.M., Drenth P.J., Koopman P.L., Muijen J.J.V., Wang Z.M. (1999) Managing Human Resources across Cultures: A Comparative Analysis of Practices in Industrial Enterprises in China and the Netherlands. International Journal of Human Resource Management, vol. 10, no 3, pp. 391-410.

Warner M. (1993) Human Resource Management "with Chinese Characteristics". International Journal of Human Resource Management, vol. 4, no 1, pp. 45-65.

Warner M. (1996) Human Resources in the People's Republic of China: The “Three Systems" Reforms. Human Resource Management Journal, vol. 6, no 2, pp. 32-43.

Warner M. (2008) Reassessing Human Resource Management "with Chinese Characteristics": An Overview: Introduction. The International Journal of Human Resource Management, vol. 19, no 5, pp. 771-801.

Xinhua (2015) Innovative, small businesses get multibillion-dollar tax cuts in China. Available at: http://www. chinadaily.com.cn/business/2015-11/20/content_22487321.htm, accessed 01.11.2017.

Xie T. (2015) China, on its way to innovation. Available at: http://english.gov.cn/policies/policy_watch/2015/05/08/ content_281475103653822.htm, accessed on 01.11.2017.

Zhao S. (1994) Human Resource Management in China. Asia Pacific Journal of Human Resources, vol. 32, no 2, pp. 3-12.

Zhu C. J. (1998) Human Resource Development in China During the Transition to a New Economic System. Asia Pacific Journal of Human Resources, vol. 35, no 3, pp. 19-44. 


\title{
The Role of IT-Management in the Digital Transformation of Russian Companies
}

\author{
Volker Nissen \\ Professor, Department of Service Information Systems, volker.nissen@tu-ilmenau.de \\ Ilmenau University of Technology, Max-Planck-Ring 14, 98693 Ilmenau, Germany
}

Tatiana Lezina

Head, Chair of Information Systems in Economics, t.lezina@spbu.ru

Andrey Saltan

Assistant, Chair of Information Systems in Economics, a.saltan@spbu.ru

St. Petersburg State University, 7/9 Universitetskaya nab., 199034 St. Petersburg, Russia

\begin{abstract}
$\mathrm{N}$ owadays many business models rely heavily upon adequate IT management practices. Quite often in developed economies, the role of IT has organically evolved over decades from a mere business support function to an efficiency driver and enabler, and finally (at least in some cases) to a driver of business innovation and digital transformation. Unlike developed countries, little is known about the role of IT in companies of countries with transitional economies, such as Russia. Historical, political, and geographical reasons have in many areas of life led to
\end{abstract}

Abstract

\section{Keywords:}

information systems management; transition economies; role of IT; digital business transformation; case study research a "Russian way of doing things". Does this also hold true for IT management? By way of case study research, this contribution investigates the features of the IT-role and use in large Russian companies that are aware of the need for digital business transformation. The obtained results allow one to not only gain a better understanding of the situation in Russian companies through the prism of IT management practices but also to identify possible trends and challenges that appear relevant for organizations in other countries in economic transition or even in developed economies as well.
Citation: Nissen V., Lezina T., Saltan A. (2018) The Role of IT-Management in the Digital Transformation of Russian Companies. Foresight and STI Governance, vol. 12, no 3, pp. 53-61. DOI: 10.17323/25002597.2018.3.53.61 
I $\mathrm{n}$ a rapidly changing business world, information technology (IT) plays an essential role in the achievement of business objectives. Historically, IT management has focused on providing regular IT services as well as being involved in business processes efficiency improvement. Later, with further IT development and consolidation, it began to play a more significant role in new product development, the creation of new business models, and the discovery of new revenue sources [Hanschke, 2010]. At the same time, companies expect IT to contribute more measurable, direct, and flexible business processes [Johannsen, Goeken, 2006]. Increasingly, this requires IT to no longer be merely an "enabler" of business processes, but also to contribute to innovation in the technical side of the business. IT can, under certain conditions, act as a "strategic weapon" in the respective company's arsenal, that is, a source of competitive advantage [Byrd, Turner, 2001].

The importance of IT as a "strategic weapon" is especially relevant in the context of the transition to a digital economy, which is currently actively discussed by the Russian scientific and business communities. The digital economy, by implementing digital transformations, implies the transition of companies to a new technological environment. Still, until now there has been a lack of consensus among researchers and practitioners about what digital transformation means and which aspects of a company's management should oversee. Accordingly, there are multiple approaches ranging from a focus on technology, to digital customer engagement, to new digital business models, and so on.

The lack of clarity often results in piecemeal initiatives, missed opportunities, and false starts in business digitalization. From the organizations' point of view, digital transformation affects all aspects related to the company's architecture including business goals, business models, business processes, etc. [Bharadwa et al., 2013; Bhattacharya, Seddon, 2009]. The prime goal of digital transformation is to gain the benefits of information technologies and information systems, such as productivity improvements, and cost reductions. Nevertheless, to obtain these results, overall organizational commitment is required. However, this advantage is only possible if organizations have good business-IT-alignment (BITA). BITA can be defined as "the degree to which the IT mission, objectives, and plans support and are supported by the business mission, objectives, and plans" [Reich, Benbasat, 1996]. To obtain this alignment a company needs to have implemented an effective IT governance, which is "an actively designed set of IT governance mechanisms" that supports an "organization's mission, strategy, values, norms, and culture" [Weill, Ross, 2004]. On the other hand, "an important driving force to achieve business value through investments in IT" is a business-IT alignment defined as the fit and integration among business and IT strategies as well as business and IT structures [de Haes, van Grembergen, 2009]. The first area covered by this study concerns the strategic benefits brought by business-IT alignment and the second concerns the fact that IT managers consider business-IT alignment a vital issue [Leonard, Seddon, 2012]. In brief, this requires intense contacts and mutual interest and understanding on all management levels between business and IT departments. With the combination of technological know-how and a profound understanding of the business side of its company, the IT department can be critical in creating new and improved products and services, business processes, or business models. This crucial strategic issue has promoted the transition of IT from a mere support function to becoming a driver for business innovation [Kießling et al., 2010], which is required for the successful business digitalization.

While in the past a CIO was rarely part of the managing board, nowadays CIOs have frequently been promoted to the executive management [Holtschke et al., 2009]. While the continuous upward development of IT in western countries can be witnessed, the question arises, what the role, tasks, and perspectives of IT are in transition economies, such as Russia. A quick answer to this question, such as "Russia lags behind in this process by about 30 years", would ignore the particularities of the Russian political and economic past, as well as the enormous size of the country. Russian people often argue that they have a unique way of development that is different from international practice but can lead to great success [Prokhorov, 2002; Zhdanov, 2014].

Moreover, the Russian economy is still in transition as opposed to developed countries like Germany or the United States. The transitive state of the economy very often leads to significant heterogeneity, both from practices and principles of governance as well as the level of technological development. Some large companies are internationally competitive; however, many companies in Russia work in niche markets without much competition for historical, political, or geographical reasons. They often do not apply international standards in business and IT-management, but still operate successfully on their markets and may to join the global trend for digital transformation. Considering this particular situation, our research aims to achieve a better understanding of the particularities with respect to the role, tasks, and perspectives of IT at Russian companies facing digital business transformation. Unfortunately, today little is known about both the role of IT at companies in countries in transition and processes of their transformation. This research aims to help to close the existing research gap and analyze to what extent IT management practices in Russia differ from the world, what the key features and challenges are, and how consistent these practices are with the goal of digital business transformation. 


\section{Related Work}

Nowadays the topic of digital business transformation is widely discussed both in academic and business communities. This transformation can be defined as a change at different levels of business organizations that incorporates both the extensive usage of digital technologies to improve existing business processes and practices and the exploration of digital innovation to transform the overall business model. The observed discussion on the priority of the technological and business aspects of digital transformation attests to the necessity of an alignment between IT and business, specifically in the integration of ITstrategy and business strategy to achieve defined goals [Bharadwa et al., 2013; Kane et al., 2015; Urbach et al., 2017]. This discussion also reviews the basic understanding of the importance of this trend, but there is still need for clarification of the respective challenges and effects [Bley et al., 2016].

From an academic point of view, the role of IT at organizations has changed over time from "IT as a support function" to "IT as a driver for business innovation" [Kießling et al., 2010]. It represent the growing importance of IT for organizations and their ability to face more strategy-oriented challenges. Accordingly, the position of the IT-manager or CIO has changed fundamentally in developed countries over the last few years. Moreover, a company's ability to change increasingly depends upon its ability to change its IT or so-called "IT agility" [Nissen, von Rennenkampf, 2015]. High IT agility can contribute to increased business agility and thus create a competitive advantage.

Within this research, the focus is on companies' current attitude concerning the role of IT as well as the alignment of IT practices with the business model and objectives. The research is overall in line with existing studies for developed countries in the literature. In the United States, a series of studies [Luftman et al., 1999; Luftman, Derksen, 2012] longitudinally explored the role and tasks of IT as well as characteristics of the CIO. Following a similar approach, the study [Nissen, Termer, 2014] investigated the status quo in Germany. The results show a certain similarity, as could be expected with both, Germany and the US as fully developed countries.

Contrary to this, the existing studies on Russian experience and practice with IT management focus mostly on narrow aspects, such as the ability to withstand and quickly recover from disruptive incidents involving unplanned downtime and potential data losses [Ivanova, Lezina, 2014]. In summary, there is not much data on how the changing role and spheres of responsibility of IT are discussed in the literature for developed countries are accepted and implemented by IT management in Russia. One of the first broader attempts to assess the role and functions of IT departments in Russian companies was undertaken in [Lezina et al., 2016]. The authors conclude that today the role of IT at many Russian companies is at best an enabler, often just an instrument to increase efficiency, and in a sizeable number of cases, it still only is a support function. In particular, there is a marked lack of viewing IT as a driver of innovation. The current contribution builds and expands upon these initial results.

\section{Research Methodology}

The conducted research addresses the use of information systems and technologies in implementing digital business transformation. Following the recommendations on examining complex and interdisciplinary phenomena linked to managerial perception, roles, and complex interaction patterns of IT management, case study research is one of the widely acknowledged qualitative research methods and seemed appropriate for the purpose of our study [Paré, 2004].

To develop a better understanding of IT-management practices at Russian companies and their role in digital business transformation, research questions were posed:

RQ1: What is the role of IT management in implementing digital business transformation and how do existing practices correspond with international ones?

RQ2: What are the major factors constraining digital business transformation practices, objectives, and strategies?

The research questions call for an exploratory research approach, considering the lack of prior investigations into these areas. Thus, a positivistic, exploratory multiple case study wasconducted. The case sampling strategy was guided by a diverse case approach. However, all companies are profitable and consider digital transformation an essential step in their immediate further development. We deliberately did not include companies directly related to the IT sector, since we were more interested in cases of companies for which IT is not a core business, but could be a valuable "strategic weapon". Companies were selected for analysis based upon differences in size, maturity level, and industry. A general overview of the selected organizations is presented in Table 1.

For the study, a series of semi-structured interviews with CIO, IT managers, and executives (at least two persons per company) from four companies were carried out. During the interviews, the following topics were addressed: general information about the company (name, industry, the number of employees, hierarchal structure, market share, etc.), vision towards digitalization (digitalization trends in their industry, strategic goals for their company, etc.), IT management practices, and their role in digital transformation (CIO role, IT department structure, IT strategy, policies). 
Table 1. Characteristics of Organizations in the Case Study

\begin{tabular}{|l|c|c|c|c|c|}
\hline Case & A & B & C & D & E \\
\hline Industry & Oil and Gas & Clothing & Bakery & Banking & Machinery \\
\hline Number of employees & $>70,000$ & $>15,000$ & $>2,500$ & $>15,000$ & $>3,000$ \\
\hline Geographical presence & Global & $\begin{array}{c}\text { Russia, China, CIS } \\
\text { countries }\end{array}$ & Russia (3 regions) & Russia & Russia \\
\hline Interview partners & $\begin{array}{c}\text { IT manager, Head } \\
\text { of Business Analysis } \\
\text { Department }\end{array}$ & $\begin{array}{c}\text { Vice CIO, Head of } \\
\text { Business Analysis } \\
\text { Department }\end{array}$ & $\begin{array}{c}\text { Senior IT manager, } \\
\text { Head of Business } \\
\text { Analysis Department }\end{array}$ & Senior IT manager & $\begin{array}{c}\text { Senior Project } \\
\text { Manager }\end{array}$ \\
\hline Source: compiled by the authors.
\end{tabular}

\section{Case Study Analysis}

Each case is analyzed on an individual basis initially based on information gathered during the interviews as is useful for exploratory case research.

\section{Case A}

This company is one of the largest Russian oil and gas companies operating in 150 countries. It is part of a holding, but it has a significant level of autonomy in its management. The parent company involves itself only at the level of strategy development and annual monitoring of its implementation.

The company management has a high level of understanding of the importance of IT. However, while digital transformation as the future of their core business is undisputed, the exact goals of such a transformation remain to be clarified. Entering the digital world is not seen as an issue of competition, but a chance to find new business opportunities, new markets, and new business models. The company has enough resources to implement this transformation, but still, the ultimate goal is not entirely clear.

In the corporate hierarchy, the IT department is subordinated to the CFO. This reflects the importance of the financial performance of IT. In general, IT operates according to a traditional decision-making scheme that requires a large number of approvals, especially when it comes to projects related to performing changes in the accounting system, automation of production, and support of business processes. However, recently the department of business analysis was allocated to a separate structural unit, and this unit has more flexibility in decision-making and project implementation. Strategically, the digital business transformation is assigned to this unit, and the unit is in charge of making propositions regarding required changes in methodology, practices, and IT-systems. Currently, the company is implementing a BI-system.

The company is the leader in its industry in successfully implementing internal projects related to digital business transformation. While transformation management does understand that data science and advanced analytics procedures should not be performed purely by IT staff, but that all business units should have access to "raw" data and be able to analyze it. Company management believes that IT should become even more decentralized, and all business units should have "mini IT" departments.

\section{Case B}

Company B specializes in the production and sale of casual clothes and sportswear as well as fitness equipment. The company's subdivisions are located in Russia, CIS countries, and China. Strategic KPIs include operational efficiency, market share, geographical presence, and profit margin. The company operates in a highly competitive environment: its main competitors are both local ventures and global enterprises with internationally known brands. The executive management of the company considers the purpose and essence of digital business transformation the only way to preserve and increase its market share in a highly competitive environment.

The IT department has a centralized structure with the CIO reporting to the CEO. Company management declares that IT has a strategic role in the company with IT managers actively involved in business analysis and development. Business profitability and performance, as well as innovative business development, are named as the principal objectives of IT. The company has a long-term IT development strategy created by the IT department in conjunction with other stakeholders and approved by the Board of Directors. However, quite often, additional IT-related projects are initiated by the company's executive management, and IT is involved only at the stage of discussing issues of implementation. The evaluation of IT performance and IT-related projects is performed in joint meetings with key internal stakeholders and based on non-formalized opinions of different business units.

The company has a portfolio of successful IT projects related to production and logistics. The company already considers itself unique regarding the level of IT use among companies in the same industry in Russia. Management believes they can replicate the success of Amazon on a smaller scale on local Russian markets. 
Following the trends in the competitive environment and facing certain challenges related to personnel qualification, the company increasingly sees the potential of IT as a cure-all and tries to increase business efficiency by minimizing the human factor in decision-making processes (for example, in stock planning). The company is more willing to invest not in the development of digital competencies of employees, but in IT. However, practice shows that this strategy has many side effects: ignoring professional expertise in making management decisions can inflict significant damage to the company in future.

\section{Case C}

Company $\mathrm{C}$ belongs to the food industry, having its offices across Russia including Moscow, St. Petersburg, and the Volga region. Management KPIs include market share, revenue, and amount of goods sold. The company operates in a highly competitive environment. The management considers brand awareness, customer focus and technological innovations as their prime competitive advantages. At present, the company considers digitally transforming parts logistics and production.

The IT department reports to the CFO and is divided into two units: a technical unit that maintains functional operation of the equipment and a software development unit. The principal role of IT in the company is to support current business processes and promote business innovations. The primary objective is to facilitate efficient production cycles, promote sales, and support other business processes. There is no IT strategy at the company. The decision-making process for the implementation and purchase of new IT solutions is most often based on the needs of the business or for a planned replacement of existing IT solutions. The core characteristic that determines the choice of particular IT solutions is their reliability. The company automated part of the production and also uses IT-functionality associated with logistics. As consumer behavior changes, the company aims to improve their IT solution, particularly in logistics to meet changing market requirements. Company $\mathrm{C}$ considers itself as an industry leader regarding IT practices.

Company C plans to implement smart contracts based on Blockchain technology. At the same time, the principal motivation for the project is reducing the price for the consumer. The company overemphasizes the technological superiority of the project and does not consider the possibility that the new technology may not be accepted by consumers, especially on the B2B market.

\section{Case D}

Company D is one of the leading Russian banks. Being a joint stock company, it is traded on Russian and foreign stock exchanges, the state is the controlling shareholder of the bank. Recently, the process of merging with several regional banks was completed and the principal difficulty was the unification of heterogeneous information systems into the group's independent banking system. Now the bank is actively involved in the process of digital transformation, following the government's policy of the digitalization of the economy.

Despite the wave of mergers and acquisitions over the past few years and the increasing share of banks with significant state ownership, the banking sector remains highly competitive, especially in the B2C segment. All critical innovations in the banking sector are associated with new technologies and overall digitalization. Fully understanding these trends, Company D's top managers state that they have a clear vision of IT and information systems both as a strategic weapons and instruments of tactical efficiency improvement. The company has enough resources to implement digital transformation but tends to overestimate the potential of advanced technologies.

Moreover, for the sake of implementing new and innovative digital projects, senior managers do not appreciate the feedback from middle managers, which can drastically reduce the effectiveness of these projects.

\section{Case E}

Company $\mathrm{E}$ is a manufacturing company that produces high-tech devices and equipment for various industries.

The IT department is separated and not involved in the process of managerial decision-making. At the same time, the IT department has a sufficient budget to purchase and develop new IT and IS solutions.

Company E has an understanding of the need and the desire to update production capacities and maybe even implement the overall digital transformation of its business, however, most initiatives in this direction cannot be implemented due to the moral backlog of the regulatory framework governing the activities of companies fulfilling government orders and operating in the military-industrial complex. The key driver for digital transformation is the opportunity to increase efficiency and accelerate business processes related to the design, development, and the launch of commercial production of new technological products.

Company E lacks explicit and formalized criteria for evaluating the activities of the IT department and the efficiency of IT projects. Most often, decisions about new projects are made as a result of the negotiation process between the company's top-managers and the IT department. The initiators of the 
Table 2. Results of Cross-Case Analysis

\begin{tabular}{|c|c|c|c|c|c|}
\hline Case & A & B & $\mathrm{C}$ & D & $\mathbf{E}$ \\
\hline Role of IT & - Business innovator & - Enabler & - Support function & $\begin{array}{l}\text { - Business } \\
\text { innovator }\end{array}$ & $\begin{array}{l}\text { - Support } \\
\text { function }\end{array}$ \\
\hline $\begin{array}{l}\text { Organizational } \\
\text { integration of } \\
\text { IT in corporate } \\
\text { structure and IT's } \\
\text { role in strategic } \\
\text { decision-making }\end{array}$ & $\begin{array}{l}\text { - Decentralized } \\
\text { - Subordinated to the CFO } \\
\text { - IT department's } \\
\text { perspective is taken into } \\
\text { account when discussing } \\
\text { ways to implement } \\
\text { strategic objectives } \\
\text { - IT can initiate projects } \\
\text { themselves; however, the } \\
\text { reconciliation process is } \\
\text { highly bureaucratized }\end{array}$ & $\begin{array}{l}\text { - Centralized } \\
\text { - Subordinated to the } \\
\text { CEO } \\
\text { - IT is actively } \\
\text { involved in business } \\
\text { development and } \\
\text { decision-making on } \\
\text { IT-related project } \\
\text { implementation }\end{array}$ & $\begin{array}{l}\text { - Centralized } \\
\text { - Subordinated to } \\
\text { the CFO } \\
\text { - Level of } \\
\text { involvement in } \\
\text { strategic decision- } \\
\text { making is low } \\
\text { - IT has sufficient } \\
\text { flexibility only in } \\
\text { implementation of } \\
\text { projects }\end{array}$ & $\begin{array}{l}\text { - Centralized } \\
\text { - IT department's } \\
\text { perspective } \\
\text { is taken into } \\
\text { account while } \\
\text { discussing ways } \\
\text { to implement } \\
\text { strategic } \\
\text { objectives }\end{array}$ & - Centralized \\
\hline $\begin{array}{l}\text { Objectives } \\
\text { of IT-related } \\
\text { projects aimed at } \\
\text { digital business } \\
\text { transformation }\end{array}$ & $\begin{array}{l}\text { - Market share retention } \\
\text { in a situation of market } \\
\text { saturation } \\
\text { - New business } \\
\text { opportunities } \\
\text { - Business process } \\
\text { improvement } \\
\text { - Quality and transparency } \\
\text { of management decisions } \\
\text { - Labor cost reduction }\end{array}$ & $\begin{array}{l}\text { - Market share retention } \\
\text { in a situation of market } \\
\text { saturation } \\
\text { - The desire to follow the } \\
\text { digital business leaders } \\
\text { - Business diversification } \\
\text { and development }\end{array}$ & $\begin{array}{l}\text { - Market share } \\
\text { retention in a } \\
\text { situation of market } \\
\text { saturation } \\
\text { - Improving financial } \\
\text { performance } \\
\text { - Operational cost } \\
\text { reduction }\end{array}$ & $\begin{array}{l}\text { - Market share } \\
\text { retention in } \\
\text { a situation of } \\
\text { market saturation } \\
\text { - The desire to } \\
\text { follow the digital } \\
\text { business leaders } \\
\text { - Following } \\
\text { political policy } \\
\text { on digital } \\
\text { business } \\
\text { transformation } \\
\end{array}$ & $\begin{array}{l}\text { - Market share } \\
\text { retention in } \\
\text { a situation } \\
\text { of market } \\
\text { saturation } \\
\text { - The desire } \\
\text { to follow } \\
\text { the digital } \\
\text { business } \\
\text { leaders }\end{array}$ \\
\hline $\begin{array}{l}\text { Key performance } \\
\text { indicators of } \\
\text { IT effectiveness } \\
\text { and associated } \\
\text { assessment of IT } \\
\text { practices }\end{array}$ & $\begin{array}{l}\text { - KPIs and assessment } \\
\text { procedures are not } \\
\text { formalized, informal } \\
\text { assessment is based on } \\
\text { financial performance }\end{array}$ & $\begin{array}{l}\text { - KPIs and assessment } \\
\text { procedures are not } \\
\text { formalized, informal } \\
\text { assessment is based on } \\
\text { financial performance }\end{array}$ & $\begin{array}{l}\text { - KPIs and } \\
\text { assessment } \\
\text { procedures are } \\
\text { not formalized, } \\
\text { informal } \\
\text { assessment usually } \\
\text { based on technical } \\
\text { indicators (number } \\
\text { of incidents, } \\
\text { number of failures, } \\
\text { etc.) }\end{array}$ & $\begin{array}{l}\text { - KPIs and } \\
\text { assessment } \\
\text { procedures are } \\
\text { formalized }\end{array}$ & $\begin{array}{l}\text { - KPIs and } \\
\text { assessment } \\
\text { procedures } \\
\text { are not } \\
\text { formalized, } \\
\text { informal } \\
\text { assessment } \\
\text { is based on } \\
\text { financial } \\
\text { performance }\end{array}$ \\
\hline $\begin{array}{l}\text { Key challenges } \\
\text { facing the } \\
\text { implementation of } \\
\text { IT-related projects } \\
\text { and the continued } \\
\text { improvement of } \\
\text { IT management } \\
\text { practices }\end{array}$ & $\begin{array}{l}\text { - Lack of qualified } \\
\text { personnel } \\
\text { - Personnel non- } \\
\text { acceptance }\end{array}$ & $\begin{array}{l}\text { - Lack of qualified } \\
\text { personnel } \\
\text { - Inefficient business } \\
\text { processes at the } \\
\text { company } \\
\text { - Large number of } \\
\text { heterogeneous, } \\
\text { often non-integrated } \\
\text { information systems }\end{array}$ & $\begin{array}{l}\text { - Lack of qualified } \\
\text { personnel } \\
\text { - High cost of IT } \\
\text { solutions } \\
\text { - Short planning } \\
\text { horizon }\end{array}$ & $\begin{array}{l}\text { - Lack of qualified } \\
\text { personnel } \\
\text { - Large number } \\
\text { of hetero- } \\
\text { geneous, often } \\
\text { non-integrated } \\
\text { information } \\
\text { systems }\end{array}$ & $\begin{array}{l}- \text { Lack of } \\
\text { regulation } \\
\text { - Lack of } \\
\text { qualified } \\
\text { personnel }\end{array}$ \\
\hline
\end{tabular}

projects are middle-level managers from various departments. In general, IT operates according to a traditional decision-making process that requires a large number of approvals.

The consolidation of the analysis of individual cases along with a cross-case analysis facilitates a deeper understanding of the cases and accentuates the differences between them. To illustrate specific characteristics of the different IT roles and management practices, Table 2 provides a comparison of these five cases.

\section{Discussion}

Our findings allowed us to answer our questions regarding role of IT in the implementation digital business transformation at Russian companies.

RQ1: What is the role of IT management in implementing digital business transformation and how do existing practices correspond with international ones?

All interviewees claimed that, at their companies, IT is considered a critical driver for the development of their companies in the age of the digital economy. However, as the example of Company C demonstrates, the reality is slightly different. It might be difficult to assess the extent to which this attitude of topmanagers and board members in developing and transition countries, including Russia, is founded upon a real understanding of the requirements and challenges of a truly digital business transformation. Alternatively, managers are perhaps just following the "fashionable" approach extensively discussed these days by the global business community. Moreover, Russia is characterized by a predisposition to follow the fashion for new technologies and practices. This often leads to the fact that companies are not critical enough about the choice of IT solutions regarding their effectiveness and appropriateness. The companies' 
top managers believe that the very fact of digitization creates a positive image and enhances the market value and importance of the company.

In the 2000s, the role of the IT department at the majority of Russian companies was limited simply to providing IT support. The owners and top managers did not see any reason to invest in IT even when without proper IT infrastructure and support, the customer base grew by $10-15 \%$ per month and with revenue and sales up by $20 \%$. The CIO / IT director was not involved in the decision-making process, and he or she was rarely a member of the board of directors. Certainly, specific IT projects were implemented, but this was done without a systematic analysis of the importance and proper economic justification.

Nowadays the situation has changed. The interviews showed that companies and organizations in Russia, especially those who have ambitious goals and the necessary resources, want to find a leap-frog solution to jump forward and overcome current problems. Nowadays, especially in Russia, digitalization and IT are considered contributors to such solutions and processes. At the same time, many companies believe that digital transformation can be implemented through the implementation of new IT without the sufficient transformation of business processes, business models, and data management practices. At these companies, despite the often large budgets for developing, purchasing, and implementing new information systems and technologies, IT remains a supporting business function rather than a driver of company development (cases $\mathrm{C}$ and $\mathrm{E}$ ). However, an alternative vision also exists, and some companies are exploring successful practices of digital transformation at domestic and foreign companies and follow the recommendations of leading analytical agencies and consulting companies (cases A and D). As a rule, these are the companies that do not have any restrictions in financing their projects and they are companies that have experience with international cooperation.

In Russia, the process of integrating the function of IT and business is lengthy. As a result, managers do not have a deep understanding of digital transformation, they only perceive it from a technological point of view and set tasks for IT managers without giving them the opportunity to influence the management processes in general.

RQ2: What are the major factors constraining digital business transformation practices, objectives, and strategies?

The first essential factor that can be considered a potential risk is the lack of rationality in conducting a cost-benefit analysis and assessment of various IT-related projects. Top-down pressure provokes an overestimation of results and an underestimation of costs. Companies in Russia, like many other transition economies, have a short planning horizon. They are not much concerned about the long-term consequences of current projects, especially if they promise significant short-term achievements. During the interviews, we figured out that none of the companies do, in fact, have metrics for assessing the effectiveness and efficiency of IT as well as any formalized assessment procedures. As a result, given the necessary resources, IT-related projects and changes in practices are quickly initiated and terminated in more or less an ad-hoc manner when new, more "advanced" technologies, practices or approaches seem to appear.

Even though all companies for research were selected from among those who position themselves as active participants in the process of digital transformation, even among them, there is a severe gap in the financial opportunities for implementing projects. There are leading companies, often with a large state participation, which has unlimited development budgets. These companies want to overcome the backlog of Western partners and competitors due to large-scale digital transformation. This approach, often called the "Russian way" by the companies themselves, does allow for achieving certain outcomes, but the economic feasibility may remain questionable. The rest of the companies are lagging behind, they do not fully understand the concept of digital transformation and do not have the necessary budgets. Leading companies have the opportunity to work by "trial and error", but for companies with smaller budgets and capabilities, verified practices are needed.

The third limitation of the observed status quo is a too technology-minded attitude concerning ITrelated projects and changes. Most of the companies participating in our case study wish to follow the international leaders from Europe and North America. Consequently, they try to apply the best available technologies supplemented with successful business practices. However, quite often the business units, production facilities, and organizational processes have a poor performance record and are not ready for the expected technological breakthrough. Moreover, all respondents mentioned a lack of specialists with the necessary qualifications. Business informatics education in Russia significantly lags behind Germany and until now, the universities are unable to meet the market demand for qualified IT specialists. This situation occurs partly because business informatics programs intended to address this shortage were first launched only in 2003 [Ivanova et al., 2015].

Among the industries, the most significant achievements in the area of digital transformation are observed at companies from the service industries. In many respects, this can be explained by the smaller scale of production processes, greater customer orientation, and fewer necessary investments.

Finally, the top-down approach often results in IT-implementations or transformation practices where there is almost no focus on usability and user's acceptance. However, when the relevant stakeholders 
do not accept business processes, they will tend to circumvent them or not even trigger these processes (or not use the associated IT-systems) at all [Lezina et al., 2016]. In addition to the factors mentioned above, this creates an increased risk to the success of IT-related projects. In summary, the current status of IT management practices in Russia provides companies with the opportunity to achieve a significant breakthrough in the short term; however, the sustainability of the results, in the long run, may be called into question especially in case of resource scarcity.

\section{Conclusions and Limitations}

Russia is an extremely heterogeneous country, with its historical and political particularities that are further exponentiated by the enormous size of its territory. In many respects, through the example of Russia, we see the development of management practices within companies that takes place in other countries with developing and transitioning economies. When we speak about the option of a "Russian way", it is necessary to account for the resource-rich structure of the economy and the heterogeneity of economic development regarding economic complexity and coherence. In particular, the idea of a Russian way of economic development and special management models is often found in the introduction of innovations, the transition to a knowledge economy, and knowledge society [Kulikov, 2016; Michailova, 2000; Ponomarev, Dezhina, 2016]. In general, the Russian way is often associated with effectiveness through inefficiency, and this research has proven that this logic is present when it comes to IT management. This IT and business management model on the basis of hierarchy and a focus on operations as well as the significant impact of the human factor can deliver noticeable results regarding digital business transformation in the short-term; however, the sustainability of the achieved results may be questionable.

This study may have certain limitations worth mentioning here. First, the responses from the five companies in the form of in-depth interviews could not be considered a significant amount of information for analysis, and this qualitative study provides perspectives on the role of IT in digital business transformation and IT-management practices. Second, the research possesses an exploratory nature and does not provide evident managerial insights. In order to enhance the validity of this case study's findings and improve the applicability and practical contributions of the study, future studies could include a broader case sample that would allow one to obtain more reliable insights. This could be supplemented with a design-based approach to support the evalucation of IT management practices to support digital business transformation.

We would like to express our gratitude to the DAAD (German Academic exchange service) for financial support in the framework of the project «Partnership with Eastern Universities».

\section{References}

Bharadwa A., Sawy O.A., Pavlou P.A., Venkatraman N. (2013) Digital business strategy: Toward a next generation of insights. MIS Quarterly, vol. 37, no 2, pp. 471-482.

Bhattacharya P.J., Seddon P.B. (2009) Role of Enterprise Systems in Business Transformations: A Management Perspective. Proceedings of the 20th Australasian Conference on Information Systems, 2-4 December 2009, Melbourne, Sydney: Australasian Association for Information Systems (AAIS), pp. 278-289.

Bley K., Leyh C., Schäffer T. (2016) Digitization of German Enterprises in the Production Sector - Do they know how 'digitized' they are?, Proceedings of the 22nd Americas Conference on Information Systems (AMCIS 2016), August 11-04, San Diego - California, USA, Atlanta, GA: Association for Information Systems (AIS), pp. 1-10.

Byrd T.A., Turner D.E. (2001) An exploratory analysis of the value of the skills of IT personnel: Their relationship to IS infrastructure and competitive advantage. Decision Sciences, vol. 32, no 1, pp. 21-47.

de Haes S., van Grembergen W. (2009) An Exploratory Study into IT Governance Implementations and its Impact on Business/IT Alignment. Information Systems Management, vol. 26, no 2, pp. 123-137.

Hanschke I. (2010) Strategic IT Management: A Toolkit for Enterprise Architecture Management, Berlin; Heidelberg: Springer-Verlag.

Holtschke B., Hauke H., Hummel T. (2009) Innovationen als Herausforderung. Quo Vadis CIO? (eds. B. Holtschke, H. Hauke, T. Hummel), Berlin; Heidelberg: Springer-Verlag, pp. 31-44.

Ivanova V., Kazakova E., Lezina T., Martyanova V., Saltan A., Siebenkäs A., Stelzer D. (2015) Comparing Bachelor Studies in Business Informatics at Universities in Russia and Germany. RUDN Journal of Informatization in Education, no 4, pp. 123-140.

Ivanova T., Lezina T. (2014) Evolutsiya biznes-informatiki kak nauki [Evolution of Business Informatics as a Science: The European, American and Russian Perspective]. Ekonomika i Upravlenie [Economics and Management], no 2 (100), pp. 44-50 (in Russian). 
Johannsen W., Goeken M. (2006) IT-Governance - neue Aufgaben des IT-Managements. HMD -Praxis Der Wirtschaftsinformatik, issue 250, pp. 7-20.

Kane G.C., Palmer D., Philips Nguyen A., Kiron D., Buckley N. (2015) Strategy, Not Technology, Drives Digital Transformation. Becoming a Digitally Mature Enterprise, Cambridge, MA: MIT Sloan Management School; Deloitte.

Kießling M., Wilke H., Kolbe L.M. (2010) Overcoming challenges for managing IT innovations in non-IT companies. Proceedings of the 16th Americas Conference on Information Systems (AMCIS 2010), August 12-15, 2010, Lima, Peru, Atlanta, GA: Association for Information Systems (AIS), pp. 1-9.

Kulikov S.B. (2016) Russian way to the knowledge-based society. Foresight, vol. 18, no 4, pp. 379-390.

Leonard J., Seddon P. (2012) A Meta-model of Alignment. Communications of the Association for Information Systems, vol. 31, no 11, pp. 231-259.

Lezina T., Nissen V., Reimer K., Saltan A. (2016) The Role and Tasks of IT in Russian Companies - A Survey of the Status Quo. Proceedings of the GSOM Emerging Markets Conference, Saint Petersburg: Saint-Petersburg University, pp. 232-234.

Luftman J., Derksen B. (2012) Key Issues for IT Executives 2012: Doing More with Less. MIS Quarterly Executive, vol. 11, no 4, pp. 207-218.

Luftman J., Papp R., Brier T. (1999) Enablers and inhibitors of business-IT alignment. Communications of the Association for Information Systems (AIS), vol. 1, article 11, pp. 1-33. Available at: https://pdfs.semanticscholar.org 19dc6/0273c9651a378d4463e038a2d33e5cf6d3b7.pdf, accessed 28.03.2018.

Michailova S. (2000) Contrasts in culture: Russian and Western perspectives on organizational change. Academy of Management Perspectives, vol. 14, no 4, pp. 99-112.

Nissen V., von Rennenkampf A. (2015) Measuring and managing IT agility as a strategic resource - examining the IT application systems landscape. Journal of Applied Informatics, vol. 10, no 6, pp. 5-30.

Nissen V., Termer F. (2014) Business - IT-Alignment: Ergebnisse einer Befragung von IT-Führungskräften in Deutschland. HMD - Praxis Der Wirtschaftsinformatik, vol. 51, no 5, pp. 549-560.

Paré G. (2004) Investigating Information Systems with Positivist Case Study Research. Communications of the Association for Information Systems (AIS), vol. 13, no 1, pp. 233-264.

Ponomarev A., Dezhina I. (2016) Approaches to the Formulation of Russia's Technological Priorities. Foresight and STI Governance, vol. 10, no 1, pp. 7-15.

Prokhorov A. (2002) Russkaya model'upravleniya [Russian Management Model], Moscow: CJSC “Zhurnal Ekspert” (in Russian).

Reich B.H., Benbasat I. (1996) Measuring the Linkage between Business and Information Technology Objectives. MIS Quarterly, vol. 20, no 1, pp. 55-81.

Urbach N., Drews P., Ross J.W. (2017) Digital Business Transformation and the Changing Role of the IT Function. MIS Quarterly Executive, vol. 16, no 2, pp. 1-4.

Weill P., Ross J.W. (2004) IT Governance: How Top Performers Manage IT Decisions Rights for Superior Results, Cambridge, MA: Harvard Business School Press.

Zhdanov D. (2014) The Russian Management Model: Between Yesterday and Tomorrow. Upravlenets, no 6 (52), pp. 40-48 (in Russian). 


\title{
The Impact of Externalities on the Innovation Activity of Russian Firms
}

\author{
Natalia Davidson \\ Associate professor, Chair of International Economics, natalya.davidson@gmail.com \\ Oleg Mariev \\ Head of the Chair of Econometrics and Statistics, o.s.mariev@urfu.ru \\ Andrey Pushkarev \\ Senior lecturer, Chair of Econometrics and Statistics, a.a.pushkarev@urfu.ru \\ Graduate School of Economics and Management, Ural Federal University, \\ 19, Mira str., Ekaterinburg 620002, Russian Federation
}

\begin{abstract}
$\mathrm{I}$

$\mathrm{n}$ this paper, we analyze the impact of externalities on firms' capacity to develop and implement innovations. We evaluate a Probit model containing both firm level factors and regional factors, such as the institutional environment, state support, and human capital. The dependent variable is a dummy variable reflecting the involvement of a firm in innovation activity. We employ data provided by BEEPS 2012-2014 for firm-level indicators and data provided by the Russian Federal State Statistics Service for region level indicators. The results confirm that at present the most important external factors affecting the

innovation activity of Russian firms are state support, both at the firm level and at the regional level, the economic situation in the region, institutions, and quality of human capital. At the same time, we found that several factors such as political stability, tax policy, and investment risks were insignificant. These results require further analysis. We also found that the impact of the factors mentioned above depends on whether a region receives state support. The results imply that a differentiated policy that considers regional characteristics will probably be more effective than a uniform policy on innovation.
\end{abstract}

Keywords: innovation activity; new products; innovation policy; regional policy; competitiveness; innovation development; external factors for innovations; institutional factors; human capital; probit model

Citation: Davidson N., Mariev O., Pushkarev A. (2018) The Impact of Externalities on the Innovation Activity of Russian Firms. Foresight and STI Governance, vol. 12, no 3, pp. 62-72. DOI: 10.17323/2500-2597.2018.3.62.72 
$\mathrm{T}$ he Russian economy remains highly dependent on mining industries, which became particularly clear after the sharp decline in energy prices in 2014. Among other things, this fact is confirmed by the country's position in global innovation and business activity rankings. The most prominent of those include the European Innovation Scoreboard (EIS), the Global Innovation Index (GII), and the Global Competitiveness Index (GCI) [Vlasova et al., 2017]. Russia is present in the last two.

The leaders in the GII 2017 ranking (it covers 127 countries) are Switzerland (67.69), Sweden (63.82), and the Netherlands (63.36); Russia with its 38.76 score holds $45^{\text {th }}$ place (three points up compared with 2015). This is due, inter alia, to the fact that R\&D expenditures in the country did not fall during the 2008-2009 crisis, and though they did decrease somewhat in 2010-2012 they grew again in 2013-2015. [Dutta et al., 2017].

The GII is based on indicators reflecting the available resources and the results achieved over the course of national innovation activities. Innovation resources include institutions, human capital, research potential, infrastructure, capacity of the domestic market, and public support provided to businesses. Innovation results include technological and economic development, and the products of creative activities [Vlasova et al., 2017]. A comparative analysis of indicators achieved by the participants in the 2013-2016 rankings reveals that Russia's relatively advanced position is due to its R\&D and innovation expenditures, the level of its human capital and knowledge creation, and the advances in certain emerging technological areas, while in terms of practical application and dissemination of knowledge the country very much lags behind [Vlasova et al., 2017].

Russia traditionally has advantages regarding certain human capital-related indicators applied in this ranking, such as tertiary education and research. Institutionally, that is, in terms of the political situation, legislation, and business environment indicators, Russia's positions in the ranking have very much improved between 2013 and 2016, though the first two of these indicators do not favourably affect innovation [Vlasova et al., 2017]. In particular, these factors may lead to businesses reducing their R\&D expenditures (Figure 1), and accordingly, reduce returns of such investments compared with potential opportunities. A detailed cost-benefit analysis of innovation-related expenditures can be found in publications on the Russian context of the GII [Gokhberg, Roud, 2012, 2016].

The structure of Russian R\&D expenditures is quite different from that of the majority of developed and developing countries. For example, according to the statistics, the largest share of $\mathrm{R} \& \mathrm{D}$ expenditures (more than 55\%) comes from public sources, and it has increased over the years. After reaching $70 \%$ in 2010 , it remained more or less unchanged since then. Meanwhile, businesses' share of the R\&D expenditures on the whole has not changed much at all, if anything, it displays a slight downward trend [HSE, 2018b]. It should be noted that during the period in question Russia pursued an active innovation policy. One of its objectives was increasing businesses' participation in funding research and innovation. In the EU and the OECD member countries, the situation is exactly the opposite: $55-65 \% \mathrm{R} \& \mathrm{D}$ expenditures are funded by companies and $25-30 \%$ by the state.

In the Global Competitiveness Index (GCI) 2015 published by the World Economic Forum for 140 countries, the top three places are held by Switzerland (5.76), Singapore (5.68), and the US (5.61). Russia is in $45^{\text {th }}$ place with a score of 4.44, up eight positions since 2014 [Schwab, 2016]. In 2016, Russia somewhat improved its position moving up from $45^{\text {th }}$ to $43^{\text {rd }}$ place and reduced the gap with the innovation leaders for 12 out of 41 relevant indicators (for five other indicators, the country's positions deteriorated). However, this did not lead to an increase in innovative activity. In the Doing Business ranking, Russia moved up from $123^{\text {rd }}$ place in 2011 to the $51^{\text {st }}$ in 2016 [Ministry of Economic Development, 2016].

The report accompanying the GCI ranking explains Russia's progress by the high level of tertiary education and infrastructure. The authors note that in addition to the sanctions and low oil prices, "inefficient government institutions, insufficient innovation potential, poorly developed financial markets,

Figure 1. Structure of Russian R\&D Expenditures in 2000-2016 (\%)
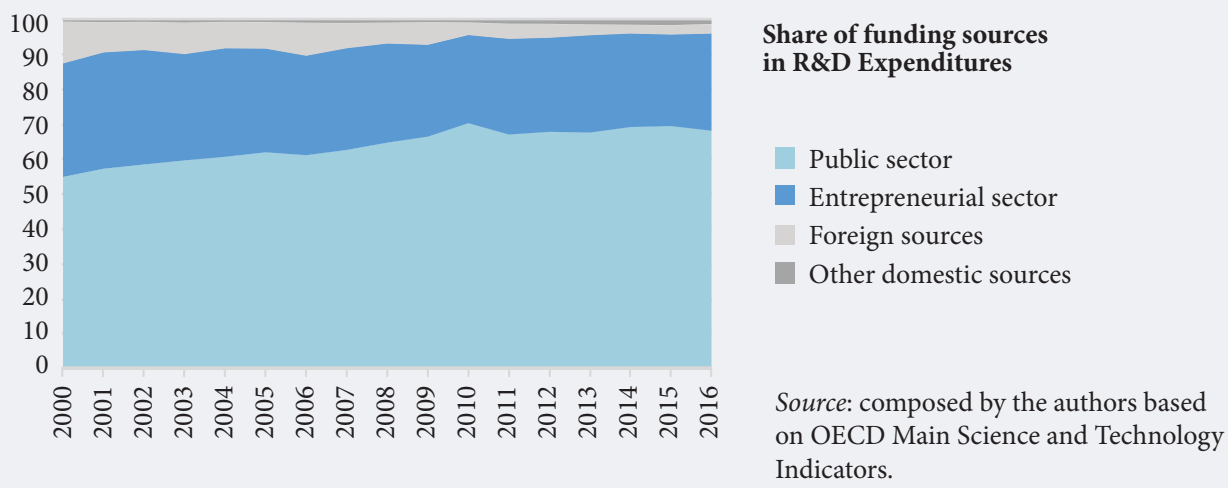
and lack of investors' trust in the financial system" also get in the way of Russia's increasing the number of its competitive advantages. According to members of the business community, barriers hindering development include "corruption, inefficient public administration, and high tax rates" which lead to the inefficient allocation of resources [Schwab, 2016].

A 2014 survey identified the following major barriers perceived by the private sector as hampering innovation: insufficient funding, inefficient tax policy, inadequate legislation and regulation practices, problems with securing public procurement orders, and insufficient qualifications of graduates. The second to last barrier, the problems with public procurement, was most frequently mentioned by small and medium entrepreneurs (58\%) and the last, poor qualification, by major players (57\%) [Ministry of Economic Development, 2016]. In a survey, company managers from 140 countries including Russia were asked how well the educational systems in their countries met the demand of the economy; in 2012 only $51 \%$ of the respondents said they were "at least moderately satisfied". In Russia, this share was even lower [Browne, Blanke, 2012].

In recent years the development of innovation infrastructure was seen as an important government policy area. However, numerous studies note insufficient demand for innovations in Russia, while existing demand is mainly met by imported technologies. Despite the modest number of domestic innovators, the country lacks special provisions and mechanisms for supporting companies with the potential to create world-class innovations [Ministry of Economic Development, 2016]. The interaction of various innovation and investment infrastructure facilities and the division of responsibilities between them also face certain problems [Nazarov, Fomin, 2015]. As a result, these facilities are frequently used less than efficiently. In terms of the share of organizations that create technological innovations in the total number of companies, in 2016 Russia was in the second to last place among European countries, with an average industry score of 7.3\%, or 1.5 percentage points lower than in 2014. The leaders in this area are Belgium (52.9\% of such organizations), Switzerland (52.7\%), and Germany (52.6\%) [HSE, 2018a].

Thus, Russian companies' innovation activities and efforts to promote them encounter certain problems that significantly limit the scope for modernizing the economy. To overcome the dependency on natural resources and alleviate the consequences of the global economic crisis, regional development priorities must be reviewed, along with improving the national innovation promotion policy [Sukhovei, Golova, 2016].

In recent years, innovation has increasingly been seen in the context of regional development and local innovation systems. This approach focuses on factors such as regions' spatial proximity, local conditions, specific characteristics of human capital, and inter-regional cooperation. Related issues also include, among others, the smart city and smart regional specialization concepts adopted in the EU and other countries [Capello, Kroll, 2016]. Identifying factors that promote companies' innovation in the regional context becomes particularly important from this perspective.

The top places in the Russian Regional Innovation Index 2015 are taken by the Tatarstan Republic, the City of Moscow, St. Petersburg, the Nizhny Novgorod Region, the Republic of Bashkortostan, and the Kaluga Region ${ }^{1}$. Russian regions display great disparity in terms of the various aspects of their innovative development and the factors affecting said development. Still, several regions have significantly improved their positions in the 2015 ranking due to better innovation policies and increased R\&D potential. Successful innovation requires coordinated action by companies, public authorities, universities, and research organizations [HSE, 2017].

Companies' innovative activities are closely connected with the long-term vision of the country's technological development. Technology Foresight studies are particularly relevant here, and the evolution of their methodologies at various stages of economic development [Gokhberg, Sokolov, 2017]. The impact of human activities on the environment, along with sustainable development objectives increase the importance of responsible research and innovation, i.e., trying to foresee and assess their possible consequences [Owen et al., 2012].

The objective of this paper is to identify factors affecting Russian companies' innovation in the scope of regional innovation systems; the results and conclusions may help increase the efficiency of local innovation activities and the interaction of their participants. Ultimately, these issues are important for the economic development of individual regions and the whole country.

The next section presents a literature review. Section 3 describes the data and an econometric assessment of the factors affecting the regional innovation activities of Russian companies. Section 4 presents the results of the study, and the final section summarizes the conclusions.

\section{Literature Review}

Innovation, as an inherent component of economic activities, has always commanded the interest of researchers specializing in various areas of social and economic sciences [Solow, 1957; Arrow, 1962; Romer, 1990; Williamson, 1965; Schumpeter, 1934; etc.]. Building on the ideas presented in the classic works by

\footnotetext{
1 The index has the following components: "Socioeconomic conditions for innovation activities", "S\&T potential", "Innovation activities", and "Quality of innovation policy" [HSE, 2016].
} 
Schumpeter, present-day researchers interpret innovation as the development of new technologies, or the adoption of existing ones [Polterovich, 2017].

Innovation is indeed linked with the production of new products and services, but it is not limited to it. For example, GII reports use a broad definition of innovation initially proposed in the Guidelines for Collecting and Interpreting Innovation Data (the Oslo Manual) [OECD, Eurostat, 2005]. According to it, innovation implies the application of new or significantly improved products (goods or services), processes, marketing, or organizational techniques in the course of business practices, to organize workplaces or establish external relations [Dutta et al., 2017]. In terms of novelty, innovations can be divided into improvements (incremental innovations) and radical innovations with no analogues in the world [Grunwald, 2011]. A sufficiently comprehensive review of more relevant empirical studies of innovation economics can be found in [Cohen, 2010].

The issue of innovation determinants has been approached, in Russian and international literature alike, from quite different perspectives, with - unsurprisingly - very different conclusions. Let us take a look at some of the studies of external and internal factors affecting companies' innovation activities.

Many researchers analyze factors affecting companies' willingness to innovate using countries with transitional economies as examples. For example, Ljiljana Bozic and Valerija Botric [Bozic, Botric, 2011] based their study on the BEEPS data for 2009; the survey's sample included 12,000 companies in 29 countries. The applied model comprised a binary dependent variable which took the value 1 if the company implemented a new product or service during the previous three years. The results revealed that the following factors were statistically significant: subsidies, pressure by customers and foreign competition, political risks, tax rates, and various country-specific effects. In particular, the authors stressed that overcoming the shortages of skilled labor could help promote innovation.

Jana Schmutzler and Edward Lorenz [Schmutzler, Lorenz, 2015] analyzed the effect of economic activities' spatial structure on businesses' openness to new knowledge and willingness to develop new products and technologies, using data from 28 regions in seven developing Latin American countries. The authors paid particular attention to the role of regional agglomeration effects combined with the tolerance level in companies' innovation activities. Empirical data was taken from the World Values Survey (WVS) for 2005-2009 and 2010-2014. A binary dependent variable was used that took the value 1 if the company developed new or improved existing products; otherwise the variable took the value 0 . The results of the study (based on the multiple probit regression method) revealed that investing in R\&D and staff training increases the probability of companies' developing new products. Also, the authors discovered a positive correlation between the tolerance level at large agglomerations and for innovative activity; companies operating predominantly in local and national markets in highly tolerant regions tended to innovate more efficiently.

Martin Srholec [Srholec, 2011] noted that innovative companies in "catch-up development" countries were primarily interested in such characteristics of the institutional environment as the business climate and stable "rules of the game" on the market. Institutional indicators applied in the logit model included, among others, the amount of time required to register a new company and settle commercial disputes, the stability of the employment index (which reflects the changes in hiring and firing rules), the level of democracy, and the highest taxation rate. The importance of most of these factors implies the need to take them into account when measuring innovative activity in Russian regions.

Martin Junge and colleagues [Junge et al., 2012] analyzed the relationship between the level of workers' education and companies' activity in the areas of product, process, organizational, and marketing innovations using an extended Cobb-Douglas function and a probit model. The Community Innovation Surveys for 2004, 2007 and 2008 were used as data sources. The authors note that an engineering education positively affects all kinds of innovation, while social sciences and humanities are particularly important for creating organizational and marketing ones. The study also established that companies creating innovations of both latter types tend to be more productive than those who are only active in one of these areas. The same applies to companies engaged in the creation of process and organizational innovations.

As to the role human capital and universities play in Russian companies' innovation, firms that cooperate with universities in order to find suitable personnel point out the low level of students' training, but on the whole were satisfied with the results of their joint research and expressed interest in using consulting services and implementing joint projects with third parties. The government is expected to apply various financial tools to promote companies' cooperation with $\mathrm{R} \& \mathrm{D}$ and educational organizations [Dezhina et al., 2017]. Universities are seen as drivers of economic growth in the scope of the "University 3.0" concept, bringing together education, research, and the commercialization of knowledge [Karpov, 2017]. In our turn, in this paper we included human capital in the number of factors important for innovation.

Foreign direct investments (FDI) remain an important innovation development factor. FDI inflow is believed to promote overall economic growth, and innovation in particular, due to the spillover effects (extensively researched and described in detail in the literature), and increased competition on the market. Such mechanisms are analyzed, for example, in [Coe, Helpman, 1995; Peri, Urban, 2006].

However, more recent studies point out that the impact of FDI on domestic businesses may not be so straightforward. For example, Francisco García and co-authors [García et al., 2013] analyzed, using 
Spanish firms as an example, the mutual dynamics of FDI and innovation activities in terms of increased competition, reduced costs for all market players, and technology transfer. The authors noted that increased competition may negatively affect innovation, while the risks associated with FDI are due to the fact that the national economy becomes dependent on decisions made by foreign partners. A large FDI inflow leads to local firms being pushed into less profitable niches, which suppresses their innovative activities. The dual impact of FDI on innovation was also noted by other researchers [Fan, $\mathrm{Hu}, 2007$; Girma et al., 2009; Wang, Kafouros, 2009]. In this paper we have analyzed this factor along with other regional determinants affecting companies' innovative activities.

Factors influencing companies' innovative development in specific Russian regions were studied in [Yermasova, 2014]; the author used relevant Rospatent data and investment potential and risk indices calculated by Expert Rating Agency for 83 Russian regions for 2008-2012. Dependent variables used in the empirical analysis included the number of patent applications and their registration statistics broken down by region. The study revealed a significant positive correlation between the increased innovation activity of companies in the sample on the one hand, and the volume of foreign direct investments, population density, economic risks, and capital investments on the other. Another study [Ivanova, 2010] established a $1 \%$ level of significance for key factors affecting regional innovation systems: the number of doctorate holders, R\&D personnel, and expenditures on technological innovation.

A common feature in most of the above studies is the use of corporate indicators such as productivity, revenues, R\&D expenditures, number of personnel, etc. Although there is no doubt that they do affect companies' innovative activities, the role of the company size definitely does not seem obvious. The larger the company is, the more opportunities it has to cut the costs through economies of scale, and the more resources it has available for long-term investments, among other things in the development of new technologies and products. That is, ultimately, it has higher chances of being engaged in innovation. This conclusion is supported by the empirical data published in [Berger, 2010; Grespi, Zuniga, 2012; Roper et al., 2008]. On the other hand, there are studies suggesting that small businesses can even surpass large companies in this area [Merivate, Pernias, 2006] given that they do not have comparable advantages, they frequently tend to be more perceptive to changes on the market. However, there are alternative opinions too, according to which the effect of firms' size on their innovation is not statistically significant [Klette, Kortum, 2002]. The correlation between the level of innovation and some other factors also seems to be quite complex [Mariev, Savin, 2010].

In recent years rapidly growing medium-sized innovative companies have become one of the main targets of the government industrial policy. In June 2016, the Russian Ministry of Economic Development launched a project aimed at supporting the leading private high-technology firms - the so-called gazelles, selected on the basis of the national TechSuccess ranking [Medovnikov et al., 2016]. A study of the ranking results for 2012-2016 revealed that the participating companies displayed a high level of uncertainty [Yusupova, Khalimova, 2017]. Particular attention was paid to the development of the national innovation system, including the reasons for its insufficient productivity in the creation, dissemination, and practical application of knowledge; the motivation of economic agents; technological externalities; and innovation-related risks [Golichenko, 2017]. The impact of national development institutes' activities on the innovative behavior of the market players was analyzed, including favorable changes in the firms' behavior following the implementation of relevant support initiatives [Simachev, Kuzyk, 2017].

Thus, we can identify the main groups of regressor indicators applied in econometric studies of innovation activity, at the national and regional levels:

1) Macroeconomic business activity indicators such as revenue, size, form of ownership, participation in import and export activities, and other cost and productivity indicators including R\&D expenditures and R\&D personnel;

2) Institutional indicators describing markets where the company operates: investment appeal, risks, taxation, entry barriers, national bureaucratic specifics, etc.;

3) Human capital indicators: labor quality, number of university graduates, companies' staff training and upgrading costs, etc.;

4) Government support indicators, typically expressed as the amount of subsidies, grants, or benefits, and accessibility of public procurement orders;

5) Other indicators including regional economic characteristics such as GRP, openness, etc.

Typically, researchers try to take into account all of the above factor groups; accordingly, we decided to include in the model presented in the next section at least one indicator from each group. This approach will allow us to assess the importance of the various indicator groups in the framework of a single model and avoid possible problems caused by the lack of potentially important variables.

\section{Input Data and Methodology}

Our study focuses on the factors promoting companies' innovation. The Business Environment and Enterprise Performance Survey (BEEPS) of Russian companies conducted in 2012-2014 was used as the source of basic input data. The survey covered 4,377 organizations in 37 Russian regions; 4,167 of 
them were private companies fully under Russian jurisdiction, 146 firms were partially owned by foreign capital, and 64 companies were publicly owned. No additional limitations were applied to the BEEPS sample. The distribution of the companies by sector, size, and location is presented in Table 1.

The information in Table 1 on the whole matches the Rosstat data. For example, according to Rosstat, wholesale and retail organizations in 2013 amounted to about $38.7 \%$ of all enterprises without account of the agriculture and mining industries ( $42.21 \%$ in the sample), and construction firms - to about $9.3 \%$ ( $10.52 \%$ in the sample). The sectoral distribution is also close to the official statistics. Therefore, we can say that in terms of industry distribution, the data is representative.

As to company sizes, the sample is biased towards medium enterprises while according to the Rosstat, small businesses make up the largest cohort. The bias is due to a number of reasons. First of all, this is due to mismatched definitions and therefore different classifications of small and medium enterprises. It cannot be ruled out that medium and large players were more willing to take part in the surveys. Correcting such a deviation from the official statistics does not seem possible; still, it seems unlikely that it will have significantly affected the results of the study, because small companies' contribution to overall business activities' results at the regional and national levels is not that substantial. Also, due to specific organizational structures, financial potential, and the very nature of their activities, small companies consider implementing innovations relatively less often, and even fewer of them have the resources to carry out such projects. Therefore, the probability of the study results being significantly biased is low.

The paper is focused on external factors that affect companies' innovation; however, certain internal determinants were taken into account as well.

The hypothesis is that companies' willingness to innovate is largely determined by their external environment. Particular attention was paid to regional aspects, which were analyzed using Rosstat data on Russian regions where the surveyed companies operated.

The analysis is based upon a probit model where a dummy indicator for new product or service implementation during the previous three years was used as a dependent variable.

The model looks as follows:

Prob(innovation $)=\left\{\begin{array}{l}1, \text { if innov }=a X_{i j}>0 \\ 0, \text { if otherwise }\end{array}\right.$ where

Prob(innovation) is the probability of companies' innovating;

Table 1. Distribution of Respondent Companies

\begin{tabular}{|c|c|c|}
\hline Characteristics & Number of companies & Share of companies (\%) \\
\hline \multicolumn{3}{|c|}{ By industry } \\
\hline Food industry & 130 & 3.08 \\
\hline Paper and paper products & 11 & 0.26 \\
\hline Textile industry & 12 & 0.28 \\
\hline Clothing & 38 & 0.90 \\
\hline Electronics & 104 & 2.46 \\
\hline Chemical industry & 125 & 2.96 \\
\hline Machinery and equipment & 129 & 3.06 \\
\hline Construction & 444 & 10.52 \\
\hline Wholesale trade & 1289 & 30.55 \\
\hline Retail trade & 467 & 11.07 \\
\hline Information and communication technologies (ICT) & 157 & 3.72 \\
\hline Other & 1314 & 31.14 \\
\hline \multicolumn{3}{|c|}{ Bysize } \\
\hline Small (<20 employees) & 1475 & 34.95 \\
\hline Medium $(20-100)$ & 2315 & 54.86 \\
\hline Large $(>100)$ & 430 & 10.19 \\
\hline \multicolumn{3}{|c|}{ By location } \\
\hline Capital city & 123 & 2.91 \\
\hline $\begin{array}{l}\text { City with a population of more than } 1 \text { million (not } \\
\text { capital) }\end{array}$ & 1077 & 25.52 \\
\hline City with a population of $250,000-1$ million. & 2586 & 61.28 \\
\hline City with a population of $50,000-250,000$ & 427 & 10.12 \\
\hline City with a population of fewer than 50,000 & 130 & 3.08 \\
\hline
\end{tabular}


Table 2. Variables

\begin{tabular}{|c|c|}
\hline Variable & Explanations \\
\hline Company size & $\begin{array}{l}\text { The dummy variable takes the value } 1 \text { if the company is large } \\
\text { (>100 employees); otherwise it takes the value } 0\end{array}$ \\
\hline Competition & Number of competitors (as assessed by managers) \\
\hline Membership in a large corporate structure & $\begin{array}{l}\text { The dummy variable takes the value } 1 \text { if the company is a part of a large } \\
\text { corporation; otherwise it takes the value } 0\end{array}$ \\
\hline Subsidies & $\begin{array}{l}\text { The dummy variable takes the value } 1 \text { if the company received subsidies } \\
\text { from any sources; otherwise it takes the value } 0\end{array}$ \\
\hline Tax rates & \multirow{5}{*}{$\begin{array}{l}\text { Basic ranking of barriers in points: not present }=0 \text {; insignificant }=1 \text {; } \\
\text { moderate }=2 ; \text { main hurdle }=3 \text {; very serious }=4 \text {. The model uses binary } \\
\text { variables }[\text { Bozic, Botric, } 2011] \text { which take the value } 1 \text { if the relevant external } \\
\text { factor constituted the main or a very serious hurdle for the company; } \\
\text { otherwise the variable takes the value } 0\end{array}$} \\
\hline Political instability & \\
\hline Corruption & \\
\hline Insufficient education level of workforce & \\
\hline Problems with access to funding & \\
\hline \multicolumn{2}{|r|}{ Regional indicators } \\
\hline Output of innovative products & \multirow[t]{2}{*}{ Logarithmic expression (2012 data) } \\
\hline FDI & \\
\hline $\begin{array}{l}\text { Share of state and municipal university graduates in the } \\
\text { total population of the region }\end{array}$ & 2012 data, $\%$ \\
\hline Investment risk associated with regions & Weight-average risk index (2012 data) \\
\hline Regions' openness & Share of foreign trade turnover in the GRP (2012 data, \%) \\
\hline Donor region (recipient) & $\begin{array}{l}\text { The dummy variable takes the value } 1 \text { if the region received grants from the } \\
\text { state; otherwise it takes the value } 0^{\star}\end{array}$ \\
\hline \multicolumn{2}{|c|}{$\begin{array}{l}\text { * Federal law “On Federal Budget for } 2014 \text { and Planning period of } 2015 \text { and 2016” № 349-FZ of 02.12.2013 (valid version of 2016) Access mode: http:// } \\
\text { www.consultant.ru/document/cons_doc_LAW_155198/, last accessed on: 25.08.2017. }\end{array}$} \\
\hline \multicolumn{2}{|c|}{ Source: calculated by the authors based on Rosstat (gks.ru) and BEEPS data [EBRD, n.d.]. } \\
\hline
\end{tabular}

$X_{i j}$ is the vector of independent variables of company $i$ and region $j$. The list of independent variables with explanations is presented in Table 2.

Table 2 shows that explanatory variables include specific characteristics of companies. We have also used indicators describing barriers hindering companies' operations, the quality of human capital, government support, and the business climate in the whole country and in specific regions. In the BEEPS framework, these factors are measured on the basis of the surveyed companies' managers' assessments, which provide an idea of their personal perception of the external environment for innovation.

Descriptive statistics of the model's variables are presented in Table 3. Innovative activity was measured on the basis of a binary variable which took the value 1 if the answer to the question "did the company develop new products or services" was positive; otherwise the variable took the value 0 .

The standard deviation values in Table 3 indicate significant fluctuations of the indicators. The average company size suggests that most of the surveyed firms were members of the small and medium businesses group. On average each company had four competitors; $7 \%$ of the enterprises were members of larger corporate structures.

The share of Russian firms that develop and implement new products or services amounted to almost $25 \%$ of the sample. It was slightly higher than the industry average figures for Russia mentioned in the introductory section. A possible explanation is that companies assessed their involvement in innovation themselves, so they could interpret it differently hence the deviation from the official statistics. Even so, this indicator value is still lower than in developed European countries. The City of Moscow has the highest values of innovative products (13.11) and FDI (15.26) logarithms. The highest risk was noted in the Murmansk Region (0.361), the lowest - in the Krasnodar Region. Specific features of its geographic location explain the Kaliningrad Region's leadership in terms of regional openness (share of foreign trade turnover in the GRP). In terms of the share of university graduates in the total population, the leader is St. Petersburg.

At the initial stage, the econometric model was applied to assess the above factors' impact upon companies' innovation for all regions generally. Then the differences between companies operating in "donor" and "recipient" regions were identified.

\section{Results}

The probit model described above was assessed using the maximum likelihood technique (Table 4). Since Moscow is very different from other regions in terms of the economic situation and innovative activity, companies based in the city were excluded from the econometric analysis. Apart from the model's coefficients, the table also presents marginal effects showing the change of probability (in \%) of 


\section{Table 3. Descriptive Statistics of the Variables}

\begin{tabular}{|c|c|c|c|c|}
\hline Variable & Mean & $\begin{array}{l}\text { Standard } \\
\text { deviation }\end{array}$ & Highest & Lowest \\
\hline $\begin{array}{l}\text { Company size (small: }<20 \text { employees, } 1 \text { point; medium: } 20-100 \text { employees, } 2 \\
\text { points; large: }>100 \text { employees, } 3 \text { points) }\end{array}$ & 1.75 & 0.62 & 3 & 1 \\
\hline Innovations (dummy variable) & 0.25 & 0.43 & 1 & 0 \\
\hline Competition: number of competitors & 3.72 & 12.08 & 100 & 0 \\
\hline $\begin{array}{l}\text { Membership in a large corporate structure (dummy variable: takes the value } 1 \\
\text { if the company is a part of a large corporation; otherwise takes the value } 0 \text { ) }\end{array}$ & 0.07 & 0.26 & 1 & 0 \\
\hline Output of innovative products & 9.87 & 1.73 & 13.11 & 5.53 \\
\hline FDI & 11.94 & 1.43 & 15.26 & 9.01 \\
\hline $\begin{array}{l}\text { Share of state and municipal university graduates in the total population of the } \\
\text { region }\end{array}$ & 0.078 & 0.027 & 0.16 & 0.03 \\
\hline Investment risk associated with regions & 0.25 & 0.05 & 0.36 & 0.17 \\
\hline Region's openness & 1.29 & 1.06 & 5.29 & 0.27 \\
\hline
\end{tabular}

companies' engagement in innovation due to the presence or absence of the above factors. The results are provided in two formats: for all variables, and individually for significant indicators.

The results show that the larger the company is, the more inclined it is to innovate. Large enterprises typically have more opportunities to invest in $R \& D$ and better access to the necessary resources. The international scope of companies' activities and receiving subsidies also have a positive impact. Marginal effects in the two models indicate that, all other conditions being equal, the availability of subsidies increases the chances of companies' developing new products or services by $12-13 \%$. Since subsidies are provided for various purposes, companies may use some of them to finance innovation. Enterprises based in recipient regions also tend to show a higher willingness to innovate.

Another incentive for innovation is increased competition. Under such circumstances companies may obtain advantages by modifying, improving, or diversifying their products to distinguish them from what the competition offers and, thus, promote demand for them.

Positive coefficients of indicators such as low quality of education, corruption, and limited access to funding seem to reflect the personal perception of more dire problems faced by the firms. Trying to innovate, companies encounter serious barriers, for example, a mismatch between university graduates' qualifications and the requirements of their jobs, and corruption.

There is a positive correlation between companies' implementing innovations, the overall innovative activity in the region, and the amount of FDI. By sharing their experience and technologies, enterprises can strengthen their market positions.

Table 4. Probit Model Estimation Results

\begin{tabular}{|c|c|c|c|c|}
\hline \multirow{2}{*}{$\begin{array}{l}\text { Dependent variable (probability that company } \\
\text { implemented innovations - new products or services) }\end{array}$} & \multicolumn{2}{|c|}{ (1) } & \multicolumn{2}{|c|}{ (2) } \\
\hline & $\begin{array}{l}\text { Estimated } \\
\text { coefficients }\end{array}$ & $\underset{\text { effects }}{\text { Marginal }}$ & $\begin{array}{l}\text { Estimated } \\
\text { coefficients }\end{array}$ & $\begin{array}{c}\text { Marginal } \\
\text { effects }\end{array}$ \\
\hline Company size & $0.14^{* * *}(0.05)$ & $0.04^{* * *}$ & $0.15^{\star * \star}(0.05)$ & $0.04^{* * *}$ \\
\hline Problems with access to funding & $0.11^{\star *}(0.06)$ & $0.03^{\star *}$ & $0.12^{* * *}(0.06)$ & $0.04^{\star *}$ \\
\hline Tax rates & $-0.01(0.05)$ & -0.03 & - & - \\
\hline Political instability & $0.08^{*}(0.06)$ & 0.02 & - & - \\
\hline Corruption & $0.18^{\star \star \star}(0.06)$ & $0.06^{* * *}$ & $0.21^{\star * *}(0.06)$ & $0.07^{\star * *}$ \\
\hline Insufficient education of workforce & $0.18^{\star * *}(0.06)$ & $0.06^{* * *}$ & $0.20^{\star * \star}(0.06)$ & $0.06^{* * *}$ \\
\hline Membership in a large corporate structure & $0.14(0.09)$ & 0.05 & - & - \\
\hline Competition & $0.01^{\star * *}(0.002)$ & $0.002^{\star * *}$ & $0.01^{* * *}(0.002)$ & $0.002^{* *}$ \\
\hline Subsidies & $0.37^{\star * *}(0.11)$ & $0.12^{* * *}$ & $0.38^{\star * *}(0.11)$ & $0.13^{* * *}$ \\
\hline Output of innovative products & $0.06^{\star * \star}(0.02)$ & $0.03^{\star * *}$ & $0.09^{\star * \star}(0.02)$ & $0.03^{\star * *}$ \\
\hline FDI & $0.06^{\star * \star}(0.02)$ & $0.02^{* * *}$ & $0.06^{\star * *}(0.02)$ & $0.02^{* * *}$ \\
\hline $\begin{array}{l}\text { Share of state and municipal university graduates in the } \\
\text { total population of the region }\end{array}$ & $-0.03^{\star * \star}(0.01)$ & $-0.01^{\star *}$ & $-0.03^{\star * \star}(0.01)$ & $-0.01^{\star * *}$ \\
\hline Investment risk associated with regions & $-0.91(0.64)$ & -0.28 & - & - \\
\hline Region's openness & $-0.1(0.07)$ & -0.03 & - & - \\
\hline Donor (recipient) regions & $0.25^{\star \star \star}(0.10)$ & $0.07^{\star * *}$ & $0.29^{* *}(0.09)$ & $0.08^{\star * *}$ \\
\hline
\end{tabular}


Table 5. Models' Evaluation Results by Region Groups

\begin{tabular}{|c|c|c|c|c|c|c|}
\hline \multirow{2}{*}{$\begin{array}{l}\text { Dependent variable (probability that } \\
\text { company implemented innovations - new } \\
\text { products or services) }\end{array}$} & \multicolumn{2}{|c|}{ All regions } & \multicolumn{2}{|c|}{ Recipient regions } & \multicolumn{2}{|c|}{ Donor regions } \\
\hline & $\begin{array}{l}\text { Estimated } \\
\text { coefficients }\end{array}$ & $\underset{\text { effects }}{\text { Marginal }}$ & $\begin{array}{c}\text { Estimated } \\
\text { coefficients }\end{array}$ & $\begin{array}{l}\text { Marginal } \\
\text { effects }\end{array}$ & $\begin{array}{c}\text { Estimated } \\
\text { coefficients }\end{array}$ & $\begin{array}{c}\text { Marginal } \\
\text { effects }\end{array}$ \\
\hline Company size & $0.15^{\star \star \star}(0.05)$ & $0.04^{* * *}$ & $0.14^{* * *}(0.05)$ & $0.04^{* * *}$ & $0.22(0.16)$ & 0.06 \\
\hline Problems with access to funding & $0.12^{* * *}(0.06)$ & $0.04^{\star \star}$ & $0.14^{\star *}(0.06)$ & $0.04^{* *}$ & $-0.08(0.18)$ & -0.03 \\
\hline Corruption & $0.20^{\star * \star}(0.05)$ & $0.06^{* * *}$ & $0.23^{\star * *}(0.06)$ & $0.07^{* * *}$ & $-0.02(0.16)$ & -0.01 \\
\hline Insufficient education of workforce & $0.21^{* * *}(0.06)$ & $0.07^{* * *}$ & $0.14^{* *}(0.06)$ & $0.04^{* *}$ & $0.68^{* * *}(0.17)$ & $0.23^{* * *}$ \\
\hline Competition & $0.01^{* * *}(0.002)$ & $0.002^{\star \star}$ & $0.01^{\star \star \star}(0.002)$ & $0.002^{* \star *}$ & $0.01^{\star}(0.01)$ & $0.003^{*}$ \\
\hline Subsidies & $0.38^{\star \star \star}(0.11)$ & $0.13^{* \star *}$ & $0.41^{\star \star \star}(0.12)$ & $0.14^{\star \star \star}$ & $0.001(0.39)$ & 0.01 \\
\hline Output of innovative products & $0.09^{* * *}(0.02)$ & $0.03^{\star * *}$ & $0.09^{\star * *}(0.02)$ & $0.03^{* * *}$ & $2.09(19.76)$ & 0.65 \\
\hline FDI & $0.06^{* * *}(0.02)$ & $0.02^{\star * *}$ & $0.05^{\star * *}(0.02)$ & $0.02^{\star * *}$ & $1.79(9.49)$ & 0.55 \\
\hline $\begin{array}{l}\text { Share of state and municipal university } \\
\text { graduates in the total population of the region }\end{array}$ & $-0.30^{\star \star}(0.1)$ & $-0.09^{* * *}$ & $-0.38^{\star * *}(0.13)$ & $-0.11^{* * *}$ & 0 (omitted) & 0 \\
\hline
\end{tabular}

As was noted, subsidies-related indicators play an important role in the models in question, which may be evidence of this innovation policy tool's efficiency. However, public resources are limited, especially during crises. Accordingly, the specific effects of other factors under consideration, combined with regional investments and without them, must be studied. To identify the differences, the sample of companies from 37 regions was divided into two groups - "donors" and "recipients". The results of the models' evaluations are presented in Table 5.

It was established that all of the factors in the table are very important for companies' willingness to innovate generally, and in the recipient regions particularly. The variable coefficients' signs did not change compared with the models presented in Table 5. The situation in the donor regions is different: the low quality of education has the biggest effect there (the marginal effect is more than five times greater than in recipient regions). The competition factor also remained important, albeit to a smaller extent.

At the same time, no statistically significant correlation between willingness to innovate and company size was found in the donor regions. The insignificant effects of corruption, subsidies, and access to funding in this group of regions can be explained by the fact that the companies there have fewer funding and institutional problems. Also, one can suppose that the economic and institutional situation would be more favorable in more successful regions than in areas receiving grants and subsidies.

In the donor regions, the variable describing the effect of FDI on innovative activity is statistically insignificant, even though its marginal effect in this group is higher than the relevant figure for subsidized regions and the average value for all regions in the sample alike. However, for all companies, and especially for those based in recipient regions, this variable is statistically significant. Therefore, it can be argued that attracting investments would be an efficient alternative for companies operating in that kind of region.

Our results suggest that the larger the company based in a recipient region is, the higher is its inclination to innovate. It seems that such firms have found market sustainability and adapted to the existing institutional environment. Previous research shows that in terms of the number of competitive small and medium manufacturing enterprises, Russia lags behind EU countries. Also, major players tend to be more able to invest in innovation on their own, without government support. At the same time, international experience shows that young, small companies also can have significant innovation potential [Yukhanaev et al., 2015]. The above specific features of companies' innovation activities should be taken into account when implementing innovation promotion policy. The overall innovation climate in the region also plays quite an important role.

Econometric analysis shows that companies' innovative activities are hindered by corruption, inadequate financial support, and insufficient qualifications of personnel. The above issues are particularly relevant in subsidized regions, which is confirmed by the higher importance of relevant coefficients in the constructed models. Therefore, innovation policy would not be efficient without using adequate tools for fighting corruption and restructuring economic and financial institutions. The provision of subsidies and tax breaks does not relieve companies of the above problems. Keeping in mind the inadequate quality of education, particular attention should be paid to supporting universities that train highly skilled professionals specializing in priority areas, and cooperate with innovative companies. No less important would be stepping up research and extending opportunities for the cooperation of businesses, universities, and the government. Personal initiative by specific company managers, researchers, and government officials would play a crucial role here, along with the government taking steps to improve the entrepreneurial climate and promote $\mathrm{R} \& \mathrm{D}$. 


\section{Conclusion}

Companies' innovation activity is linked with their long-term vision of technological development in their regions, and in the country as a whole. Combined with an efficient regulation policy, innovation contributes to achieving sustainable economic growth.

An analysis of the factors affecting innovation by Russian companies revealed indicators that should be taken into account when shaping federal and regional innovation policies. The availability of subsidies, level of competition, company size, and regional environmental factors such as the amount of FDI and the output of innovative products are key factors affecting innovative activity. Major barriers hindering innovation include the poor quality of education, corruption, and limited access to funding. The effect of the above factors in different types of regions is not the same: in donor regions the level of competition and the quality of education have a particularly strong effect on innovation. Therefore, differentiated innovation policies which would take into account the specific features of the regions could be expected to yield the best results.

Different regulation models can be applied to promote innovation, for example, subsidizing R\&D and patenting costs. More affordable alternatives can also be considered, in particular improving government policy to attract FDI. Another effective approach would be improving the competitive environment, which is confirmed by the assessment of institutional factors.

The modeling results show that corruption significantly affects the development of innovations; therefore adopting efficient tools to fight corruption and promote a favorable business climate (which hinders corrupt practices in itself) seem to be in order. It was also established that in all kinds of regions, the successful implementation of innovation potential directly depends upon the quality of human capital in the education and research spheres.

The identified factors deserve particular attention when shaping regional policies to promote the development of innovation systems. Our conclusions largely match the results of previous studies, which may be evidence of their compatibility, correctness, and certain sustainability. The experience accumulated by leading countries in the field of shaping effective innovation policies, and their relevant institutions generally can be borrowed to improve Russia's innovation policy, taking into account the disparity of its regions.

The study was supported by the Russian Foundation for Basic Research (project №18-010-01190 "Models for analysing innovation development factors and comparative advantages in the Russian economy"). The authors are grateful to Karina Nagieva, postgraduate student at the Higher School of Economics and Management of the Ural Federal University, for her contributions to this study. The authors would also like to thank participants of the conference hosted by the HSE Centre for Market Studies and Spatial Economics (St. Petersburg, June, 2016) for their valuable comments. Sole responsibility for any possible mistakes lies with the authors.

\section{References}

Arrow K. (1962) Economic welfare and the allocation of resources for invention. The Rate and Direction of Inventive Activity (ed. R.R. Nelson), Princeton, NJ: Princeton University Press.

Berger M. (2010) The innovation-productivity link - Comparing Thailand with a sample of OECD countries. Paper presented at the Fourth Conference on Micro Evidence on Innovation in Developing Economies, Tartu, Estonia, May 27-28, 2010. Available at: https://www.merit.unu.edu/meide/papers/2010/Berger.pdf, accessed 15.04.2017.

Bozic L., Botric V. (2011) Innovation Propensity in the EU Candidate Countries. Transition Studies Review, vol. 18, pp. $405-417$.

Browne C., Blanke J. (2012) The Global Competitiveness Report 2012-2013, Geneva: The World Economic Forum.

Capello R., Kroll H. (2016) From theory to practice in smart specialization strategy: Emerging limits and possible future trajectories. European Planning Studies, vol. 24, no 8, pp. 1393-1406.

Coe D., Helpman E. (1995) International R\&D Spillovers. European Economic Review, vol. 39, no 5, pp. 859-887.

Cohen W.M. (2010) Fifty years of empirical studies of innovative activity and performance. Handbook of the Economics of Innovation (eds. B.H. Hall, N. Rosenberg), Amsterdam; Boston; Heidelberg: Elsevier, vol. 1, pp. 129-212.

Dezhina I.G., Medovnikov D.S., Rozmirovich S.D. (2017) Otsenki sprosa rossiiskogo srednego tekhnologicheskogo biznesa na sotrudnichestvo s vuzami [Evaluating the Demand of Russian Medium-Size Technological Companies in Cooperation with Higher Educational Institutes]. Journal of the New Economic Association, no 4 (36), pp. 81-105 (in Russian).

Dutta S., Lanvin B., Wunsch-Vincent S. (eds.) (2015) The Global Innovation Index 2015: Effective Innovation Policies for Development, Fontainebleau, Ithaca, Geneva: Cornell University, INSEAD, WIPO.

Dutta S., Lanvin B., Wunsch-Vincent S. (eds.) (2017) The Global Innovation Index 2017: Innovation Feeding the World, Fontainebleau, Ithaca, Geneva: Cornell University, INSEAD, WIPO.

EBRD (n.d.) Business Environment and Enterprise Performance Survey (BEEPS). Available at: http://ebrd-beeps.com/data/, accessed 02.08.2017.

Ermasova N.B. (2014) Faktory, vliyayushchie na innovatsionnuyu aktivnost' organizatsii [Factors Influencing the Innovation Activity of Organizations]. Ekonomika. Upravlenie. Pravo, no 3, pp. 495-503.

Fan S.C., Hu Y. (2007) Foreign direct investment and indigenous technological efforts: Evidence from China. Economics Letters, no 96, pp. 253-258.

García F., Jin B., Salomon R. (2013) Does inward foreign direct investment improve the innovative performance of local firms? Research Policy, vol. 42, pp. 231-244.

Girma S., Gong Y., Görg H. (2009) What Determines Innovation Activity in Chinese State-owned Enterprises? The Role of Foreign Direct Investment. World Development, vol. 37, no 4, pp. 866-873.

Gokhberg L., Roud V. (2012) The Russian Federation: A New Innovation Policy for Sustainable Growth. The Global Innovation Index 2012: Stronger Innovation Linkages for Global Growth (eds. S. Dutta, B. Lanvin, S. Wunsch-Vincent), Fontainebleau, Ithaca, Geneva: Cornell University, INSEAD, WIPO, pp. 121-130. 
Gokhberg L., Roud V. (2016) How to Design a National Innovation System in a Time of Global Innovation Networks: A Russian Perspective. The Global Innovation Index 2016. Winning with Global Innovation (eds. S. Dutta, B. Lanvin, S. Wunsch-Vincent), Fontainebleau, Ithaca, Geneva: Cornell University, INSEAD, WIPO. P. 159-168.

Gokhberg L., Sokolov A. (2017) Technology foresight in Russia in historical evolutionary perspective. Technological Forecasting and Social Change, vol. 119, pp. 256-267.

Golichenko O. (2017) Gosudarstvennaya politika i provaly natsional'noi innovatsionnoi sistemy [Public policy and national innovation system failures]. Voprosy Ekonomiki, no 2, pp. 97-108 (in Russian).

Grespi G., Zuniga P. (2012) Innovation and Productivity: Evidence from Six Latin America Countries. World Development, vol. 40, no 2, pp. 273-290.

Grunwald A. (2011) Responsible Innovation: Bringing together Technology Assessment, Applied Ethics, and STS Research. Enterprise and Work Innovation Studies, vol. 7, pp. 9-31.

Hall B.H., Rosenberg N. (2010) Chapter 1. Introduction to the Handbook. Handbook of the Economics of Innovation (eds. B.H. Hall, N. Rosenberg), Amsterdam, Boston, Heidelberg: Elsevier, vol. 1, pp. 3-9.

HSE (2017) Reiting innovatsionnogo razvitiya sub"ektov Rossiiskoi Federatsii [Russian Regional Innovation Scoreboard], issue 5 (ed. L.M. Gokhberg), Moscow: HSE (in Russian).

HSE (2018) Indikatory innovatsionnoi deyatel'nosti 2018 [Indicators of Innovation in Russian Federation 2018], Moscow: HSE (in Russian).

Ivanova O.P. (2010) Formirovanie innovatsionnoi regional'noi sredy kak determinanty povysheniya konkurentosposobnosti predpriyatij [Formation of an Innovative Regional Environment as Determinants of Enhancing Enterprise Competitiveness]. Problemy sovremennoi ekonomiki [Problems of Modern Economics], no 2, pp. 47-55 (in Russian).

Junge M., Severgnini B., Srensen A. (2012) Evidence on the Impact of Education on Innovation and Productivity (Copenhagen Business School Working Paper 2-2012), Copenhagen: Copenhagen Business School. Available at: http://openarchive. cbs.dk/bitstream/handle/10398/8498/Junge_Severgnini_S\%C3\%B8rensen.pdf?sequence=1, accessed 14.06.2018.

Karpov A. (2017) Sovremennyi universitet kak draiver ekonomicheskogo rosta: modeli i missii [Modern university as an economic growth driver: Models \& missions]. Voprosy Ekonomiki, no 3, pp. 58-76.

Klette T.J., Kortum S. (2002) Innovating Firms and Aggregate In-novation. Journal of Political Economy, vol. 112, no 5, pp. 986-1018.

Mariev O.S., Savin I.V. (2010) Faktory innovatsionnoi aktivnosti rossiiskikh regionov: modelirovanie i empiricheskii analiz [Factors of innovation activity of Russian regions: Modeling and empirical analysis]. Ekonomika regiona, no 3, pp. 235-244 (in Russian).

Medovnikov D., Oganesyan T., Rozmirovich S. (2016) Kandidaty v chempiony: srednie bystrorastushchie kompanii i programmy ikh podderzhki [Candidates for champions: Medium-sized fast-growing companies and programs for their support]. Voprosy Ekonomiki, no 9, pp. 50-66 (in Russian).

Merivate E.J., Pernias J.C. (2006) Innovation complementarity and scale of production. Journal of Industrial Economics, vol. 54, no 1, pp. 1-30.

Ministry of Economic Development (2016) Natsional'nyi doklad ob innovatsiyakh v Rossii [National report on innovations in Russia], Moscow: RF Ministry of Economic Development (in Russian). Available at: https://www.rvc.ru/upload/RVK innovation_2016_v.pdf, accessed 06.08.2018.

Mokyr J. (2010) The contribution of economic history to the study of innovation and technical change: 1750-1914. Handbook of the Economics of Innovation (eds. B.H. Hall, N. Rosenberg), Amsterdam, Boston, Heidelberg: Elsevier, vol. 1, pp. 12-50.

Nazarov M.A., Fomin E.P. (2015) Problemy razvitiya innovatsionnoi infrastruktury v rossiiskoi ehkonomike [Features of innovation infrastructure development in Russian economy]. Ekonomicheskie nauki [Economic Sciences], no 4 (125), pp. 38-43 (in Russian).

OECD, Eurostat (2005) Oslo Manual. The measurement of scientific and technological activities. Proposed guidelines for collecting and interpreting technological innovation data, Paris: OECD; Eurostat.

Owen R., Macnaghten P.M., Stilgoe J. (2012) Responsible Research and Innovation: From Science in Society to Science for Society, with Society. Science and Public Policy, vol. 39, no 6, pp. 751-760. DOI:10.1093/scipol/scs093.

Peri G., Urban D. (2006) Catching-up to foreign technology? Evidence on the "Veblen-Gerschenkron" effect of foreign investments. Regional Science and Urban Economics, vol. 36, pp. 72-98.

Polterovich V.M. (2017) Teoriya endogennogo ekonomicheskogo rosta i uravneniya matematicheskoi fiziki [The Theory of Endogenous Economic Growth and Equations of Mathematical Physics]. Journal of the New Economic Association, no 2 (34), pp. 193-201 (in Russian).

Romer P.M. (1990) Endogenous technological change. Journal of Political Economy, vol. 98, no 5, pt. 2, pp. 71-102.

Roper S., Du J., Love J. (2008) Modelling the innovation value chain. Research Policy, vol. 37, no 6-7, pp. 961-977.

Schmutzler J., Lorenz E. (2015) Tolerance, agglomeration and enterprise innovation performance: A multi-level analysis of Latin American regions. Gredeg, vol. 43, pp. 1-30.

Schumpeter J.A. (1934) The Theory of Economic Development, Boston, MA: Harvard University Press.

Schwab K. (2016) The Global Competitiveness Report 2015-2016, Geneva: The World Economic Forum.

Simachev Yu., Kuzyk M. (2017) Vliyanie gosudarstvennykh institutov razvitiya na innovatsionnoe povedenie firm: kachestvennye effekty [The impact of state development institutions on the innovative behavior of firms: Qualitative effects]. Voprosy Ekonomiki, no 2, pp. 109-135 (in Russian).

Sokolov A., Chulok A. (2014) Russian Se T Foresight 2030: Identifying new drivers of growth, Brussels: European Commission. Available at: https://ec.europa.eu/jrc/sites/jrcsh/files/fta2014-t1Practice_177.pdf, accessed 21.04.2018.

Solow R. (1957) Technical change and the aggregate production function. Review of Economics and Statistics, vol. 39, pp. 312-320.

Srholec M. (2011) A multilevel analysis of innovation in developing countries. Industrial and Corporate Change, vol. 20, no 6, pp. 1539-1569.

Sukhovei A.F., Golova I.M. (2016) Obosnovanie transformatsii prioritetov nauchno-tekhnologicheskogo razvitiya regionov RF v usloviyakh global'nogo krizisa [Substantiation of the transformation of the priorities of scientific and technological development of the regions of the Russian Federation in the conditions of the global crisis]. Ekonomika regiona, vol. 12, no 3, pp. 911-923 (in Russian).

Vlasova V., Kuznetsova T., Roud V. (2017) Analiz draiverov i ogranichenii razvitiya Rossii na osnove informatsii Global'nogo innovatsionnogo indeksa [Drivers and limitations of Russia's development based on the evidence provided by the Global Innovation Index]. Voprosy Ekonomiki, no 8, pp. 24-41 (in Russian).

Wang C., Kafouros M.I. (2009) What factors determine innovation performance in emerging economies? Evidence from China. International Business Review, vol. 18, no 6, pp. 606-616.

Williamson O.E. (1965) Innovation and market structure. Journal of Political Economy, vol. 73, pp. 67-73.

Yukhanaev A., Fallon G., Baranchenko Y., Anisimova A. (2015) An investigation into the formal institutional constraints that restrict entrepreneurship and SME growth in Russia. Journal of East-West Business, vol. 21, no 4, pp. 313-341.

Yusupova A., Halimova S. (2017) Kharakteristiki, osobennosti razvitiya, regional'nye i otraslevye determinanty vysokotekhnologichnogo biznesa v Rossii [Characteristics, features of development, regional and sectoral determinants of high-tech business in Russia]. Voprosy Ekonomiki, no 12, pp. 142-154 (in Russian). 


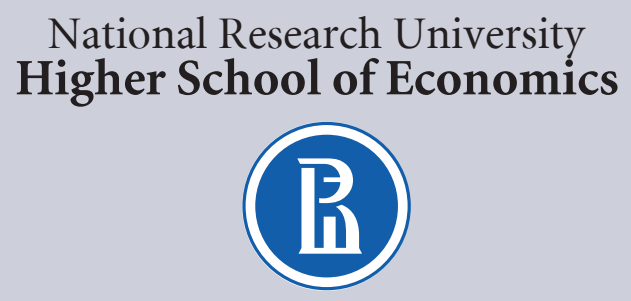

Institute for Statistical Studies
and Economics of Knowledge

Editor-in-Chief — Leonid Gokhberg, First Vice-Rector, HSE, and Director, ISSEK, HSE, Russian Federation

Deputy Editor-in-Chief - Alexander Sokolov, HSE, Russian Federation

\section{EDITORIAL BOARD}

Tatiana Kuznetsova, HSE, Russian Federation Dirk Meissner, HSE, Russian Federation Yury Simachev, HSE, Russian Federation Thomas Thurner, HSE, Russian Federation, and University of Cape Town, South Africa

Executive Editor - Marina Boykova Development Manager — Nataliya Gavrilicheva Literary Editors - Yakov Okhonko, Caitlin Montgomery Proofreader - Ekaterina Malevannaya Designer - Mariya Salzmann

Layout - Mikhail Salazkin

\section{Address:}

National Research University Higher School of Economics 20, Myasnitskaya str., Moscow, 101000, Russia

Tel: +7 (495) 621-40-38

E-mail: foresight-journal@hse.ru

http://foresight-journal.hse.ru/en/

Periodicity - quarterly

ISSN 2500-2597

ISSN 2312-9972 (online)

ISSN 1995-459X (Russian print version)

\section{Publisher:}

National Research University

Higher School of Economics

(C) National Research University

Higher School of Economics, 2018

\section{EDITORIAL COUNCIL}

Igor Agamirzyan, HSE, Russian Federation

Andrey Belousov, Administration of the President of the Russian Federation

Cristiano Cagnin, Center for Strategic Studies and Management (CGEE), Brazil

Elias Carayannis, George Washington University, United States

Mario Cervantes, Directorate for Science, Technology and Industry, OECD

Charles Edquist, Lund University, Sweden

Ted Fuller, University of Lincoln, UK

Luke Georghiou, University of Manchester, United Kingdom

Karel Haegeman, EU Joint Research Centre (JRC)

Attila Havas, Institute of Economics, Hungarian Academy of Sciences

Michael Keenan, Directorate for Science, Technology and Industry, OECD

Alexander Khlunov, Russian Science Foundation

Andrey Klepach, Bank for Development and Foreign Economic Affairs, Russian Federation

Mikhail Kovalchuk, National Research Centre "Kurchatov Institute», Russian Federation

Yaroslav Kuzminov, HSE, Russian Federation

Carol S. Leonard, HSE, Russian Federation, and

University of Oxford, United Kingdom

Jonathan Linton, HSE, Russian Federation, and University of Sheffield, United Kingdom

Ian Miles, HSE, Russian Federation, and University of Manchester, United Kingdom

Rongping Mu, Institute of Policy and Management, Chinese Academy of Sciences

Fred Phillips, University of New Mexico and Stony Brook University - State University of New York, United States Wolfgang Polt, Joanneum Research, Austria

Ozcan Saritas, HSE, Russian Federation, and University of Manchester, United Kingdom

Klaus Schuch, Centre for Social Innovation, Austria

Nicholas Vonortas, HSE, Russian Federation, and George Washington University, United States

Angela Wilkinson, World Energy Council and University of Oxford, United Kingdom 

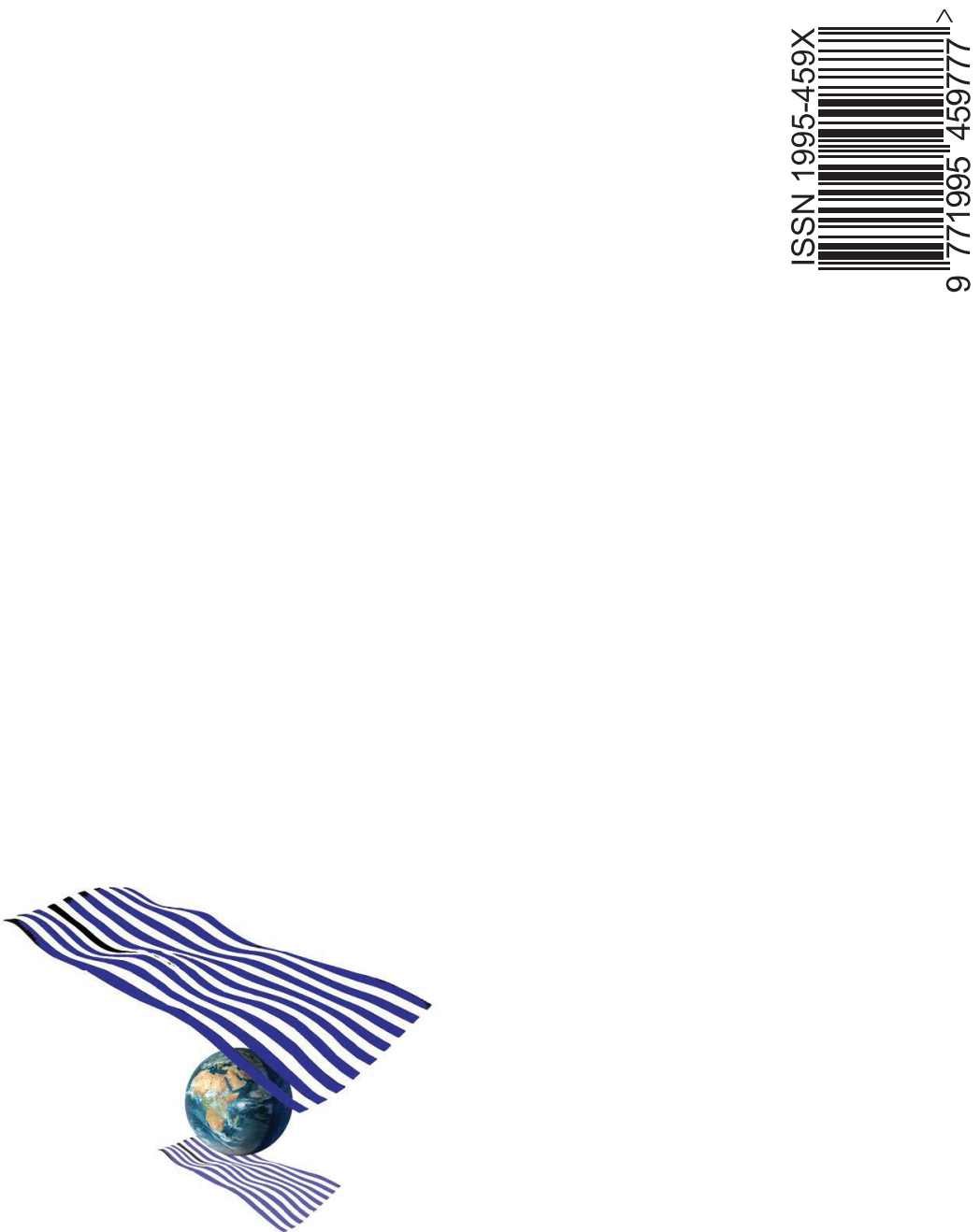

\section{Website}

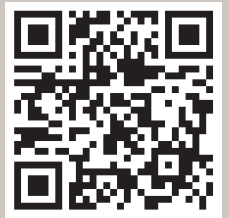

Co Download on the

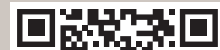

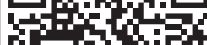

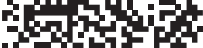

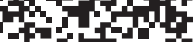

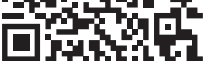

GETION

Google Play

口점 4 in: $+2$ 回留 